\title{
Revision of the endemic Malagasy leafhopper tribe Platyjassini (Hemiptera: Cicadellidae: Iassinae)
}

\author{
Christopher H. DIETRICH ${ }^{1, *}$, Raysa Brito de MAGALHÃES ${ }^{2}$ \& Daniela M. TAKIYA ${ }^{3}$ \\ ${ }^{1}$ Illinois Natural History Survey, Prairie Research Institute, University of Illinois, 1816 S. Oak St., \\ Champaign, IL 61820, USA. \\ ${ }^{2,3}$ Laboratório de Entomologia, Departamento de Zoologia, Universidade Federal do Rio de Janeiro, \\ Caixa Postal 68044, Rio de Janeiro, 21941-971, RJ Brazil. \\ *Corresponding author: chdietri@illinois.edu \\ ${ }^{2}$ Email: ray.bmagalhaes@gmail.com \\ 33Email: takiya@acd.ufrj.br

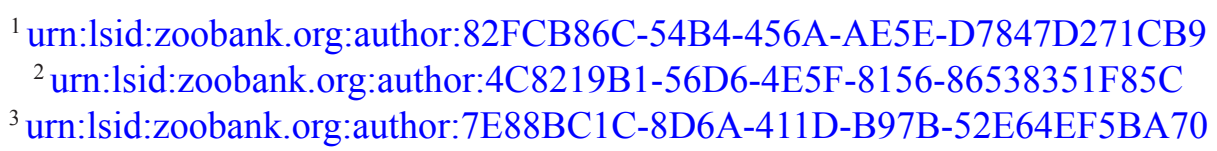

\begin{abstract}
The leafhopper tribe Platyjassini, endemic to Madagascar, is revised, largely based on specimens obtained in a recent bioinventory project led by the California Academy of Sciences. Platyjassini was previously known based on the type genus, Platyjassus Evans, 1953, and four described species. Betsileonas marmorata (Blanchard, 1840), the largest leafhopper recorded from Madagascar, presently known from a few specimens collected $>100$ years ago and recently considered a genus and species incertae sedis within Cicadellidae, is newly placed in Platyjassini. Fourteen new genera and 54 new species are described and illustrated, and three new combinations are proposed. Pachyjassus gen. nov. includes three new species: Pachyjassus alatus sp. nov., Pachyjassus basifurcatus sp. nov. and Pachyjassus ranomafanensis sp. nov. Pallijassus gen. nov. is erected to include two species previously placed in Platyjassus, Pallijassus reticulatus (Evans, 1959) comb. nov. and Pallijassus stenospatulatus (Evans, 1959) comb. nov. Petalojassus gen. nov. includes one new species, Petalojassus ochrescens sp. nov. Phaiojassus gen. nov. includes seven new species: Phaiojassus acutus sp. nov., Phaiojassus bispinosus sp. nov., Phaiojassus constrictus sp. nov., Phaiojassus grandis sp. nov., Phaiojassus spatulatus sp. nov., Phaiojassus undulatus sp. nov. and Phaiojassus unispinosus sp. nov. Pictojassus gen. nov. includes three new species: Pictojassus kirindiensis sp. nov., Pictojassus productus sp. nov. and Pictojassus tulearensis sp. nov. Platyjassella gen. nov. includes six new species: Platyjassella ancora sp. nov., Platyjassella andohahelensis sp. nov., Platyjassella attenuata sp. nov., Platyjassella cormorana sp. nov., Platyjassella emarginata sp. nov. and Platyjassella immaculata sp. nov. Platyjassula gen. nov. includes four new species: Platyjassula cyclura sp. nov., Platyjassula heterofurca sp. nov., Platyjassula isofurca sp. nov. and Platyjassula mahajangensis sp. nov. In addition to the type species, Platyjassus viridis Evans, 1953, Platyjassus includes 11 new species: Platyjassus acutus sp. nov., Platyjassus asymmetricus sp. nov., Platyjassus fisheri sp. nov., Platyjassus griswoldi sp. nov., Platyjassus harinhalai sp. nov., Platyjassus irwini sp. nov., Platyjassus pedistylus sp. nov., Platyjassus pennyi sp. nov., Platyjassus pictipennis sp. nov., Platyjassus symmetricus sp. nov. and Platyjassus
\end{abstract}


vestigius sp. nov. Plerujassus gen. nov. includes one new species, Plerujassus brunnescens sp. nov., in addition to Plerujassus appendiculatus (Evans, 1959) comb. nov., previously placed in Platyjassus. Plexijassus gen. nov. includes one new species, Plexijassus caliginosus sp. nov. Pseudocurtara gen. nov. includes three new species: Pseudocurtara minima sp. nov., Pseudocurtara nigripicta sp. nov. and Pseudocurtara quadrata sp. nov. Pseudocyrta gen. nov. includes one new species, Pseudocyrta hyalina sp. nov. Pseudomarganana gen. nov. includes two new species: Pseudomarganana olivacea sp. nov. and Pseudomarganana rosea sp. nov. Pulchrijassus gen. nov. includes eight new species: Pulchrijassus anjozorobensis sp. nov., Pulchrijassus eunsunae sp. nov., Pulchrijassus pallescens sp. nov., Pulchrijassus roseus sp. nov., Pulchrijassus rubrilineatus sp. nov., Pulchrijassus sindhuae sp. nov., Pulchrijassus talatakelyensis sp. nov. and Pulchrijassus toamasinensis sp. nov. Punctijassus gen. nov. includes three new species: Punctijassus circularis sp. nov., Punctijassus compressus sp. nov. and Punctijassus ivohibensis sp. nov. Illustrated keys to genera and species are provided.

Keywords. Auchenorrhyncha, Madagascar, morphology, taxonomy, biogeography.

Dietrich C.H., de Magalhães R.B. \& Takiya R.M. 2020. Revision of the endemic Malagasy leafhopper tribe Platyjassini (Hemiptera: Cicadellidae: Iassinae). European Journal of Taxonomy 695: 1-89.

https://doi.org/10.5852/ejt.2020.695

\section{Introduction}

In his review of the Cicadellidae of Madagascar, Evans (1953) described a new monotypic tribe, Platyjassini, based on the type genus Platyjassus Evans, 1953 and containing a single species, $P$. viridis Evans, 1953. Subsequently, Evans (1959) described three additional species of Platyjassus, distinguishing them from the type species based on external morphological characters. Later, Linnavuori \& Quartau (1975) illustrated the male genitalia of $P$. viridis. Krishnankutty et al. (2016) included six unidentified species of Platyjassini in their comprehensive phylogenetic analysis of Iassinae, recovering Platyjassini as a monophyletic, early-diverging lineage of the subfamily. Their molecular divergence time analysis suggested that the tribe diverged from other Iassinae during the Cretaceous period, approximately 90 million years ago, coinciding with a time after Madagascar had separated from Africa but before it became completely isolated from the Indian subcontinent. This analysis also indicated that the crown group of Platyjassini began diversifying during the early Paleogene.

A recent biodiversity inventory project in Madagascar, led by entomologists at the California Academy of Sciences (San Francisco, USA), has yielded a wealth of leafhopper specimens from all major vegetation zones and regions of the island. Previous taxonomic studies of particular leafhopper genera based largely on this material (Krishnankutty \& Dietrich 2011a, 2011b) have increased the known species diversity of these groups in Madagascar by $83-87 \%$. Study of available specimens of Platyjassini has revealed an even higher percentage ( $92 \%$ ) of undescribed species for this group.

Little is known about the ecology of Platyjassini, a group poorly represented in previous collections from Madagascar. Recent collection records indicate that species of the tribe are distributed throughout Madagascar and occur in habitats ranging from lowland dry forest and savanna to montane rainforest. Nearly all the specimens from the recent bioinventory project were collected in Malaise traps in various forest parks and preserves. Many of the species appear to be restricted to particular regions and vegetation types and most are known only from a few specimens. Given the large proportion of species represented by single specimens, further collecting in Madagascar, particularly employing other techniques such as light trapping and forest canopy fogging, will likely reveal many additional species of Platyjassini. The tribe is here revised comprehensively and keys are provided for identification of the known genera and species. 


\section{Materials and methods}

Morphological terminology follows Dietrich (2005). Habitus photographs were taken using a Canon SLR camera attached to an automated lift, which facilitated capture of images at multiple focal planes. These image stacks were subsequently combined using Zerene Stacker. These photos are arranged in pairs of dorsal and lateral habitus for each species on Figs 1-3 with a $1 \mathrm{~mm}$ scale bar shown to the left of each dorsal habitus. Photos of genitalia immersed in glycerine were obtained using a Q-Imaging Micropublisher camera attached to an Olympus BX41 compound microscope with image stacks combined using CombineZP. All images were edited to improve contrast and/or color balance and erase backgrounds using Adobe Photoshop. To conserve space on figure plates, some ventral views of the male genitalia show only one of the styles. Genitalia photos (Figs 4-18) were re-sized to facilitate shape comparison and are not to scale. Distribution maps (Fig. 24) were generated using QGIS 3.0 with a shape layer from The Nature Conservancy's terrestrial ecoregions of the world. Specimens examined are deposited in the following entomological collections:

BMNH $=$ Natural History Museum, London, UK

CAS $=$ California Academy of Sciences, San Francisco, USA

DZRJ = Departamento de Zoologia, Universidade Federal do Rio de Janeiro, Brazil

INHS = Illinois Natural History Survey, University of Illinois, Urbana-Champaign, USA

MNHN = Museum national d'histoire naturelle, Paris, France

\section{Results}

Order Hemiptera Linnaeus, 1758

Suborder Auchenorrhyncha Duméril, 1806

Infraorder Cicadomorpha Evans, 1946

Superfamily Membracoidea Rafinesque, 1815

Family Cicadellidae Latreille, 1825

Subfamily Iassinae Walker, 1870

Tribe Platyjassini Evans, 1953

Platyjassini Evans, 1953: 113 (type genus: Platyjassus Evans, 1953).

\section{Description}

HaBitus. Medium-sized to large (4.9-19.0 mm) pale yellow (green in life) or brown leafhoppers, with or without red, yellow or brown markings. Body moderately to strongly depressed (Figs 1-3).

HEAD. With crown flat to slightly convex, usually produced, with two or more transverse carinae delimiting crown-face transition (Figs 23D-F). Ocelli on crown well separated from anterior margin and eyes. Face (Figs 23D-E) flattened to slightly convex; antenna inserted near anterodorsal corner of eye, shorter than head width; antennal ledge oblique, sharply carinate but not concealing antennal base, or amalgamated with marginal rim of crown; lateral frontal sutures absent or extended only to dorsal margin of face; gena slightly to strongly emarginate below eye, partially to completely concealing proepisternum; lorum flat, not extended to lateral margin of face; anteclypeus flat to slightly convex, distinctly broadened distally; rostrum short, not extended beyond middle coxae.

Thorax. Pronotum (Figs 1-3) with transverse striations indistinct to well developed, lateral margins carinate and slightly to strongly divergent posterad of eyes, usually wider than head. Forewing venation (Fig. 23G) including at least one s, two r-m and three m-cu crossveins, appendix well developed, much wider than inner apical cell, extended to or near wing apex. Hindwing venation complete, with 

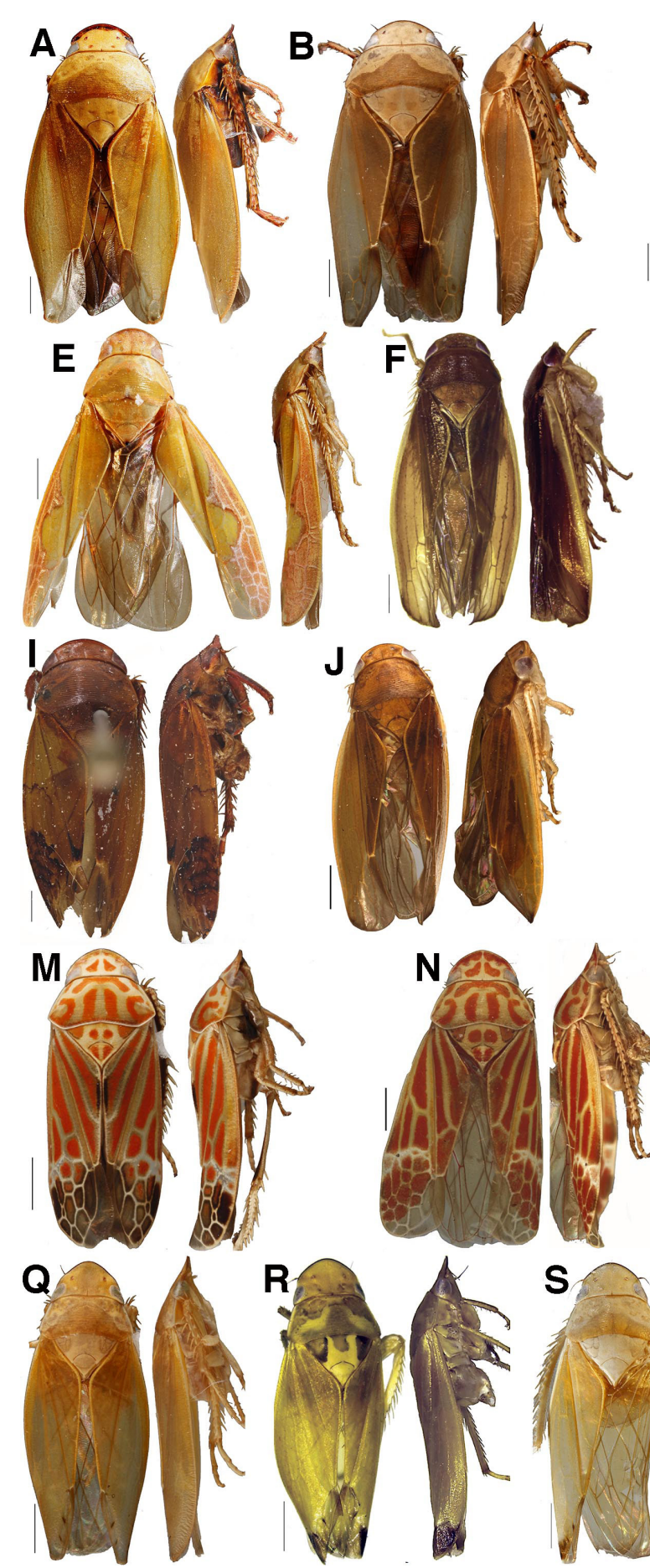
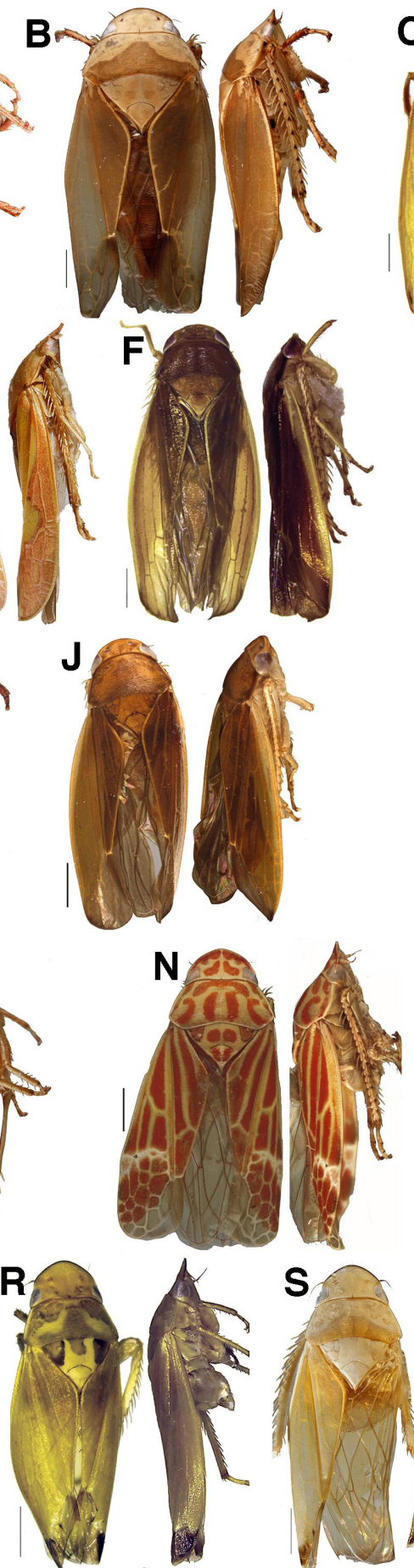
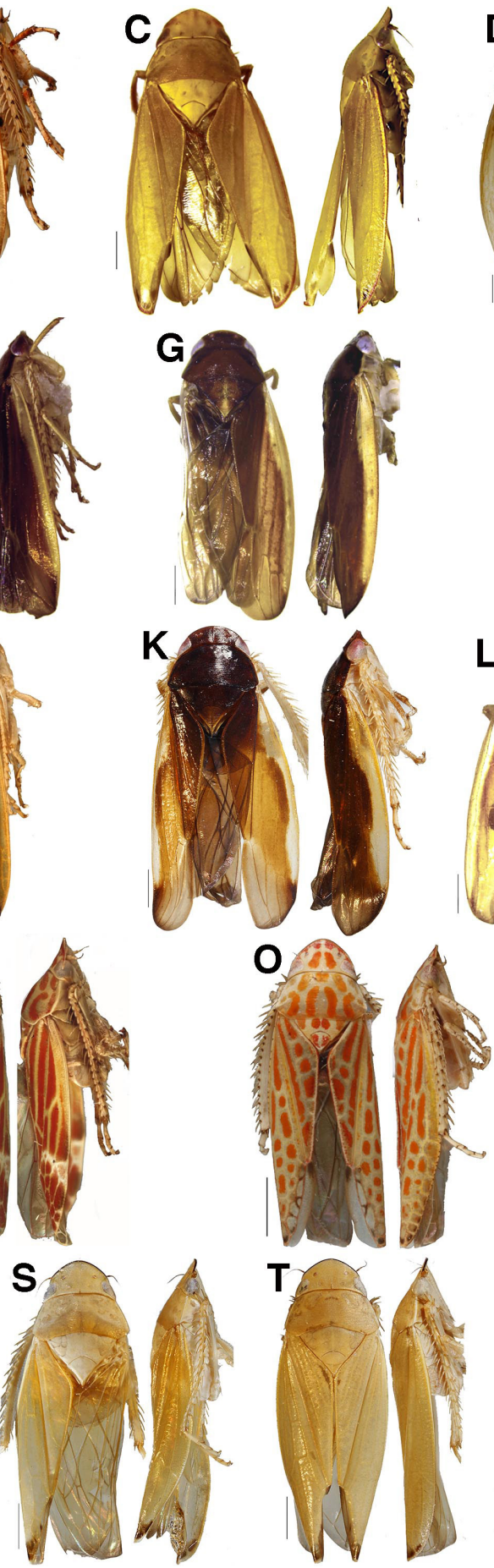
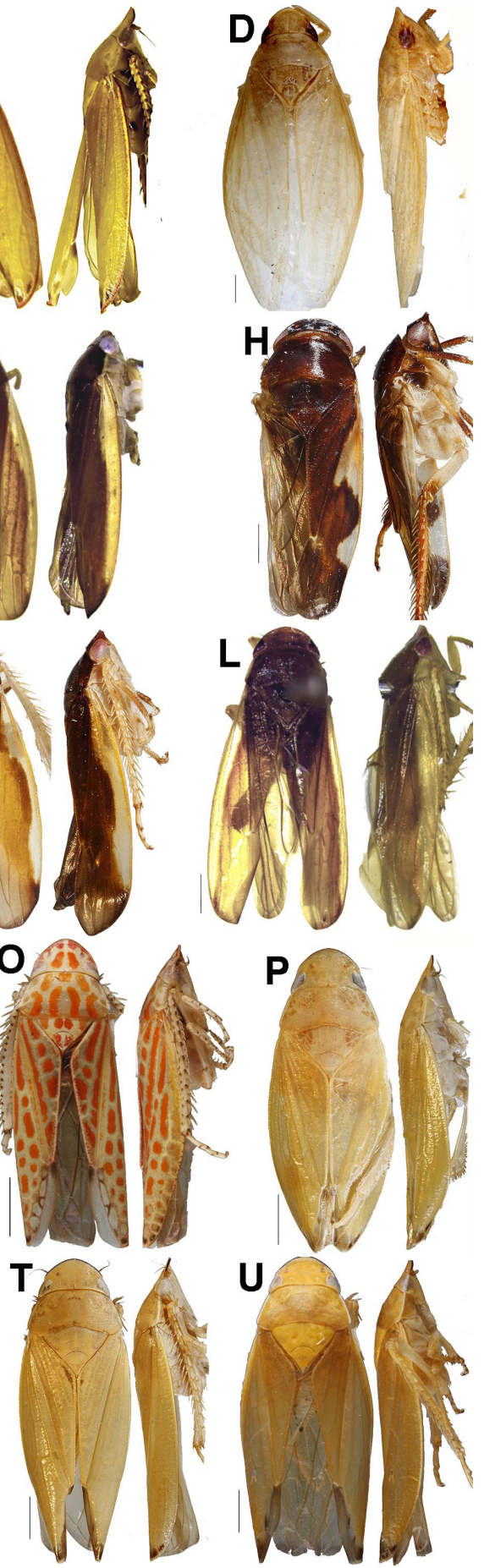

Fig. 1. Platyjassini, dorsal and lateral habitus of males. A. Pachyjassus alatus sp. nov. B. Pachyjassus basifurcatus sp. nov. C. Pachyjassus ranomafanensis sp. nov. D. Pallijassus stenospatulatus (Evans, 1959). E. Petalojassus ochrescens sp. nov. F. Phaiojassus acutus sp. nov. G. Phaiojassus bispinosus sp. nov. H. Phaiojassus constrictus sp. nov. I. Phaiojassus grandis sp. nov. J. Phaiojassus spatulatus sp. nov. K. Phaiojassus undulatus sp. nov. L. Phaiojassus unispinosus sp. nov. M. Pictojassus kirindiensis sp. nov. N. Pictojassus productus sp. nov. O. Pictojassus tulearensis sp. nov. P. Platyjassella ancora sp. nov. Q. Platyjassella andohahelensis sp. nov. R. Platyjassella attenuata sp. nov. S. Platyjassella cormorana sp. nov. T. Platyjassella emarginata sp. nov. U. Platyjassella immaculata sp. nov. Scale bars $=1 \mathrm{~mm}$. 


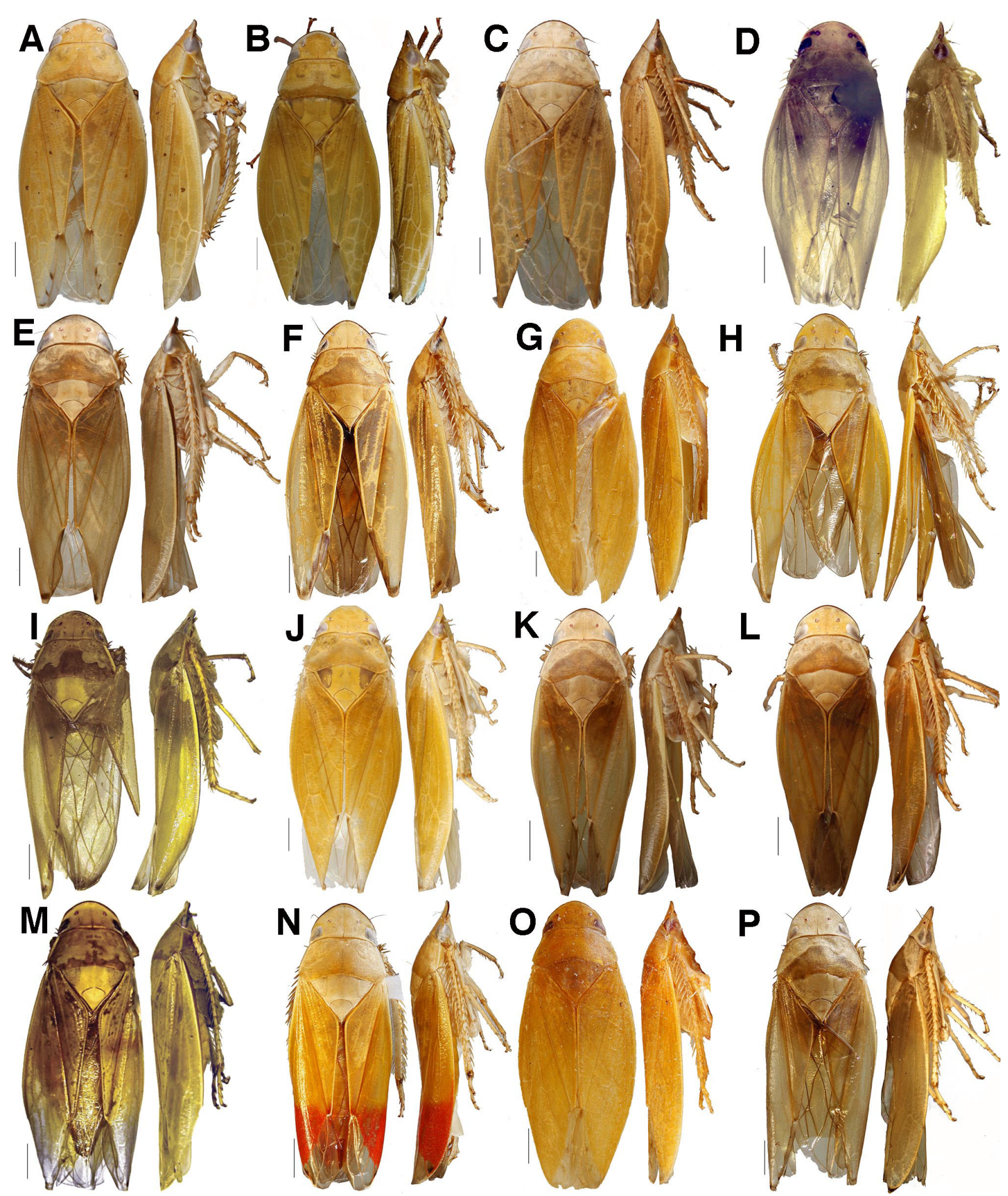

Fig. 2. Platyjassini, dorsal and lateral habitus of males. A. Platyjassula cyclura sp. nov. B. Platyjassula heterofurca sp. nov. C. Platyjassula isofurca sp. nov. D. Platyjassula mahajangensis sp. nov. E. Platyjassus acutus sp. nov. F. Platyjassus pennyi sp. nov. G. Platyjassus viridis Evans, 1953. H. Platyjassus asymmetricus sp. nov. I. Platyjassus fisheri sp. nov. J. Platyjassus griswoldi sp. nov. K. Platyjassus harinhalai sp. nov. L. Platyjassus irwini sp. nov. M. Platyjassus pedistylus sp. nov. N. Platyjassus pictipennis sp. nov. O. Platyjassus symmetricus sp. nov. P. Platyjassus vestigius sp. nov. Scale bars $=1 \mathrm{~mm}$. 

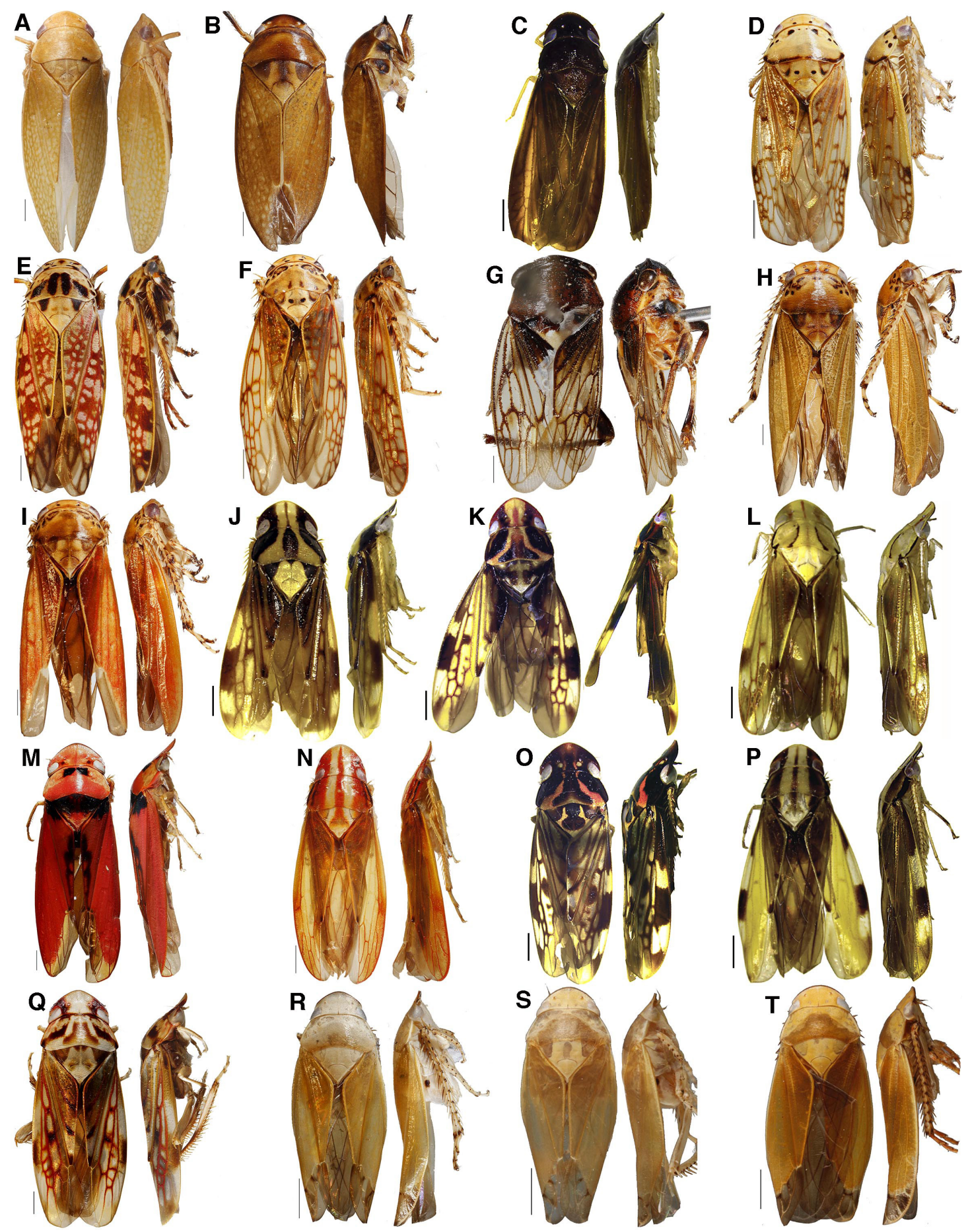

Fig. 3. Platyjassini, dorsal and lateral habitus of males. A. Plerujassus appendiculatus (Evans, 1959). B. Plerujassus brunnescens sp. nov. C. Plexijassus caliginosus sp. nov. D. Pseudocurtara minima sp. nov. E. Pseudocurtara nigripicta sp. nov. F. Pseudocurtara quadrata sp. nov. G. Pseudocyrta hyalina sp. nov. H. Pseudomarganana olivacea sp. nov. I. Pseudomarganana rosea sp. nov. J. Pulchrijassus anjozorobensis sp. nov. K. Pulchrijassus eunsunae sp. nov. L. Pulchrijassus pallescens sp. nov. M. Pulchrijassus roseus sp. nov. N. Pulchrijassus rubrilineatus sp. nov. O. Pulchrijassus sindhuae sp. nov. P. Pulchrijassus talatakelyensis sp. nov. Q. Pulchrijassus toamasinensis sp. nov. R. Punctijassus circularis sp. nov. S. Punctijassus compressus sp. nov. T. Punctijassus ivohibensis sp. nov. Scale bars $=1 \mathrm{~mm}$. 
R4+5 and M1+2 partially (Fig. 23H) to completely confluent (Fig. 23I). Front femur with AM1 well developed, other setae of AM poorly differentiated or absent; row IC uniseriate or with setae scattered near apex; AV usually with several long, stout setae; tibia cylindrical or with dorsal surface somewhat flattened, row $\mathrm{PD}$ with widely spaced macrosetae; $\mathrm{AD}$ weakly differentiated; ventral rows moderately to well differentiated. Middle femur usually with several widely spaced macrosetae in AD and PD. Hind femur macrosetal formula usually $2+2+1$, with penultimate pair close-set; supernumerary macrosetae sometimes present; tibia with all macrosetal rows well differentiated and extended for nearly full length of tibia, PD macrosetae more numerous and usually slightly longer than in $\mathrm{AD}$; tarsomere I with dorsoapical pair of macrosetae, plantar rows variably developed, pecten with four or more platellae.

AbDomen. Male abdomen with 2S apodemes usually well developed, capitate (Fig. 21E); sternite VII enlarged, posterior margin truncate, slightly produced or slightly emarginate, concealing at least basal half of subgenital plates with genital capsule in resting position. Pygofer (Fig. 21F) broadly fused to valve, base well sclerotized dorsally, lobes with numerous scattered macrosetae in distal half, with or without appendages. Subgenital plates (Fig. $21 \mathrm{G}$ ) separate to base, freely articulated to valve, narrow at base, broadened toward middle, then tapered to slightly compressed apices, usually extended to or near pygofer apex, with or without macrosetae, usually with some long, fine setae along dorsolateral margin. Style (Fig. 19H) narrow and sinuate basally, with short apodeme and elongate apophysis often bearing denticuli ventrally. Connective (Figs 19H, 20H) with median anterior lobe variably developed, articulated to aedeagus. Aedeagus with dorsal apodeme usually well developed, shaft usually curved dorsad, with or without processes. Ovipositor with dorsal sculpturing of first valvulae strigate (Fig. 16A) or (rarely) imbricate-areolate (Fig. 17Q); second valvulae usually broad distally with dorsal margin serrate distally (Fig. 16R), rarely narrow with two widely spaced dorsal teeth (Fig. 16C).

\section{Remarks}

As mentioned by Evans (1953), Platyjassini are superficially similar to members of the endemic New World iassine tribe Gyponini in having the crown usually well delimited and flattened, with the ocelli on the crown and well separated from the anterior margin and eyes. The two tribes also have a similar structure of the male and female genitalia, forewing venation and leg chaetotaxy. Platyjassini differ from Gyponini in having the anteclypeus broadened apically, the forewing appendix much wider than the inner apical cell, and the hindwing with veins $\mathrm{R} 4+5$ and $\mathrm{M} 1+2$ partially to completely confluent.

\section{Checklist of Platyjassini Evans, 1953}

Betsileonas Kirkaldy, 1903

Betsileonas marmorata (Blanchard, 1840). Southern Madagascar.

Pachyjassus gen. nov.

Pachyjassus alatus sp. nov. Mahajanga.

Pachyjassus basifurcatus sp. nov. Toliara.

Pachyjassus ranomafanensis sp. nov. Antananarivo.

Pallijassus gen. nov.

Pallijassus reticulatus (Evans, 1959) comb. nov. Mahajanga and Toliara.

Pallijassus stenospatulatus (Evans, 1959) comb. nov. Antananarivo, Mahajanga and Toliara.

Petalojassus gen. nov.

Petalojassus ochrescens sp. nov. Fianarantsoa.

Phaiojassus gen. nov.

Phaiojassus acutus sp. nov. Fianarantsoa.

Phaiojassus bispinosus sp. nov. Antananarivo and Fianarantsoa.

Phaiojassus constrictus sp. nov. Antsiranana. 
Phaiojassus grandis sp. nov. Antsiranana.

Phaiojassus spatulatus sp. nov. Antsiranana.

Phaiojassus undulatus sp. nov. Antsiranana.

Phaiojassus unispinosus sp. nov. Antananarivo, Fianarantsoa and Toliara.

Pictojassus gen. nov.

Pictojassus kirindiensis sp. nov. Toliara.

Pictojassus productus sp. nov. Toliara.

Pictojassus tulearensis sp. nov. Toliara.

Platyjassella gen. nov.

Platyjassella ancora sp. nov. Antsiranana and Toamasina.

Platyjassella andohahelensis sp. nov. Toliara.

Platyjassella attenuata sp. nov. Toliara.

Platyjassella cormorana sp. nov. Mahajanga.

Platyjassella emarginata sp. nov. Antananarivo.

Platyjassella immaculata sp. nov. Toliara.

Platyjassula gen. nov.

Platyjassula cyclura sp. nov. Mahajanga.

Platyjassula heterofurca sp. nov. Mahajanga and Toliara.

Platyjassula isofurca sp. nov. Toliara.

Platyjassula mahajangensis sp. nov. Antsiranana and Mahajanga.

Platyjassus Evans, 1953

Platyjassus acutus sp. nov. Fianarantsoa.

Platyjassus asymmetricus sp. nov. Fianarantsoa.

Platyjassus fisheri sp. nov. Antsiranana.

Platyjassus griswoldi sp. nov. Antananarivo and Mahajanga.

Platyjassus harinhalai sp. nov. Toliara.

Platyjassus irwini sp. nov. Antananarivo.

Platyjassus pedistylus sp. nov. Fianarantsoa.

Platyjassus pennyi sp. nov. Fianarantsoa.

Platyjassus pictipennis sp. nov. Antsiranana and Mahajanga.

Platyjassus symmetricus sp. nov. Mahajanga.

Platyjassus vestigius sp. nov. Fianarantsoa.

Platyjassus viridis Evans, 1953. Antananarivo, Antsiranana, Mahajanga and Fianarantsoa.

Plerujassus gen. nov.

Plerujassus appendiculatus (Evans, 1959) comb. nov. Mahajanga and Toliara.

Plerujassus brunnescens sp. nov. Mahajanga.

Plexijassus gen. nov.

Plexijassus caliginosus sp. nov. Antsiranana and Fianarantsoa.

Pseudocurtara gen. nov.

Pseudocurtara minima sp. nov. Antananarivo and Antsiranana.

Pseudocurtara nigripicta sp. nov. Toamasina.

Pseudocurtara quadrata sp. nov. Antananarivo, Antsiranana and Fianarantsoa.

Pseudocyrta gen. nov.

Pseudocyrta hyalina sp. nov. Antsiranana.

Pseudomarganana gen. nov.

Pseudomarganana olivacea sp. nov. Antananarivo and Fianarantsoa.

Pseudomarganana rosea sp. nov. Fianarantsoa. 
Pulchrijassus gen. nov.

Pulchrijassus anjozorobensis sp. nov. Antananarivo.

Pulchrijassus eunsunae sp. nov. Antsiranana.

Pulchrijassus pallescens sp. nov. Fianarantsoa.

Pulchrijassus roseus sp. nov. Fianarantsoa.

Pulchrijassus rubrilineatus sp. nov. Fianarantsoa.

Pulchrijassus sindhuae sp. nov. Antananarivo and Fianarantsoa.

Pulchrijassus talatakelyensis sp. nov. Fianarantsoa.

Pulchrijassus toamasinensis sp. nov. Toamasina.

Punctijassus gen. nov.

Punctijassus circularis sp. nov. Toliara.

Punctijassus compressus sp. nov. Toliara.

Punctijassus ivohibensis sp. nov. Toliara.

\section{Key to genera of Platyjassini (males)}

1. Dorsal coloration nearly uniformly yellow or light brown (or green in life), without distinct pattern consisting of numerous colored spots or larger maculae (Fig 1A), at most with small black spot or dark infuscation near apex of forewing clavus or corium, or fuscous crown margin .........2

- Dorsal coloration not uniformly yellow or light brown, either mostly dark brown, red or black (Fig. 1F), or with pattern consisting of numerous conspicuous spots or larger maculae (Figs 1N, 3D, J) ........8

2. Crown in dorsal view without acute anterolateral extension distinctly overlapping eye (Figs 21A, 23B)

- Crown in dorsal view with acute anterolateral extension distinctly overlapping eye (Figs 22A, $23 \mathrm{~A}-\mathrm{B})$

3. Frontoclypeus punctate, without transverse striations (Fig. 23D) ...........Pallijassus gen. nov.

- Frontoclypeus transversely rugose (Fig. 23E) Plerujassus gen. nov.

4. Length of male $6.7 \mathrm{~mm}$ or less; aedeagus symmetrical or nearly so, or, if distinctly asymmetrical, with only distal processes present (Figs 7D, 15E)

- Length of male $>6.7 \mathrm{~mm}$; aedeagus either symmetrical with paired basal processes or distinctly asymmetrical, with single process arising from atrium and well separated from shaft (Fig. 10F, except Platyjassus asymmetricus sp. nov. with asymmetrical process near shaft apex, Fig. 9C) ......6

5. Hind coxa and apex of femur without black spot; male pygofer lobe often with sclerotized dorsal appendage or with apex emarginate (Fig. 7E, O); style apophysis with numerous conspicuous denticuli (Fig. 7B, F)

Platyjassella gen. nov.

- Hind coxa and apex of femur each with distinct black spot (Figs 3R-S, 23F); male pygofer lobe rounded distally, without processes (Fig. 15A); style apophysis without distinct denticuli (Fig. 15C)

Punctijassus gen. nov.

6. Male style with two prominent acute projections apically (not foot-like, Fig. 8B); pygofer sometimes with ventral process (Fig. $8 \mathrm{H}$ ) Platyjassula gen. nov.

- Male style apex foot-like with short heel and more elongated toe (Fig. 10D), or with single acute point (Fig. 10K); pygofer without ventral process

7. Anterolateral extension of crown overlapping $<1 / 2$ of anterolateral margin of eye (Figs 1A, 23A); hind coxa and apex of femur each with distinct black spot (Fig. 23F); aedeagus with pair of long basal processes (Fig. 4A, E)

Pachyjassus gen. nov. 
- Anterolateral extension of crown overlapping $>1 / 2$ of anterolateral margin of eye (Fig. 23B); hind coxa and apex of femur without black spots; aedeagus with basal process absent, or present but unpaired and asymmetrical Platyjassus Evans, 1953

8. Vertex in dorsal view with acute lateral extension overlapping anterolateral margin of eye (Figs $3 \mathrm{C}, \mathrm{J}, 23 \mathrm{~B})$

- Vertex in dorsal view without acute lateral extension overlapping anterolateral margin of eye (Figs $3 \mathrm{D}, \mathrm{I}, 23 \mathrm{~F})$

9. Body length including forewings $15 \mathrm{~mm}$ or more, head distinctly wider than pronotum

Betsileonas Kirkaldy, 1903

- Body length including forewings $<13 \mathrm{~mm}$, head narrower than pronotum

10. Dorsal color pattern consisting of symmetrical red spots or pale green transcommissural marking (Fig. 1M-O); hindwing veins RP and MA confluent for short distance, then separate distally ......11

- Dorsal markings not as above, usually consisting of distinct longitudinal stripes (Fig. 3C, J-Q); hindwing veins RP and MA completely confluent distally .12

11. Dorsum with numerous conspicuous symmetrical red spots Pictojassus gen. nov.

- Dorsum with pale green transcommissural marking Petalojassus gen. nov.

12. Forewing vein $\mathrm{R}$ without supernumerary branches extended to costal margin, with extra crossveins usually present between veins $\mathrm{R}, \mathrm{M}$ and $\mathrm{CuA}$; dorsum usually with bold symmetrical pattern of dark and pale markings (Fig. 3J-Q)

Pulchrijassus gen. nov.

- Forewing vein $\mathrm{R}$ with one or more long supernumerary branches extended to costal margin, without extra crossveins between veins $\mathrm{R}, \mathrm{M}$. and $\mathrm{CuA}$; dorsum nearly uniform dark brown or black (Fig. 3C) Plexijassus gen. nov.

13. Forewing with numerous supernumerary crossveins (Fig. 3F) Pseudocurtara gen. nov.

- Forewing with, at most, 1-2 supernumerary crossveins (Fig. 3G-I) .14

14. Forewing mostly hyaline, appendix crenulate (Fig. 3G); hind femur with supernumerary macrosetae Pseudocyrta gen. nov.

- Forewing membrane with extensive opaque sclerotization, appendix flat, not crenulate (Fig. $3 \mathrm{H}-\mathrm{I})$; hind femur macrosetae $2+2+1$ . .15

15. Crown with pair of round black spots posterad of ocelli, pronotum with anterior group of irregular black maculae (Fig. 3H-I); aedeagus symmetrical, with pair of lateral spines closely paralleling shaft

Pseudomarganana gen. nov.

- Crown without pair of round black spots, pronotum unicolorous, without group of anterior maculae (Fig. 1F); aedeagus usually asymmetrical, with spines variously arranged .....Phaiojassus gen. nov.

Betsileonas Kirkaldy, 1903

Thaumastus Stål, 1864b: 67 (type species: Ledra marmorata Blanchard, 1840; nec Thaumastus Martens, 1860).

Betsileonas Kirkaldy, 1903: 13, nom. nov. (type species: Ledra marmorata Blanchard, 1840).

\section{Remarks}

This monotypic genus was placed in Penthimiini by Evans (1947) but later returned to Ledrini by Evans (1953). Jones \& Deitz (2009) treated it as a genus incertae sedis because their morphology-based 
phylogenetic analysis failed to support its inclusion in Ledrinae. The genus is known only from a few very old museum specimens and was not encountered in the recent extensive terrrestrial arthropod inventory of Madagascar, suggesting that Betsileonas is now either extremely rare or extinct. Males remain unknown, but several characters mentioned or illustrated for the genus by Jones \& Deitz (2009) support its placement in Platyjassini, including the spatulate head with dorsal ocelli well separated from the crown apex, the rugose texture on the crown, the anterolateral extensions of the vertex overlapping the eyes, and the distally fused RP and MA in the hindwing. The ovipositor structure also resembles that of some other Platyjassini. Known from a single species, the genus is easily distinguished from other Platyjassini by its very large size (length $15-19 \mathrm{~mm}$ ), the head being distinctly wider than the pronotum and its marmorate dorsal color pattern (see Jones \& Deitz 2009: pl. 5c).

Betsileonas marmorata (Blanchard, 1840)

Ledra marmorata Blanchard, 1840: 194.

Thaumastus marmorata - Stål, 1864: 67.

Betsileonas marmorata - Kirkaldy, 1903: 13.

\section{Remarks}

Jones \& Deitz (2009) reported that Blanchard's type specimen of this species is lost, but they included this species in their morphological data matrix for Ledrinae and provided a color habitus photo and photos of the ovipositor of a non-type specimen from the MNHN. They noted that males were not available, although abdomens of some specimens were missing, and all available specimens were badly damaged.

Pachyjassus gen. nov. urn:1sid:zoobank.org:act:81F0C558-8097-4710-95E4-24E8D1C0A211

Figs $1 \mathrm{~A}-\mathrm{C}, 4 \mathrm{~A}-\mathrm{I}, 16 \mathrm{~A}-\mathrm{F}$

\section{Type species}

Pachyjassus basifurcatus sp. nov.

\section{Diagnosis}

This genus may be distinguished by the following combination of features: body robust, dorsum stramineous without distinct spots or stripes, vertex overlapping less than half of anterolateral margin of eye, crown transversely striate anteriorly, margin spatulate; forewing with few supernumerary crossveins in distal half; hindwing veins $\mathrm{R} 4+5$ and $\mathrm{M} 1+2$ confluent preapically but separate near apex; hind femur macrosetal formula usually $2+2+1$; aedeagus with pair of long basal processes.

\section{Etymology}

The genus name, a masculine noun, combines the Greek 'pachys' ('thick') with '-jassus', a common suffix for members of this subfamily, referring to the relatively robust body form of members of the genus.

\section{Description}

HaBitus. Medium-sized platyjassines $(7.0-8.6 \mathrm{~mm})$. Color stramineous with darker pigment at apex of forewing, prominent black spot at apex of middle and hind femur and laterally on hind coxa.

HEAD. Crown flattened, somewhat concave in lateral view, granulose with inconspicuous transverse striations; anterior margin produced, spatulate, forming hood over dorsal part of face, lateral extension 


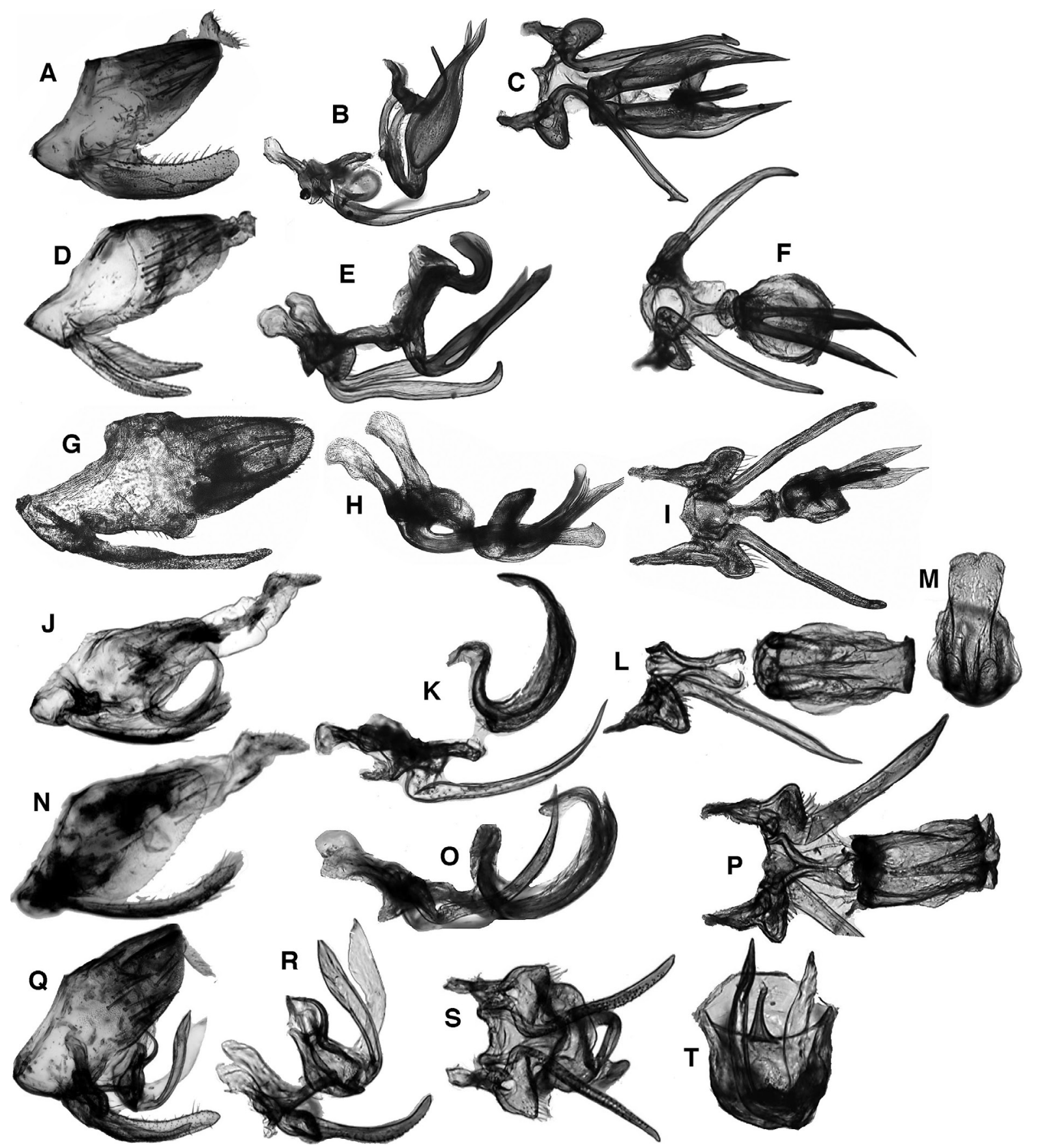

Fig. 4. Pachyjassus gen. nov., Pallijassus gen. nov. and Petalojassus gen. nov. - A-C. Pachyjassus alatus sp. nov. A. Genital capsule, lateral view. B. Genitalia, lateral view. C. Same, ventral view. D-F. Pachyjassus basifurcatus sp. nov. D. Genital capsule, lateral view. E. Genitalia, lateral view. F. Same, ventral view. - G-I. Pachyjassus ranomafanensis sp. nov. G. Genital capsule, lateral view. H. Genitalia, lateral view. I. Same, ventral view. - J-M. Pallijassus reticulatus (Evans, 1959). J. Genital capsule, lateral view. K. Genitalia, lateral view. L. Same, ventral view. M. Aedeagus, posterior view. N-P. Pallijassus stenospatulatus (Evans, 1959). N. Genital capsule, lateral view. O. Genitalia, lateral view. P. Same, ventral view. - Q-T. Petalojassus ochrescens sp. nov. Q. Genital capsule, lateral view. R. Genitalia, lateral view. S. Same, ventral view. T. Aedeagus, posterior view. Photos not to scale. 
overlapping less than half of eye margin; ocelli anteromesad of eyes. Frontoclypeus moderately convex, with slight median dorsal depression; antennal ledge transverse, strongly overlapping frontoclypeus; lateral frontal suture present above antennal ledge but not extended to crown margin; gena slightly emarginate below eye, but completely concealing proepisternum; lorum small, flat; anteclypeus slightly convex, lateral margins only slightly divergent distally; rostrum slender, surpassing front trochanters but not extended beyond middle coxae.

THORAX. Pronotum strongly declivous, in profile continuing contour of posterior part of crown, much wider than head, lateral margins strongly divergent posterad, transverse striations well delimited. Forewing with few supernumerary crossveins in distal half, appendix broad and extended to wing apex, inner apical cell relatively short. Hindwing veins $\mathrm{R} 4+5$ and $\mathrm{M} 1+2$ confluent preapically but separate near apex. Front femur row IC with $\sim 10-14$ setae somewhat irregularly arranged basally; AV with several stout setae in basal half, dorsal surface of tibia somewhat flattened, PD and AD each with 4 widely spaced macrosetae. Hind femur macrosetal formula $2+2+1$ (rarely $2+2+1+1)$, tibial row AD with one or more smaller setae between successive macrosetae; tarsomere I plantar row single and weakly developed.

ABDOMEN. Male pregenital sternite distinctly longer than sternite VII, posterior margin truncate. Male pygofer base band-like, dorsally with median posterior projection; lobe separated from base by membranous vertical cleft, with numerous macrosetae in distal half, apex broadly rounded, processes and spines absent, ventral margin with slight lobe near base bearing several fine setae. Subgenital plate with few macrosetae, dorsolateral margin with row of long, fine setae. Style apophysis slender, smooth, without denticuli, apex curved dorsad with blunt tip. Aedeagus with paired processes arising at base, shaft simple, without processes. Female abdominal sternite VII obtusely emarginate. Second valvulae slender, parallel-sided through most of length, with two widely spaced dorsal preapical teeth and series of smaller, close-set teeth distally on dorsal margin.

\title{
Remarks
}

This genus is similar to Punctijassus gen. nov. in overall structure and in having paired black spots on the legs, but the included species are larger, with extra crossveins in the forewing, and have basal processes of the aedeagus paired rather than single.

Key to species of Pachyjassus gen. nov. (males)

1. Male pygofer with rounded lobe near midlength of posteroventral margin (Fig. 4G); basal processes of aedeagus closely adjacent to shaft (Fig. 4H) ..........Pachyjassus ranomafanensis gen. et sp. nov.

- Male pygofer without lobe near midlength of posteroventral margin; basal processes of aedeagus well separated from shaft basally (Fig. 4E)

2. Aedeagus with shaft strongly compressed and broad in lateral view, basal processes parallelsided through most of length (Fig. 4E) achyjassus basifurcatus gen. et sp. nov.

- Aedeagus with shaft tubular and slender, basal processes strongly expanded near base, then tapered (Fig. 4B) Pachyjassus alatus gen. et sp. nov.

\author{
Pachyjassus alatus gen. et sp. nov. \\ urn:1sid:zoobank.org:act:AA191E72-BDD2-4A5F-A8A8-2E2A25D3C29D
}

Figs $1 \mathrm{~A}, 4 \mathrm{~A}-\mathrm{C}$

\section{Etymology}

The species name 'alatus' ('winged') refers to the wing-like processes of the aedeagus. 


\section{Material examined}

Holotype

MADAGASCAR • O'; "MADAGASCAR: Mahajanga Prov: Parc National Tsingy de Bemaraha, $3.4 \mathrm{~km}$ 93 E, Bekopaka, Tombeau Vazimba, Elev 50m, 6-10 Nov. 2001, 198'31" S 4449'41" E, coll: Fisher, Griswold et al. California Acad. of Sciences, malaise trap, in tropical dry forest, coll. code: BLF4233"; CAS.

\section{Description}

Length of male $7.8 \mathrm{~mm}$ (female unknown). Color and structural features as described for genus except darker overall, with face, thoracic ventral sclerites and femora mostly black, tibiae and tarsi reddish, at least dorsally. Hind tibial rows PD, AD and AV with 20, 14 and 15 macrosetae, respectively. Style apophysis slender, sinuate, with short preapical dorsolateral projection. Connective with anterior margin acutely produced. Aedeagus with atrium V-shaped in posterior view; shaft slender, tubular, arising from venter of atrium, curved dorsad and tapered distally, apex blunt, gonopore at apex; with pair of long ventral processs movably articulated to sides of atrium fused near base, then divided distally, each branch expanded near base in lateral view, then irregularly tapered to apex, much longer than shaft.

Pachyjassus basifurcatus gen. et sp. nov.

urn:1sid:zoobank.org:act:FE31A841-0710-4589-AE7B-3690A3AFC5DB

Figs 1B, 4D-F, 16A-C

\section{Etymology}

The species name refers to the basally forked ventral process of the aedeagus.

\section{Material examined}

\section{Holotype}

MADAGASCAR • ô; "MADAGASCAR: Tulear Province, Beza Mahafaly Reserve, Parcelle I near

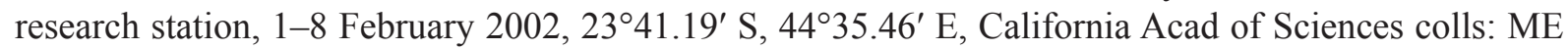
Irwin, FD Parker, R. Harin'Hala, malaise trap in dry deciduous forest, elev 165 m, MA-02-14A-14"; CAS.

\section{Paratypes}

MADAGASCAR - Toliara • 2 ồं; Andohahela National Park, Tsimelahy, Parcelle II; $24^{\circ} 56.21^{\prime}$ S, 463․60' E; alt. 180 m; 15-26 Feb. 2003; M. Irwin, F. Parker and R. Harin’Hala leg.; Malaise trap; transitional forest; MA-02-20-16; INHS -1 ; ; same collection data as for preceding; 26 Jan.-5 Feb. 2003; MA-02-20-14; CAS • 1 क; Andohahela National Park, Ihazofotsy Parcelle III; 2449.85' S, 4632.17' E; 24 Feb.-6 Mar. 2003; M. Irwin, F. Parker and R. Harin’Hala leg.; alt. 80 m; Malaise trap; in dry spiny forest; MA-02-21-11; INHS.

\section{Description}

Length of male $7.0-7.7 \mathrm{~mm}$, female $8.6 \mathrm{~mm}$. Color and structural features as described for genus; venter including face mostly dull stramineous, except ventral surface of antennal ledge and anterolateral margin of pronotum below carina dark brown. Hind tibial rows PD, AD and AV with 17-18, 11-12 and 14-16 macrosetae, respectively. Style apophysis somewhat broadened near midlength, without preapical projection. Connective with anterior margin roundly produced. Aedeagus with atrium disc-like, shaft strongly compressed, arising from dorsum of atrium, extended posterad, then strongly recurved, somewhat expanded distally, apex obliquely rounded, gonopore on posterior surface of apex; long ventral process arising from ventral end of atrium, forked near base, with two parallel and somewhat asymmetrical branches extended posterodorsad nearly to level of shaft apex. Female sternite VII with posterior margin broadly angulately emarginate. Ovipositor as described for genus. 
Pachyjassus ranomafanensis gen. et sp. nov. urn:1sid:zoobank.org:act:F28B2344-C70F-4929-8DD1-32B48A2A8E7C

Figs $1 \mathrm{C}, 4 \mathrm{G}-\mathrm{I}, 16 \mathrm{D}-\mathrm{F}$

\section{Etymology}

The species is named for the national park where the holotype was collected.

\section{Material examined}

Holotype

MADAGASCAR - O'; "MADAGASCAR: Province Fianarantsoa, Parc National Ranomafana, Belle

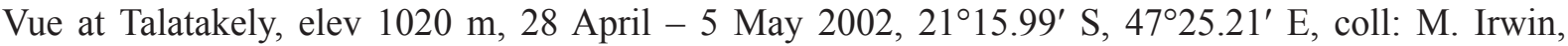
R. Harin'Hala, California Acad of Sciences, malaise, secondary tropical forest, MA-02-09C-27”; CAS.

\section{Paratypes}

MADAGASCAR - Antananarivo $\bullet 1$ $\partial^{\lambda}, 1$; Parc National Ranomafana, Belle Vue at Talatakely; $21^{\circ} 15.99^{\prime} \mathrm{S}, 47^{\circ} 25.21^{\prime} \mathrm{E}$; alt. $1020 \mathrm{~m}$; 31 Mar.-7 Apr. 2002; MA-02-09C-23; CAS • 1 đ̊; $3 \mathrm{~km} 41^{\circ} \mathrm{NE}$

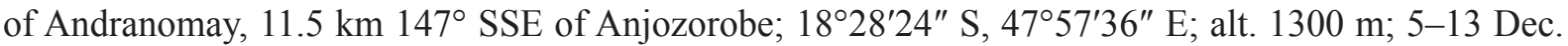
2000; Fisher, Griswold et al. leg.; Malaise trap; montane rainforest; coll. code: BLF2375; CAS • 1 ○; same collection data as for preceding; INHS.

\section{Description}

Length of male 7.1-7.3 mm, female $9.4 \mathrm{~mm}$. Crown with marginal rim black ventrally, but anterodorsal part of frontoclypeus pale ochraceous; middle and hind femur without black spot on anterior surface of apex. Crown shorter than pronotum, anterior margin broadly rounded. Hind tibial rows PD, AD and AV with 17-20, 14 and 13-15 macrosetae, respectively. Male pygofer with large semicircular ventral lobe near midlength, just basad of membranous cleft separating distal part of lobe. Style apophysis slender throughout, somewhat sinuate, rugulose ventrally, apex slightly broadened, rounded ventrally and with short, acute tip dorsally. Connective with anterior margin truncate. Aedeagus with atrium ovoid, with short, distinctly separate, broadly V-shaped dorsal connective; shaft slender, tubular basally, curved dorsad, gonopore preapical on posteroventral surface; apical extension of shaft compressed, forming continuous curve with rest of shaft, rounded apically in lateral view; with two pairs of ventral processes arising from base, one pair large, compressed and broadened distally in ventral view, with tapered apices extended beyond shaft apex, only slightly divergent from shaft in lateral and ventral views, second pair dorsad of and partly enclosed by first pair, slender and curved slightly dorsad distally, slightly shorter than shaft. Female abdominal sternite VII with slight median notch.

\section{Remarks}

This species is less robust than the other two species of the genus and also differs in having the aedeagal processes closely adjacent to the shaft and the transverse striations of the crown very weakly developed.

Pallijassus gen. nov.

urn:1sid:zoobank.org:act:C83C42E2-0DDF-4C51-9E7D-F2746E9980F6

Figs. 1D, 4J-P, 16G-I, 20-21

\section{Type species}

Platyjassus stenospatulatus Evans, 1959.

\section{Etymology}

The genus name, a masculine noun, combines the Latin prefix 'palli-' ('pale') with '-jassus', a common suffix for genera in this subfamily, and refers to the relatively pale overall coloration of the included species. 


\section{Diagnosis}

This genus may be distinguished by the following combination of features: body robust; dorsum pale yellow, stripes or spots, if present, inconspicuous; vertex not overlapping anterolateral margin of eye, crown transversely striate anteriorly; frontoclypeus punctate; forewing venation reticulate; hindwing veins $\mathrm{R} 4+5$ and $\mathrm{M} 1+2$ confluent preapically but separate near apex; hind femur macrosetal formula $2+2+1+1+1+1$; aedeagus with shaft depressed, without distinct processes.

\section{Descripton}

Habitus. Large platyjassines $(9.2-12.3 \mathrm{~mm})$. Color pale stramineous, darker markings absent or inconspicuous.

HEAD. Crown flattened, with numerous irregular transverse striations becoming less prominent posteriorly, anterior margin strongly produced, spatulate, forming hood over dorsal part of face, only slightly overlapping eye margin; ocelli anteromesad of eyes, relatively large and close to eyes. Frontoclypeus moderately convex, punctate medially, without median dorsal depression; antennal ledge oblique, strongly overlapping frontoclypeus; lateral frontal suture present above antennal ledge but not extended to crown margin; gena slightly emarginate below eye, proepisternum partially exposed; lorum small, flat; anteclypeus convex, lateral margins evenly divergent distally; rostrum slender, not surpassing front trochanters.

THORAX. Pronotum slightly declivous, in profile much wider than head, lateral margins strongly divergent posterad, texture finely punctate, transverse striations obsolete. Forewing with numerous supernumerary crossveins, appendix broad and extended to wing apex, inner apical cell elongate, slender. Hindwing veins $\mathrm{R} 4+5$ and M1+2 confluent preapically but separate near apex. Front femur row IC with setae in single row; AV with single row of stout setae in basal half, tibia dorsal surface rounded, PD and AD macrosetae only partially differentiated. Hind femur macrosetal formula $2+2+1+1+1+1$, tibial row $\mathrm{AD}$ with one or more smaller setae between successive macrosetae; tarsomere I with two plantar rows, pecten with 4 platellae.

ABDomen. Male pregenital sternite slightly longer than sternite VII, posterior margin truncate. Pygofer base band-like, dorsally with median posterior projection; lobe separated from base by membranous vertical cleft, with numerous macrosetae in distal half, apex rounded, processes and spines absent, ventral margin without distinct group of fine setae. Subgenital plate with median longitudinal row of macrosetae, dorsolateral margin with row of long fine setae distally. Style apophysis slender, acuminate, without conspicuous denticuli. Aedeagus with shaft depressed and weakly sclerotized, curved dorsad; gonopore preapical on posterior surface. Female abdominal sternite with posterior margin produced. First valvulae with dorsal sculpturing strigate. Second valvulae slender throughout length, dorsal margin with two widely spaced, prominent teeth preapically.

\section{Remarks}

This genus is erected to receive Platyjassus stenospatulatus Evans, 1959 and Platyjassus reticulatus Evans, 1959. It differs from Platyjassus s. str. in the relatively pale overall coloration (probably light green in life), relatively narrow head lacking anterolateral extensions of the vertex overlapping the eyes, and in having the forewing venation reticulate.

\section{Key to species of Pallijassus gen. nov.}

1. Forewing with supernumerary crossveins concentrated in distal half; antennal pedicel and apex of clavus pale yellow (Fig. 21A, C) .Pallijassus stenospatulatus (Evans, 1959)

- Forewing with supernumerary crossveins distributed throughout; antennal pedicel and apex of clavus dark brown (Fig. 20A, C) ..Pallijassus reticulatus (Evans, 1959) 
Pallijassus reticulatus (Evans, 1959) comb. nov.

Fig. 20

Platyjassus reticulatus Evans, 1959: 500.

\section{Material examined}

\section{Holotype}

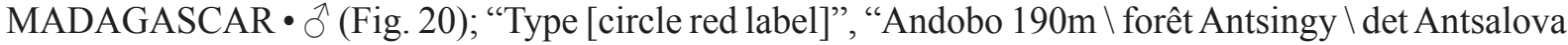
$\backslash$-II-57 P. Griv[eaud].", "Institut \ scientifique $\backslash$ MADAGASCAR", "Museum Paris $\backslash$ MNHN(EH) \ 2358", "Platyjassus $\backslash$ reticulatus Evans $\backslash$ J. W. Evans det., 1955[?]”, "ABDOMEN $\backslash$ DISSECTED BY $\backslash$ O. EVANGELISTA $\backslash \widehat{O} \backslash \mathrm{O}$. Evangelista det. '17”; MNHN(EH) 2358.

Paratype (according to original description)

MADAGASCAR • $\bigcirc$; "PARATYPE [blue label]", "Institut $\backslash$ scientifique $\backslash$ MADAGASCAR", "Museum Paris $\backslash$ MNHN(EH) $\backslash 2360$ ", "Analavelona $\backslash 1320$ m", "Platyjassus $\backslash$ reticulatus Evans $\backslash$ J. W. Evans det., 1958"; MNHN.

\section{Other material}

MADAGASCAR • 2 q ; Toliara, Bereboka, 60 km NE of Morondava; 18-23 May 1983; J.S. Noyes and M.C. Day leg.; B.M. 1983-201; BMNH.

\section{Description}

Length of male $10.0 \mathrm{~mm}$; female $12.3 \mathrm{~mm}$. Dorsum with midline of crown paler than adjacent areas, pronotum mottled, basolateral triangles of mesonotum paler than adjacent areas, antennal pedicel and apex of clavus dark brown. Head distinctly shorter than pronotum, anterior margin parabolic. Forewing with supernumerary crossveins numerous and distributed more or less evenly from base to apex. Hind tibial rows $\mathrm{PD}, \mathrm{AD}$ and $\mathrm{AV}$ with 25, 15 and 20 macrosetae, respectively. Male pygofer lobe with apex bluntly angulate. Style apophysis with series of transverse ventral rugae in basal half, apex abruptly curved dorsad. Connective with anterior margin trapezoidally produced. Aedeagus with atrium ovoid in posterior view, shaft narrow basally, broadening distally in ventral view, with conspicuous pair of lateral preapical spines, without anteriorly extended apical flap.

Pallijassus stenospatulatus (Evans, 1959) comb. nov. Figs 1D, 4J-P, 21

Platyjassus stenospatulatus Evans, 1959: 499.

\section{Material examined}

\section{Holotype}

MADAGASCAR • $\widehat{O}$ (Figs 21 A-D, without abdomen, $\widehat{O}$ according to original description); "Type [circle red label]", "Ampijoroa", "prés Tsaramandroso", "XII.51 \(R.P[aulian].)", "Platyjassus $\backslash$ stenopatulatus $\backslash$ J. W. Evans det., 19 Evans", "Institut $\backslash$ scientifique $\backslash$ MADAGASCAR", "Museum Paris $\backslash$ MNHN(EH) \2359"; MNHN(EH) 2359.

\section{Paratypes}

MADAGASCAR - Mahajanga • 1 đ (Fig. 21E-I); "Morondava fôret Sud de Befasy; I-56; R.Paulian; MNHN(EH) 2361; Platyjassus stenopatulatus Evans J.W. Evans det. 1958, abdomen dissected by O. Evangelista det. '17"; $\mathrm{MNHN}(\mathrm{EH}) 2361$ • 1 đ̄; "Morondava fôret Sud de Befasy; I-56; R.Paulian; MNHN(EH) 2361; Platyjassus stenopatulatus Evans J. W. Evans det. 19??; Brit. Mus 1958-489”; $\mathrm{BMNH}$ 
Other material

MADAGASCAR - Toliara • 3 đðં; Beza Mahafaly Reserve, Parcelle II near Bellevue; $23^{\circ} 41.39^{\prime}$ S, 44 $34.53^{\prime}$ E; alt. 180 m; 10-21 Nov. 2001; M. Irwin and R. Harin'Hala leg.; Malaise trap; in spiny forest; MA-02-14B-02; CAS. - Antananarivo - 3 수; 46 km NE of Ankazobe, Ambohitantely; $18^{\circ} 11.88^{\prime} \mathrm{S}$, $47^{\circ} 16.89^{\prime}$ E; alt. 700 m; 20 Jan.-1 Feb. 2004; M. Irwin and R. Harin'Hala leg.; Malaise trap; in sclerophyll forest; MA-27-14; CAS • 1 đ; same collection data as for preceding; INHS.

\section{Description}

Length of male 9.2-10.0 mm. Dorsum with indistinct median longitudinal band extended from crown apex to scutellum. Head distinctly shorter than pronotum, anterior margin parabolic. Hind tibial rows $\mathrm{PD}, \mathrm{AD}$ and $\mathrm{AV}$ with 22, 12 and 21 macrosetae, respectively. Male pygofer lobe relatively short with apex rounded. Style apophysis slender, smooth, apex attenuate, weakly curved dorsad. Connective with anterior margin bilobed. Aedeagus with atrium quadrate in posterior view, shaft broad and parallel-sided in ventral view, curved dorsad, without conspicuous pair of lateral preapical spines; with anteriorly extended apical flap curved slightly to strongly anterad (cf. Fig. 4K, O).

\section{Remarks}

The holotype of P. stenopatulatus from Ampijoroa (MNHN(EH) 2359) does not have an abdomen; therefore, the present interpretation of the male genitalia of this species is based on the two male paratypes from Morondava (MNHN(EH) 2361 and BMNH). Based on external features, the paratypes appear to be conspecific with the holotype. Some other more recently collected males listed above are similar to the paratypes and here considered conspecific, but the apex of the aedeagus varies from being strongly curved, as in the paratypes (Figs. 4P, 21I), to less strongly curved (Fig. 4K).

\section{Petalojassus gen. nov. urn:1sid:zoobank.org:act:55AF7FD6-B01E-4D09-B630-6F76B21C1D52}

Figs 1E, 4Q-T, 16J-L

\section{Type species}

Petalojassus ochrescens sp. nov.

\section{Etymology}

The genus name, a masculine noun, combines 'petalo-' ('flat') with '-jassus', a common suffix for generic names in this subfamily, and refers to the strongly flattened anterior margin of the head.

\section{Diagnosis}

This genus may be distinguished by the following combination of features: body medium-sized; dorsum ochraceous with opaque transcommissural marking on forewing; vertex strongly overlapping anterolateral margin of eye, crown texture uniformly shagreen; hindwing veins $\mathrm{R} 4+5$ and $\mathrm{M} 1+2$ confluent preapically but separate near apex; hind femur macrosetal formula $2+2+1$; style with denticuli; aedeagus with pair of processes arising from atrium.

\section{Description}

Habitus. Medium-sized platyjassines $(6.9-8.3 \mathrm{~mm})$. Dorsum ochraceous with symmetrical pattern of opaque pigmentation on forewings.

HEAD. Crown flattened, uniformly shagreen, anterior margin strongly produced, spatulate, forming shelf over dorsal part of face, strongly overlapping eye margin; ocelli anteromesad of eyes, relatively distant from eyes and from anterior margin of crown. Frontoclypeus moderately convex, punctate medially, 
without median dorsal depression; antennal ledge represented by curved carina below crown margin; lateral frontal suture obsolete above antennal pit; ena narrow and emarginate below eye, proepisternum largely exposed; orum small, flat; anteclypeus slightly convex, lateral margins slightly divergent distally; rostrum slender, not surpassing front trochanters.

Thorax. Pronotum slightly declivous, in profile continuing contour of crown, much wider than head, lateral margins strongly divergent posterad, transverse striations distinct. Forewing with numerous supernumerary crossveins in distal half between $\mathrm{R}, \mathrm{M}$ and $\mathrm{Cu}$, appendix broad and extended to wing apex, inner apical cell relatively short, very slender. Hindwing veins R4+5 and M1+2 confluent preapically but divergent distally. Front femur row IC with setae in irregular row; AV with irregular row of stout setae in basal half, tibia dorsal surface rounded, $\mathrm{PD}$ and $\mathrm{AD}$ macrosetae only partially differentiated. Hind femur macrosetal formula $2+2+1$, tibial row $\mathrm{AD}$ without smaller setae between successive macrosetae; tarsomere I with two plantar rows, PV row setae stout, with crenulate bases.

AвDOMEN. Male pregenital sternite distinctly longer than sternite VII, posterior margin truncate. Pygofer base band-like, dorsally with median posterior projection; lobe separated from base by membranous cleft, with numerous macrosetae in distal half, apex broadly rounded, processes and spines absent, ventral margin without distinct group of fine setae. Subgenital plate relatively broad and strongly depressed, without macrosetae, dorsolateral margin with long, fine setae. Style apophysis slender, acuminate, without preapical projection, denticulate ventrally. Connective Y-shaped, stem longer than arms, anterior margin concave. Aedeagus with shaft simple, curved dorsad, asymmetrical basal processes present, arising from enlarged atrium. Female abdominal sternite VII trilobed posteriorly. First valvulae with dorsal sculpturing strigate. Second valvulae slightly broadened medially, with slight angulate dorsal peak, without distinct teeth distally, dorsal margin weakly crenulate preapically.

\section{Remarks}

This genus resembles Platyjassus overall and in the form of the male genitalia, but differs in its more elongate body, reticulate forewing with a distinctive transcommissural marking and in having two processes instead of one arising from the aedeagal atrium.

Petalojassus ochrescens gen. et sp. nov. urn:1sid:zoobank.org:act:88482295-0FE0-455E-B2B1-8BDD4198F754

Figs 1E, 4Q-T, 16J-L

\section{Etymology}

The species name refers to the ochraceous dorsal coloration.

\section{Material examined}

\section{Holotype}

MADAGASCAR • O’; "MADAGASCAR: Province Fianarantsoa, Parc National Ranomafana, Belle Vue

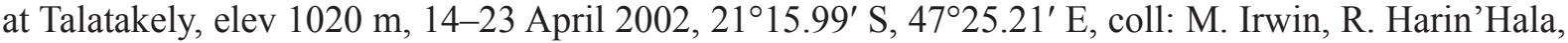
California Acad of Sciences, malaise, secondary tropical forest MA-02-09C-25"; CAS.

\section{Paratypes}

MADAGASCAR - Fianarantsoa - 1 i ; Parc National Ranomafana, radio tower at forest edge; $21^{\circ} 15.05^{\prime}$ S, $47^{\circ} 24.43^{\prime}$ E; alt. 1130 m; 16 Oct. -8 Nov. 2001; M. Irwin and R. Harin'Hala leg.; Malaise trap; mixed tropical forest; MA-02-09B-01; INHS • 1 ; $50 \mathrm{~km} \mathrm{~S}$ of Farafangana, Mahabo Mananivo,

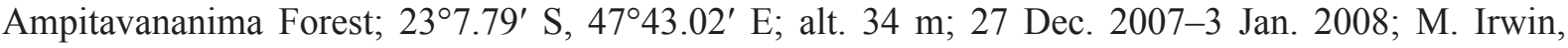
F. Parker and R. Harin'Hala leg.; Malaise trap; in low altitude littoral rainforest; MG-35-46; CAS • 
1 q; Ranomafana JIRAMA water works; $21^{\circ} 14.91^{\prime} \mathrm{S}, 4^{\circ} 27.13^{\prime} \mathrm{E}$; alt. 690 m; 21-28 Jan. 2002; M. Irwin and R. Harin'Hala leg.; Malaise trap; near river; MA-02-09D-13; CAS.

\section{Descripton}

Length of male $6.9-7.0 \mathrm{~mm}$; female $7.5-8.3 \mathrm{~mm}$. Dorsum with paired black spots on posterolateral corner of pronotum, forewing with large, symmetrical, bilobed, transcommissural olive green marking covering most of clavus and part of corium. Hind tibial rows PD, AD and AV with 21-23, 13 and 13-16 macrosetae, respectively. Style apophysis somewhat broadened near midlength, gradually curved dorsad, coarsely denticulate ventrally, apex obliquely tapered. Aedeagus with atrium shield-like; shaft arising medially from dorsal part of atrium, very short and slender, curved dorsad, gonopore apical; large process arising from ventral part of atrium to right of shaft, curved dorsad and surpassing shaft apex, apex flattened and tapered to sharp point; second poorly sclerotized process arising from right ventrolateral corner of atrium, slightly shorter than first ventral process. Female abdominal sternite VII with lateral lobes much narrower than median lobe. Ovipositor as described for genus.

\section{Phaiojassus gen. nov. urn:1sid:zoobank.org:act:21A6CADD-C0DF-4BDC-88EB-D6FAFF6B84A7 \\ Figs $1 \mathrm{~F}-\mathrm{L}, 5,16 \mathrm{M}-\mathrm{O}$}

\section{Type species}

Phaiojassus acutus sp. nov.

\section{Etymology}

The genus name, a masculine noun, combines the Greek 'phaios' ('dusky') with '-jassus', a common suffix for genera in this subfamily, and refers to the usually dark dorsal coloration.

\section{Diagnosis}

This genus may be distinguished by the following combination of features: body medium-sized; dorsum usually mostly brown with contrastingly paler forewing costa; vertex not overlapping anterolateral margin of eye, crown transversely striate anteriorly; forewing without supernumerary crossveins; hindwing veins $\mathrm{R} 4+5$ and $\mathrm{M} 1+2$ confluent preapically but separate near apex; hind femur macrosetal formula $2+2+1$; style elongate and slender, without denticuli; aedeagus usually with unpaired preapical process on shaft.

\section{Description}

HABitus. Medium sized platyjassines $(6.7-9.6 \mathrm{~mm})$. Color variable, usually heavily marked with dark brown.

Fig. 5 (next page). Phaiojassus gen. nov. - A-D. Phaiojassus acutus sp. nov. A. Genital capsule, lateral view. B. Genitalia, lateral view. C. Same, ventral view. D. Aedeagus, posterior view. - E-H. Phaiojassus bispinosus sp. nov. E. Genital capsule, lateral view. F. Genitalia, lateral view. G. Same, ventral view. H. Aedeagus, posterior view. - I-L. Phaiojassus constrictus sp. nov. I. Genital capsule, lateral view. J. Genitalia, lateral view. K. Same, ventral view. L. Aedeagus, posterior view. - M-P. Phaiojassus grandis sp. nov. M. Genital capsule, lateral view. N. Genitalia, lateral view. O. Same, ventral view. P. Aedeagus, posterior view. - Q-T. Phaiojassus spatulatus sp. nov. Q. Genital capsule, lateral view.

R. Genitalia, lateral view. S. Same, ventral view. T. Aedeagus, posterior view. - U-X. Phaiojassus undulatus sp. nov. U. Genital capsule, lateral view. V. Genitalia, lateral view. W. Same, ventral view. $\mathbf{X}$. Aedeagus, posterior view. - Y-BB. Phaiojassus unispinosus sp. nov. Y. Genital capsule, lateral view. Z. Genitalia, lateral view. AA. Same, ventral view. BB. Aedeagus, posterior view. Photos not to scale. 


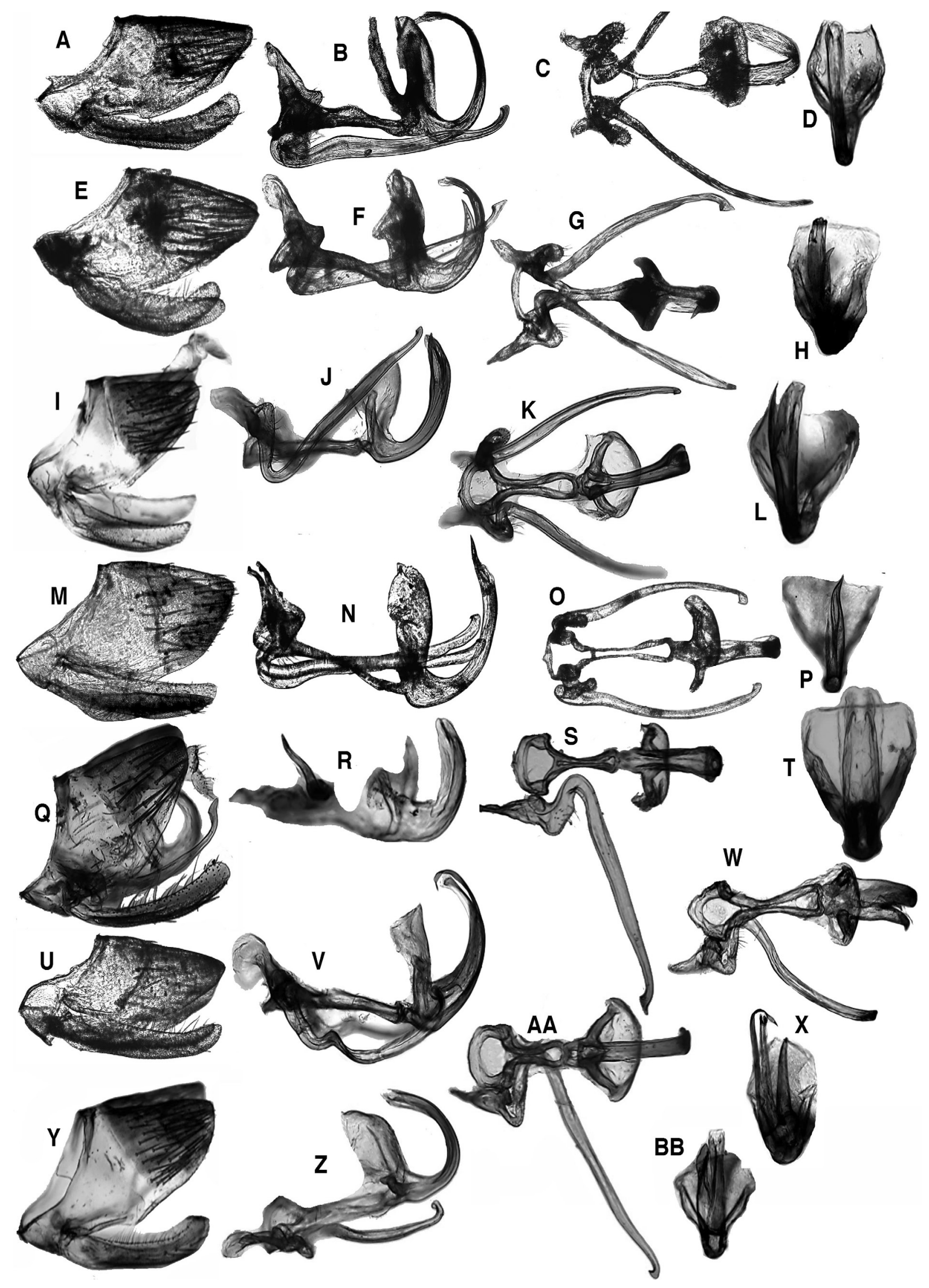


HEAD. Crown declivous, slightly convex, with numerous well delimited transverse striations over entire length, anterior margin well delimited by parallel transverse carinae but not spatulate, forming only slight ledge over dorsal part of face, without anterolateral extension over eye; ocelli anteromesad of eyes, closer to eyes than to midline. Frontoclypeus moderately convex, with median dorsal depression; antennal ledge oblique, not overlapping frontoclypeus; lateral frontal suture extended to crown margin above antennal ledge; gena slightly emarginate below eye and relatively broad more ventrad, completely concealing proepisternum; lorum small, flat; anteclypeus slightly convex, lateral margin strongly divergent distally; ostrum broad, not extended beyond front trochanters.

THORAX. Pronotum declivous, in profile continuing contour of crown, much wider than head, lateral margins strongly divergent posteriorly, transverse striations well delimited. Forewing without supernumerary crossveins, appendix broad and extended to wing apex, inner apical cell relatively long. Hindwing veins R4+5 and M1+2 confluent preapically, then separate near apex. Front femur rows IC and AV well delimited, with stout setae of similar sizes, somewhat irregular; dorsal surface of tibia rounded, PD with three or more widely spaced macrosetae. Hind femur macrosetal formula $2+2+1$, tibial row AD usually with one smaller seta between each successive pair of macrosetae; tarsomere I plantar row single.

AвDOMEN. Male pregenital sternite distinctly longer than sternite VII, posterior margin truncate or slightly emarginate. Male pygofer base band-like, dorsally without median posterior projection; lobe fused to base, with numerous macrosetae in distal half, processes and spines absent, ventral margin with sparse group of fine setae. Subgenital plate with median longitudinal row or band of macrosetae, dorsolateral margin with sparse long fine setae. Style apophysis very slender, without ventral denticuli, apex curved dorsomesad, with acute dorsal preapical angle. Connective stem long, arms weakly developed, anterior margin convex. Aedeagus with atrium $\mathrm{V}$-shaped in posterior view, shaft slightly to strongly asymmetrical, one or more unpaired basal or prepical processes usually present. Female pregenital sternite with posterior margin truncate, with median notch. First valvulae slender, tapered, dorsal sculpturing strigate. Second valvulae slender, tapered, with two indistinct, widely spaced preapical dorsal teeth.

\section{Remarks}

This genus is structurally similar to Pseudocurtara gen. nov., but differs in the mostly uniform dark brown dorsal coloration, absence of paired black spots on the crown and lack of reticulate venation in the forewing.

\section{Key to species of Phaiojassus gen. nov. (males)}

1. Dorsum dark brown, except for pale continuous marginal band along forewing costa (Fig. 1F) ...2

- Dorsum ochraceous or dark brown, forewing costa without pale band, if present, discontinuous (Fig. 1H-I)

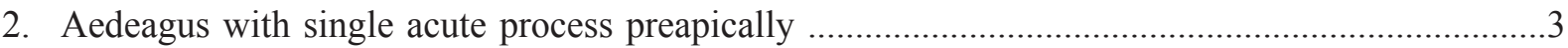

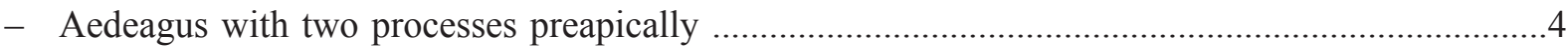

3. Aedeagus apex well sclerotized and acute (Fig. 5D) .............Phaiojassus acutus gen. et sp. nov.

- Aedeagus apex membranous and blunt (Fig. 5BB) .......Phaiojassus unispinosus gen. et sp. nov.

4. Forewing with pale costal area distinctly narrower near midlength than basally and preapically (Fig. 1K)

Phaiojassus undulatus gen. et sp. nov.

- Forewing with pale costal area nearly uniform in width throughout length .................................5

5. Spines of aedeagal shaft asymmetrical, one large and one small (Fig. 5F, H)

- Spines of aedeagal shaft both small, symmetrical (Fig. 5T) ...Phaiojassus spatulatus gen. et sp. nov. 
6. Dorsum uniformly ochraceous, without dark brown pattern (Fig. 1I)

Phaiojassus grandis gen. et sp. nov.

- Dorsum dark brown with two triangular stramineous areas along forewing costal margin (Fig. 1H)

Phaiojassus constrictus gen. et sp. nov.

Phaiojassus acutus gen. et sp. nov.

urn:1sid:zoobank.org:act:786C828E-0FC8-4E5F-9C5E-174334577872

Figs $1 \mathrm{~F}, 5 \mathrm{~A}-\mathrm{D}, 16 \mathrm{M}-\mathrm{O}$

\section{Etymology}

The species name refers to the acute apex of the aedeagus.

\section{Material examined}

\section{Holotype}

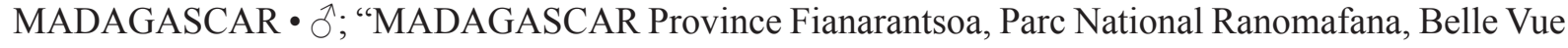

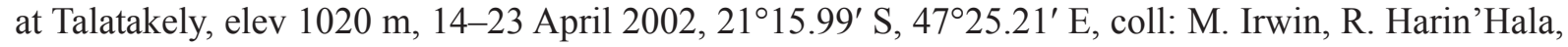
California Acad of Sciences, malaise, secondary tropical forest, MA-02-09C-25"; CAS.

\section{Paratypes}

MADAGASCAR - Fianarantsoa - 1 ภ, 1 q; Parc National Ranomafana, Belle Vue at Talatakely; $21^{\circ} 15.99^{\prime} \mathrm{S}, 47^{\circ} 25.21^{\prime} \mathrm{E}$; alt. 1020 m; 14-23 Apr. 2002; M. Irwin and R. Harin'Hala leg.; Malaise trap; secondary tropical forest; MA-02-09C-25; CAS -1 त; same collection data as for preceding; INHS •

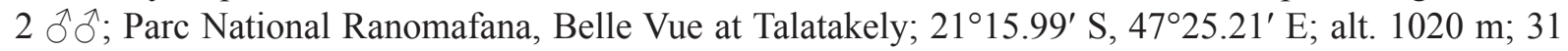

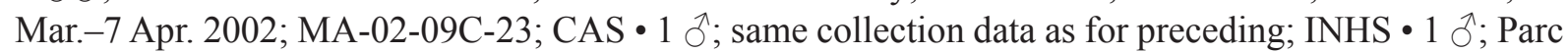
National Ranomafana, Belle Vue at Talatakely; $21^{\circ} 15.99^{\prime}$ S, 47²5.21' E; alt. 1020 m; 21-28 Jan. 2002; MA-02-09C-13; CAS • 1 ○ं; Parc National Ranomafana, Belle Vue at Talatakely; $21^{\circ} 15.99^{\prime} \mathrm{S}, 47^{\circ} 25.21^{\prime} \mathrm{E}$; alt. 1020 m; 22-28 Nov. 2001; MA-02-09C-04; INHS.

\section{Description}

Length of male $6.7-7.0 \mathrm{~mm}$; female $8.2 \mathrm{~mm}$. Dorsum uniformly dark brown except for pale stramineous costal area of forewing, venter uniformly pale stramineous. Hind tibial rows PD, AD and AV with 1920, 12 and 15 macrosetae, respectively. Style apophysis with apex rounded. Connective with anterior margin evenly convex. Aedeagus with shaft slender, strongly curved dorsad, flattened, belt-like and slightly twisted through most of length, apex rounded in posterior view, gonopore preapical on posterior surface; small digitiform process arising near apex on left side and extended distad nearly to shaft apex.

Phaiojassus bispinosus gen. et sp. nov. urn:1sid:zoobank.org:act:DA54C203-7E27-4245-9D46-17CC86CBBEE2

Figs $1 \mathrm{G}, 5 \mathrm{E}-\mathrm{H}$

\section{Etymology}

The species name refers to the pair of spines on the aedeagus.

\section{Material examined}

\section{Holotype}

MADAGASCAR - $\hat{0}$; "MADAGASCAR Province Fianarantsoa, Parc National Ranomafana, Vohiparara, at broken bridge, el $1110 \mathrm{~m}, 12-19$ March 2002, 21 ${ }^{\circ} 13.57^{\prime} \mathrm{S}, 47^{\circ} 22.19^{\prime} \mathrm{E}$, coll: M. Irwin, R. Harin'Hala, California Acad of Sciences, malaise trap in high altitude rainforest, MA-02-09A-20"; CAS. 


\section{Paratype}

MADAGASCAR - Antananarivo • 1 $\delta^{\circ} ; 3 \mathrm{~km} 41^{\circ} \mathrm{NE}$ of Andranomay, $11.5 \mathrm{~km} 147^{\circ} \mathrm{SSE}$ of Anjozorobe; $18^{\circ} 28^{\prime} 24^{\prime \prime}$ S, 47 57' 36" E; alt. 1300 m; 5-13 Dec. 2000; Fisher, Griswold et al. leg.; montane rainforest; beating low vegetation; BLF2398; INHS.

\section{Description}

Length of male 7.2-7.7 mm (female unknown). Dorsum uniformly dark brown except for stramineous costal area of forewing, venter pale stramineous. Hind tibial rows PD, AD and AV with 18, 12 and 11-13 macrosetae, respectively. Style with apex of apophysis sharply angulate. Connective with anterior margin evenly convex. Aedeagus with shaft evenly curved dorsad, dorsal surface flattened in distal half, apex membranous, gonopore apical on posterior surface; with small, unpaired digitiform process arising on left side of shaft near apex and extended distad but not reaching shaft apex; larger unpaired acute process arising on right side near shaft midlength and extended distad but not surpassing process on left side.

Phaiojassus constrictus gen. et sp. nov. urn:lsid:zoobank.org:act:3B5A987A-64FF-402E-A6D9-6DD58BBDF56C

Figs $1 \mathrm{H}, 5 \mathrm{I}-\mathrm{L}$

\section{Etymology}

The species name refers to the dark dorsal color pattern, which gives individuals the appearance of having a medial constriction.

\section{Material examined}

\section{Holotype}

MADAGASCAR • $\jmath^{\Uparrow}$; "MADAGASCAR: Antsiranana, Ambondrobe, 41.1km $175^{\circ}$ Vohemar, 29 November 2004, 134ㄴ $55^{\prime \prime}$ S 05006'06" E, California Acad. of Sciences, coll. B.L.Fisher, elev 10 $\mathrm{m}$, yellow pan trap, littoral rainforest, BLF11098"; CAS.

\section{Paratype}

MADAGASCAR - Antsiranana - 1 đ’; Parc National Montagne d'Ambre; 12 $30^{\prime} 52^{\prime \prime}$ S, 49 $10^{\prime} 53^{\prime \prime}$ E; alt. 960 m; 4-19 Mar. 2001; M. Irwin and R. Harin'Hala leg.; Malaise trap; MA-0101A-08; INHS.

\section{Description}

Length of male 7.0-7.5 mm (female unknown). Dorsum dark brown except for two triangular stramineous areas on costal area of forewing, one near base and one preapical. Hind tibial rows PD, AD and AV with 19, 13 and 14 macrosetae, respectively. Style apophysis with apex bluntly angulate. Connective with anterior margin evenly convex. Aedeagus with shaft relatively robust, curved dorsad, tubular basally, depressed and slightly twisted distally, gonopore apical on posterior surface; with large acute process arising on left side preapically and extended to apex.

Phaiojassus grandis gen. et sp. nov.

urn:1sid:zoobank.org:act:277BDE0E-87FF-4107-B914-027A84815A69

Figs 1I, 5M-P

\section{Etymology}

The species name refers to the relatively large size of the species. 


\section{Material examined}

\section{Holotype}

MADAGASCAR • \’; "MADAGASCAR: Antsiranana Province, Réserve Spéciale de l'Ankarana, 13.6

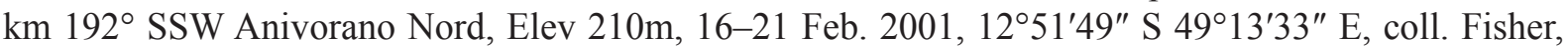
Griswold et al., Calif. Academy of Sciences, beating low veg. in tropical dry forest, code: BLF3016"; CAS.

\section{Paratype}

MADAGASCAR - Antsiranana • ${ }^{\top}$; Réserve Spéciale de l'Ankarana, $13.6 \mathrm{~km} 192^{\circ} \mathrm{SSW}$ of Anivorano Nord; 12 51'49" S, 49¹3'33" E; alt. 210 m; 16-20 Feb. 2001; Fisher, Griswold et al. leg.; Malaise trap; tropical dry forest; coll. code: BLF3011; INHS.

\section{Description}

Length of male $9.6 \mathrm{~mm}$ (female unknown). Color ochraceous, anterior margin of head and anteclypeus pale red, coxae and femora mostly dark brown, distal parts of legs crimson. Hind tibial rows PD, AD and AV with 22, 13 and 14 macrosetae, respectively. Style apophysis with apex rounded. Connective with anterior margin with small, angulate medial projection. Aedeagus with shaft evenly curved dorsad, tubular, gonopore arising preapically on left side, right side extended beyond gonopore and acuminate, slightly sinuate in posterior view.

Phaiojassus spatulatus gen. et sp. nov.

urn:1sid:zoobank.org:act:99676FE5-D671-4867-A135-03B2A6BAD817

Figs 1J, 5Q-T

\section{Etymology}

The species name refers to the spatulate shaft of the aedeagus.

\section{Material examined}

Holotype

MADAGASCAR - ${ }^{7}$; "MADAGASCAR: Province d'Antisirana, Parc National Montagne d'Ambre

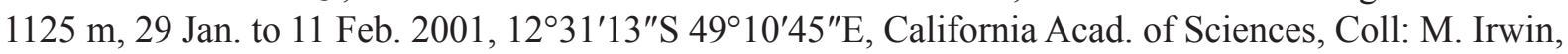
R. Harin'Hala, malaise trap, MA-01-01D-03"; CAS.

\section{Description}

Length of male $6.2 \mathrm{~mm}$ (female unknown). Dorsum uniformly dark brown except for stramineous costal area of forewing, venter pale stramineous. Hind tibial rows PD, AD and AV with 18, 14 and 15 macrosetae, respectively. Style with apex of apophysis sinuate, curved dorsad and then slightly posterad, with short, obtuse preapical angle. Aedeagus with shaft relatively short and broad in lateral and posterior views, evenly curved dorsad, dorsal surface flattened and membranous in distal half, with pair of small, distally extended submedial spines preapically on posterior surface, closely appressed to shaft flanking small preapical gonopore, shaft apex truncate in posterior view.

Phaiojassus undulatus gen. et sp. nov. urn:1sid:zoobank.org:act:930DA66A-3201-49D3-AF35-5ADEECC52CD6

Figs. $1 \mathrm{~K}, 5 \mathrm{U}-\mathrm{X}$

\section{Etymology}

The species name refers to the undulate margin of the area of dark pigmentation on the forewing. 


\section{Material examined}

\section{Holotype}

MADAGASCAR - ${ }^{\lambda}$; "MADAGASCAR: Province d'Antsiranana, dry forest, $7 \mathrm{~km} \mathrm{~N}$ of Joffreville, 426 m, 13-20 January 2007, $12^{\circ} 27^{\prime} \mathrm{S}, 49^{\circ} 14^{\prime} \mathrm{E}$, California Acad. of Sciences, Coll: M. Irwin, R. Harin'Hala, malaise trap MA-01-07-15"; CAS.

\section{Description}

Length of male $7.6 \mathrm{~mm}$ (female unknown). Dorsum uniformly dark brown except for stramineous costal area of forewing, stramineous area with wider areas near base and at level of apex of clavus with narrower intervening area. Hind tibial rows PD, AD and AV with 19,12 and 17 macrosetae, respectively. Style with apex of apophysis rounded, with slight dorsal preapical angle. Connective with anterior margin strongly produced and angulate. Aedeagus with shaft evenly curved dorsad, slender, tubular, tapered, gonopore apical; long, slender process arising preapically on left side of shaft and strongly recurved beyond shaft apex; second, broader acuminate process arising preapically on right side of shaft and not extended to shaft apex.

\section{Phaiojassus unispinosus gen. et sp. nov. urn:1sid:zoobank.org:act:01097938-1320-46F9-85BD-EF7D7DCDE55F}

Figs $1 \mathrm{~L}, 5 \mathrm{Y}-\mathrm{BB}$

\section{Etymology}

The species name refers to the presence of a single spine on the aedeagus.

\section{Material examined}

\section{Holotype}

MADAGASCAR - O’; "MADAGASCAR: Toliara Foret Ivohibe $55.0 \mathrm{~km}$ N Tolagnaro 2-4 Dec 2006, $24^{\circ} 34^{\prime} 08^{\prime \prime}$ S $047^{\circ} 12^{\prime} 14^{\prime \prime}$ E, California Acad of Sciences, coll. B.L.Fisher et al., malaise trap elev $200 \mathrm{~m}$, rainforest BLF15448"; CAS.

\section{Paratypes}

MADAGASCAR - Fianarantsoa - 1 o ; Parc National Ranomafana, Vohiparara, at broken bridge; $21^{\circ} 13.57^{\prime} \mathrm{S}, 47^{\circ} 22.19^{\prime} \mathrm{E}$; alt. $1110 \mathrm{~m}$; 22-29 Apr. 2002; M. Irwin and R. Harin'Hala leg.; Malaise trap;

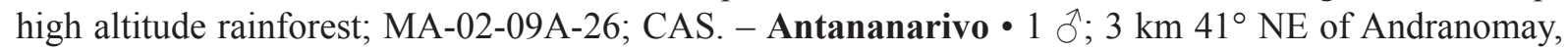

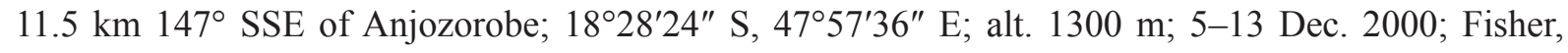
Griswold et al. leg.; Malaise trap; montane rainforest; coll. code: BLF2372; INHS.

\section{Description}

Length of male 6.7-7.0 mm (female unknown). Dorsum uniformly dark brown except for stramineous costal area of forewing, venter pale stramineous. Hind tibial rows PD, AD and AV with 21, 10-12 and 13-14 macrosetae, respectively. Style with apex of apophysis bluntly angulate. Connective with anterior margin evenly convex. Aedeagus with shaft evenly curved dorsad, dorsal surface trough-like, apex weakly bilobed in posterior view, gonopore apical on posterior surface; with large, unpaired, asymmetrically spatulate process arising on left side of shaft near midlength, extended along shaft but not reaching shaft apex.

Pictojassus gen. nov. urn:1sid:zoobank.org:act:89A1C1BB-71EA-4203-BBA6-EEA900E5DE31

Figs $1 \mathrm{M}-\mathrm{O}, 6,16 \mathrm{P}-\mathrm{X}$

\section{Type species}

Pictojassus kirindiensis sp. nov. 


\section{Etymology}

The name, a masculine noun, is formed by combining 'picto-', meaning 'painted', with '-jassus', a common suffix for genera of Iassinae, and referring to the presence of orange or red markings on the dorsum.

\section{Diagnosis}

This genus may be distinguished by the following combination of features: body medium-sized; dorsum pale, with numerous symmetrical red markings; vertex strongly overlapping anterolateral margin of eye, crown transversely rugose; distal half of forewing with supernumerary crossveins; hindwing veins R4+5 and $\mathrm{M} 1+2$ confluent preapically but separate near apex; hind femur macrosetal formula $2+2+1$; style slender, without denticuli; aedeagus with one or more distal processes.

\section{Description}

Habitus. Small to medium-sized platyjassines $(5.4-6.5 \mathrm{~mm})$. Color stramineous, with extensive symmetrical orange or red dorsal markings on head, pronotum and forewing.

HEAD. Crown declivous, convex, with numerous irregular transverse rugae, anterior margin produced, spatulate, forming hood over dorsal part of face, lateral extension overlapping more than half of eye margin; ocelli anteromesad of eyes. Frontoclypeus moderately convex without median depression; antennal ledge transverse, strongly overlapping frontoclypeus; lateral frontal suture present above antennal ledge but not extended to crown margin; gena slightly emarginate below eye, partly exposing

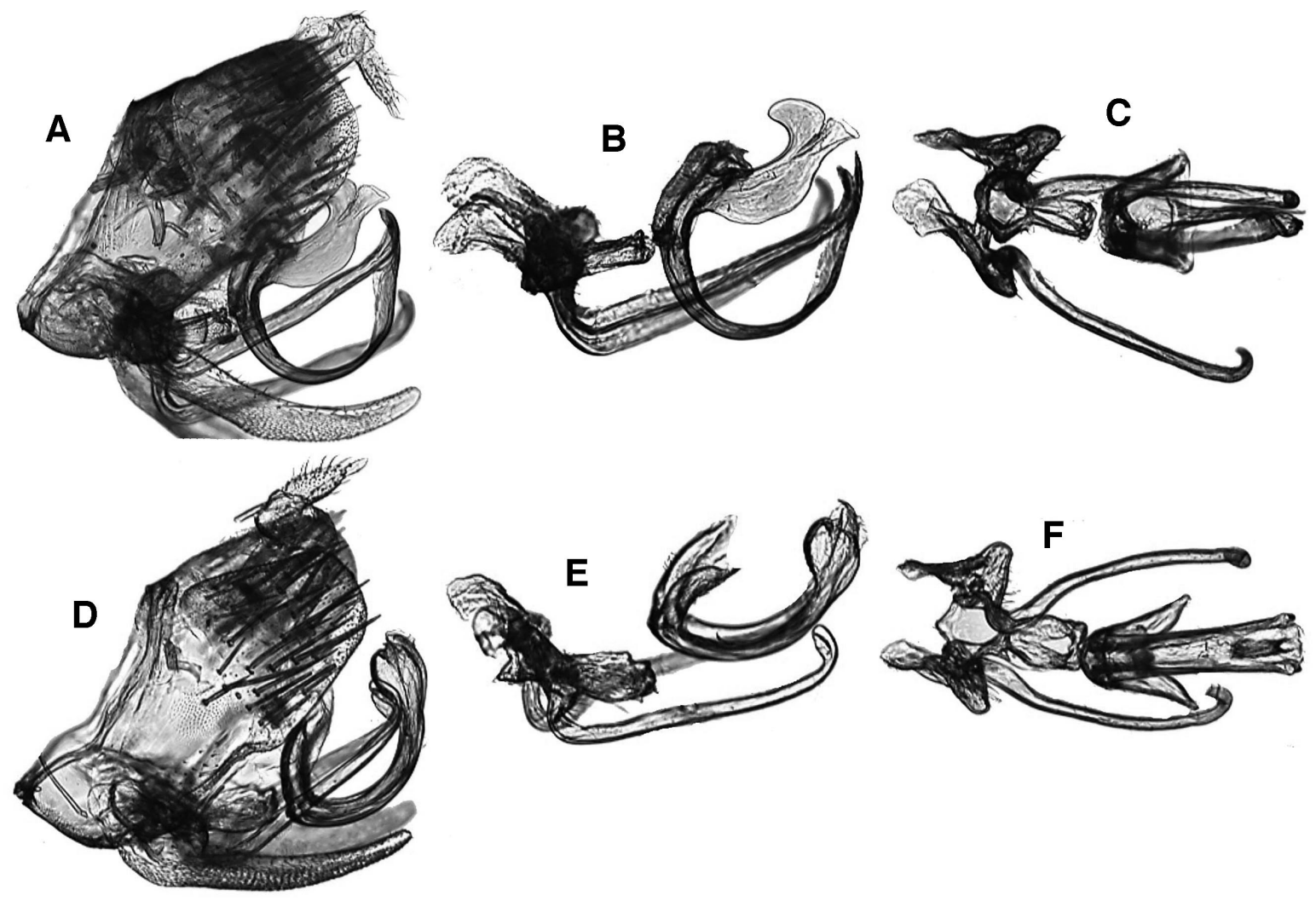

Fig. 6. Pictojassus gen. nov. - A-C. Pictojassus kirindiensis sp. nov. A. Genital capsule, lateral view. B. Genitalia, lateral view. C. Same, ventral view. - D-F. Pictojassus tulearensis sp. nov. D. Genital capsule, lateral view. E. Genitalia, lateral view. F. Same, ventral view. Photos not to scale. 
proepisternum; lorum small, flat; anteclypeus slightly convex, lateral margins evenly divergent distally; rostrum slender, not surpassing front trochanters.

Thorax. Pronotum declivous, in profile continuing contour of crown, much wider than head, lateral margins strongly divergent posterad. Forewing distal half with supernumerary crossveins; appendix extended to wing apex, slightly broader than inner apical cell, inner apical cell relatively short. Hindwing veins R4+5 and M1+2 confluent preapically but separate near apex. Front femur row IC with $\sim 10-14$ setae, somewhat irregularly arranged; AV with 5 stout setae in basal half, dorsal surface of tibia rounded, PD with 4 widely spaced macrosetae. Hind femur macrosetal formula $2+2+1$, tibial row AD with one or more smaller setae between successive macrosetae; tarsomere I plantar row single and weakly developed.

ABDomen. Male pygofer base band-like, dorsally with median projection; lobe separated from base by membranous vertical cleft, with numerous macrosetae in distal half, apex broadly rounded, processes and spines absent. Subgenital plate without macrosetae, lateral margin with row of small, stout setae and few inconspicuous long, fine setae. Style apophysis slender, smooth, without denticuli, apex abruptly bent dorsad, with rounded tip, recurved dorsomesad in ventral view. Connective with stem longer than arms, anterior margin angulately produced. Aedeagus with atrium V-shaped in posterior view, with weakly sclerotized plate connecting arms of V; shaft with one or more preapical processes. Female sternite VII variable interspecifically. First valvulae broad through most of length, dorsal sculpture strigate. Second valvulae abruptly broadened near midlength, dorsal margin in distal half minutely and irregularly serrate.

\title{
Remarks
}

This genus differs from others in the tribe in having numerous symmetrical red or orange markings on the head, pronotum, and forewings.

\section{Key to species of Pictojassus gen. nov.}

1. Forewing clavus without crossveins (Fig. 1M); female abdominal sternite VII with posterior margin bilobed (Fig. 16P)

Pictojassus kirindiensis gen. et sp. nov.

- Forewing clavus with one or more crossveins; female abdominal sternite VII with posterior margin produced or truncate

2. Body length $<6 \mathrm{~mm}$, forewing clavus with several crossveins (Fig. 1O); female abdominal sternite VII with posterior margin truncate (Fig. 16V) .........Pictojassus tulearensis gen. et sp. nov.

- Body length $>6 \mathrm{~mm}$, forewing clavus with single crossvein connecting Pcu to claval suture distally (Fig. 1N); female abdominal sternite VII with posterior margin roundly produced (Fig. 16S) ...

..Pictojassus productus gen. et sp. nov.

\author{
Pictojassus kirindiensis gen. et sp. nov. \\ urn:1sid:zoobank.org:act:B1443AC5-FED4-4CA5-9B6E-A4C26A389BAC
}

Figs $1 \mathrm{M}, 6 \mathrm{~A}-\mathrm{C}, 16 \mathrm{P}-\mathrm{R}$

\section{Etymology}

The species name is based on that of the Forêt de Kirindy, where most of the studied specimens were collected. 


\section{Material examined}

\section{Holotype}

MADAGASCAR - 3; "MADAGASCAR: Tulear Province, Cap Ste Marie Special Reserve, el 37 m,

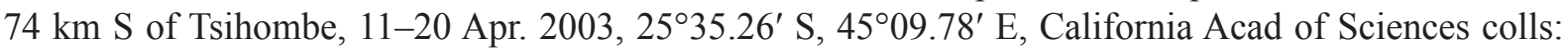
M. Irwin, F. Parker, R. Harin'Hala. malaise trap spiny bush MA-02-23-23”; CAS.

\section{Paratypes}

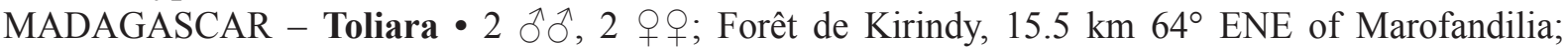
$20^{\circ} 02^{\prime} 42^{\prime \prime} \mathrm{S}, 44^{\circ} 39^{\prime} 44^{\prime \prime} \mathrm{E}$; alt. 100 m; 28 Nov.-3 Dec. 2001; Fisher, Griswold et al. leg.; Malaise trap; tropical dry forest; coll. code: BLF4601; CAS $\bullet 1 \widehat{\jmath}, 1$ \&; same collection data as for preceding; INHS.

\section{Description}

Length of male $5.4 \mathrm{~mm}$, female $6.3 \mathrm{~mm}$. Color stramineous, with symmetrical red markings on dorsum. Small brown spots present on legs but not on forewing costal margin; forewing clavus with inner orange stripe unbroken, corium with apical third extensively marked with dark brown, dorsal part of face, mesosternum, medial part of hind coxa and posterior surfaces of hind legs dark brown. Crown much shorter than pronotum, anterior margin broadly rounded, lateral extensions overlapping. Forewing clavus without crossveins, inner apical cell not subdivided by extra crossveins, clavus without crossveins. Hind tibial rows $\mathrm{PD}, \mathrm{AD}$ and $\mathrm{AV}$ with 18, 13 and 16 macrosetae, respectively. Male pregenital sternite much longer than sternite VII, posterior margin slightly bilobed. Aedeagus with shaft strongly compressed, relatively broad in lateral view, apex with rounded recurved anterior lobe and posterior tube-like extension bearing apical gonopore; base with elongate median ventral process evenly curved, well separated from shaft, with apex twisted and slightly asymmetrical. Female sternite VII with posterior margin broadly bilobed. Second valvulae with distinct hump on dorsal margin, separated from serrate distal region by V-shaped notch, serrate section straight.

Pictojassus productus gen. et sp. nov. urn:1sid:zoobank.org:act:C91464DC-9411-4CBC-BA2E-FC416653279F

Figs $1 \mathrm{~N}, 16 \mathrm{~S}-\mathrm{U}$

\section{Etymology}

The species name refers to the produced posterior margin of sternite VII in the female.

\section{Material examined}

\section{Holotype}

MADAGASCAR • + ; "MADAGASCAR: Tulear Province, Andohahela Nat'1 Park, Ihazofotsy Parcelle III, 244ㄱ.85' S, 46³2.17' E, 4-15 October 2003, California Acad of Sciences, colls: M. Irwin, F. Parker, R. Harin'Hala, elev 80 m, malaise trap - in dry spiny forest, MA-02-21-34”; CAS.

\section{Description}

Length of female $6.5 \mathrm{~mm}$ (male unknown). Color stramineous, with symmetrical red markings on dorsum and small brown dots on front and middle femora, corresponding to setal bases; forewing clavus with red stripes continuous, corium with areas of brown pigment restricted to apex. Crown distinctly shorter than pronotum, anterior margin parabolic, lateral extensions overlapping approximately half of eye margin. Forewing clavus with single crossvein connecting vein PCu to claval suture distally, inner apical cell not subdivided by crossvein. Hind tibial rows PD, AD and AV with 18, 13 and 17 macrosetae, respectively; tarsomere I pecten with five platellae. Female sternite VII with posterior margin convexly produced. Second valvulae with distinct hump on dorsal margin, separated by relatively broad concavity from serrate distal section, serrate section slightly convex. 


\section{Remarks}

Although only known from a single female, this species is readily separated from the other two known species of the genus by its relatively large size, the distinctive shape of abdominal sternite VII and the second valvulae, and the presence of a single distal crossvein in the forewing clavus.

Pictojassus tulearensis gen. et sp. nov.

urn:1sid:zoobank.org:act:10D5E6BE-7854-4126-AA98-31C94B24350F

Figs 1O, 6D-F, 16V-X

\section{Etymology}

The species name is derived from that of the province of the type locality.

\section{Material examined}

Holotype

MADAGASCAR - \} \text { ; "MADAGASCAR: Tulear Province, Cap Ste Marie Special Reserve, el 150m, }

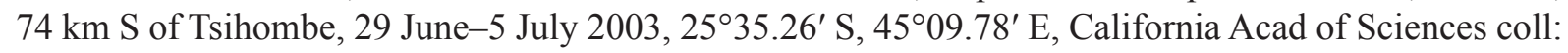
M. Irwin, R. Harin'Hala malaise trap in bush MA-23A-03"; CAS.

\section{Paratypes}

MADAGASCAR - Toliara • 1 đ̊; Andohahela National Park, Tsimelahy, Parcelle II; 2456.21' S, 46³7.60' E; alt. 180 m; 28 Jan.-12 Feb. 2004; M. Irwin, F. Parker and R. Harin'Hala leg.; Malaise trap; transitional forest; MA-02-20-53; CAS 1 万े; same collection data as for preceding; INHS • 1 ;

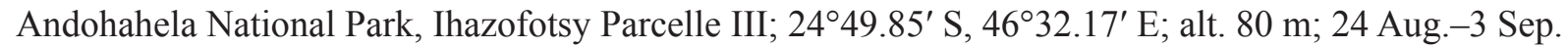
2003; M. Irwin, F. Parker and R. Harin'Hala leg.; Malaise trap; dry spiny forest; MA-02-21-31; CAS.

\section{Description}

Length of male $5.0 \mathrm{~mm}$, female $5.7 \mathrm{~mm}$. Color stramineous, with symmetrical red markings on dorsum and small brown dots on legs, corresponding to setal bases, and along forewing costal margin; forewing clavus with inner stripe broken into four spots, corium with areas of brown pigment restricted to apex. Crown distinctly shorter than pronotum, anterior margin parabolic, lateral extensions overlapping slightly more than half of eye margin. Forewing clavus with numerous crossveins, inner apical cell subdivided by one or more extra crossveins. Hind tibial rows PD, AD and AV with 18, 11 and 14 macrosetae, respectively; tarsomere I pecten with five platellae. Male pregenital sternite slightly longer than sternite VII, posterior margin truncate. Aedeagus with atrium weakly developed, shaft slender, evenly curved dorsad, dorsal margin trough-like, apex with rounded anterior lobe bearing apical gonopore and pair of slightly recurved posterolateral spines. Female sternite VII with posterior margin truncate. Second valvulae with dorsal margin forming nearly right angle at base of broadened area that forms continuous, nearly horizontal line in distal two thirds.

\section{Platyjassella gen. nov. urn:1sid:zoobank.org:act:357BA8C1-96C0-4BA1-A814-CA0358CE0697}

Figs 1P-U, 7, 16Y-AA

\section{Type species}

Platyjassella andohahelensis sp. nov.

\section{Etymology}

The genus name, a feminine noun, is a diminutive form of Platyjassus, referring to the relatively small body size of the included species. 


\section{Diagnosis}

This genus may be distinguished by the following combination of features: body relatively small; color pale stramineous, without distinct spots or stripes; vertex strongly overlapping anterolateral margin of eye, crown uniformly shagreen; hindwing veins $\mathrm{R} 4+5$ and $\mathrm{M} 1+2$ confluent preapically but separate near apex; hind femur macrosetal formula $2+2+1$; style with ventral denticuli; aedeagus with one or more distal processes.

\section{Descripton}

HaBitus. Small (5.5-6.7 mm), pale stramineous or green platyjassines.

HEAD. Crown flat, uniformly shagreen, anterior margin produced, spatulate, forming hood over dorsal part of face, lateral extension overlapping at least half of eye margin; ocelli anteromesad of eyes. Frontoclypeus moderately convex, with median depression anterodorsally; antennal ledge transverse to slightly oblique, overlapping frontoclypeus; lateral frontal suture present above antennal ledge but not extended to crown margin; gena slightly emarginate below eye, partly exposing proepisternum; lorum small, flat; anteclypeus slightly convex, lateral margins evenly divergent distally; rostrum slender, not surpassing posterior margin of mesosternum.

Thorax. Pronotum declivous, in profile continuing contour of crown, much wider than head, lateral margins strongly divergent posterad, transverse striations weakly delimited. Forewing without supernumerary crossveins, appendix extended to apex, wider than inner apical cell, inner apical cell relatively short. Hindwing veins $\mathrm{R} 4+5$ and $\mathrm{M} 1+2$ confluent preapically but separate near apex. Front femur row IC with setae in single row; AV with few stout setae in basal half, tibia dorsal surface rounded, PD with 4 widely spaced macrosetae. Hind femur macrosetal formula $2+2+1$, tibial row AD with one or more smaller setae between successive macrosetae; tarsomere I plantar row single and weakly developed, pecten with 4 platellae.

AвDomen. Male pregenital sternite slightly longer than sternite VII. Pygofer base with tergite variably shaped; lobe separated from base by membranous cleft, with or without dorsal appendage, lobe apex variably shaped. Subgenital plate with few macrosetae in submarginal band. Style apophysis slender, with numerous conspicuous ventral denticuli; apex tapered to a single point. Connective with stem as short as or shorter than arms, median anterior lobe absent. Aedeagus without basal processes, shaft slender and well sclerotized, with one or more distal apical or preapical processes usually present, gonopore apical. Female sternite VII with small median notch on posterior margin. First valvular broad through most of length, dorsal sculpture strigate. Second valvulae strongly broadened beyond midlength, dorsal margin in distal half with rounded hump followed by broad concavity and preapical tapered area without distinct teeth.

\section{Remarks}

This genus resembles Platyjassus in its uniform pale stramineous (or light green) coloration, overall structure and absence of supernumerary forewing crossveins, but differs in its smaller size and in some aspects of the male genitalia. Most species of Platyjassus (all except $P$. asymmetrica sp. nov.) also have a basal process on the aedeagus that extends distad (the preapical process of $P$. asymmetrica sp. nov. also extends distad). In contrast, species of Platyjassella gen. nov. lack a basal process on the aedeagus and usually have one or more distal processes that extend laterad or basad. Although species of Platyjassella gen. nov. are very similar to each other in external appearance, the genus is more heterogeneous than other genera of Platyjassini in the form of the male pygofer and style, suggesting that it may be further subdivided once the fauna becomes better known. 


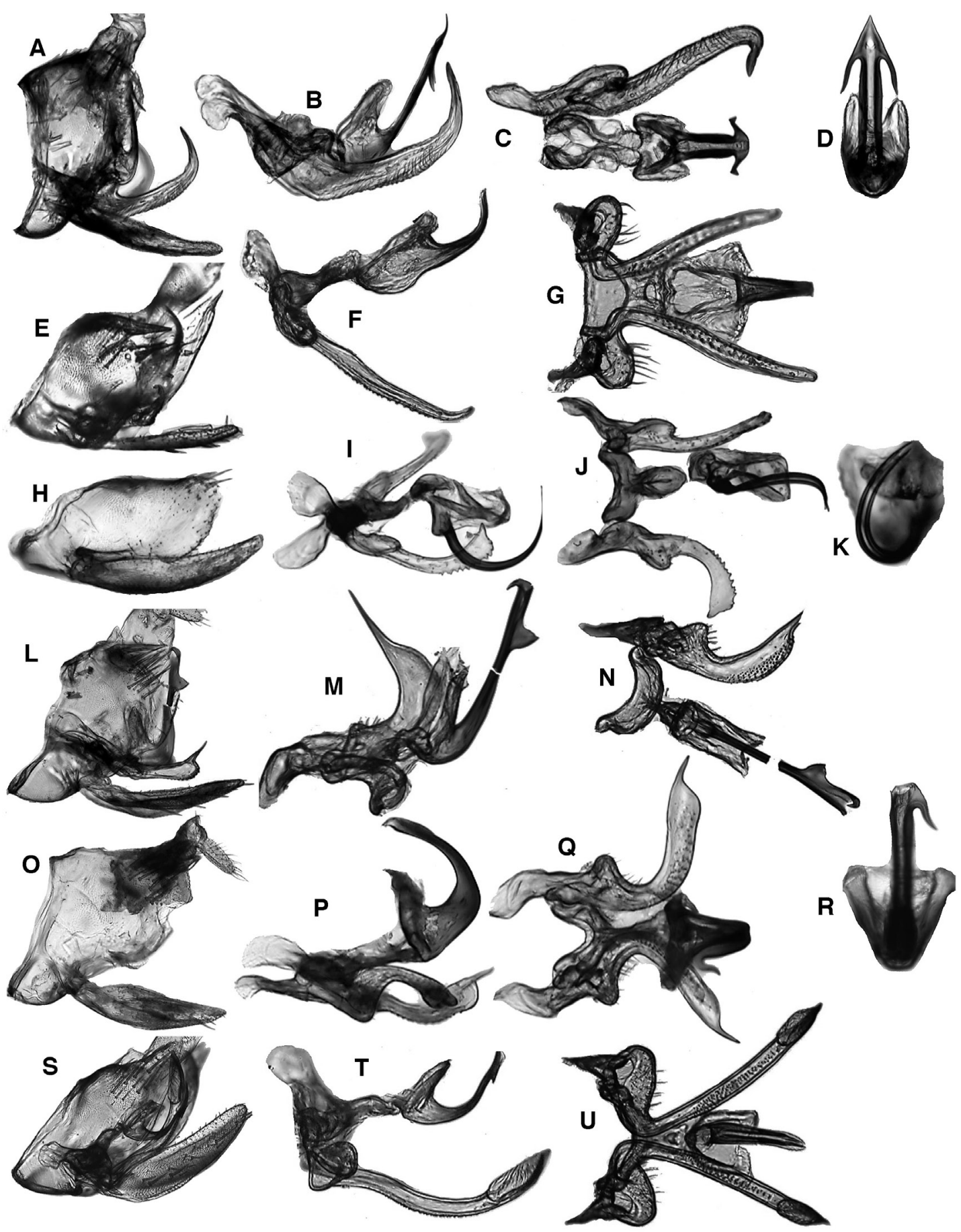

Fig. 7. Platyjassella gen. nov. - A-D. Platyjassella ancora sp. nov. A. Genital capsule, lateral view. B. Genitalia, lateral view. C. Same, ventral view. D. Aedeagus, posterior view. - E-G. Platyjassella andohahelensis sp. nov. E. Genital capsule, lateral view. F. Genitalia, lateral view. G. Same, ventral view. - H-K. Platyjassella attenuata sp. nov. H. Genital capsule, lateral view. I. Genitalia, lateral view (aedeagal shaft broken near midlength). J. Same, ventral view. K. Aedeagus, posterior view. L-N. Platyjassella cormorana sp. nov. L. Genital capsule, lateral view. M. Genitalia, lateral view. N. Same, ventral view. - O-R. Platyjassella emarginata sp. nov. O. Genital capsule, lateral view. P. Genitalia, lateral view. Q. Same, ventral view. R. Aedeagus, posterior view. - S-U. Platyjassella immaculata sp. nov. S. Genital capsule, lateral view. T. Genitalia, lateral view. U. Same, ventral view. Photos not to scale. 
Key to species of Platyjassella gen. nov. (males)

1. Pygofer with dorsal appendage (Fig. 7E)

- Pygofer without dorsal appendage (Fig. 7H)

2. Pygofer lobe acuminate apically (Fig. 7E); aedeagus without apical processes (Fig. 7F)

Platyjassella andohahelensis gen. et sp. nov.

- Pygofer lobe rounded apically (Fig. 7L); aedeagus with apical processes (Fig. 7M)

Platyjassella cormorana gen. et sp. nov.

3. Aedeagus asymmetrical; style apex avicephaliform (Fig. 7I-J)

- Aedeagus symmetrical with pair of preapical retrorse spines ventrally; style apex acuminate or scoop-like (Fig. 7D, T)

4. Aedeagus with shaft relatively broad, apex with single recurved process arising from right side of shaft (Fig. 7R)

Platyjassella emarginata gen. et sp. nov.

- Aedeagus with shaft extremely slender, apex with pair of short projections (Figs 7I-K)

Platyjassella attenuata gen. et sp. nov.

5. Aedeagus with pair of small preapical spines ventrally; style apex scoop-like (Fig. 7T)

..Platyjassella immaculata gen. et sp. nov.

- Aedeagus with pair of large retrorse apicolateral processes; style apex acuminate (Fig. 7D)

..Platyjassella ancora gen. et sp. nov.

Platyjassella ancora gen. et sp. nov.
urn:Isid:zoobank.org:act:0A4FA694-B203-47B8-9F37-CBD12CF19CAC

Figs 1P, 7A-D

\section{Etymology}

The species name refers to the anchor-like apex of the aedeagus.

\section{Material examined}

\section{Holotype}

MADAGASCAR - O; $^{\text {; }}$ "MADAGASCAR: Province d'Antsiranana, Parc National Montagne d'Ambre, 12³1'13" S, 49¹0'45" E, 1125 m, 5-21 April 2001, California Acad. of Sciences Coll: M. Irwin, R. Harin'Hala; malaise trap; MA-01-01D-07"; CAS.

\section{Paratype}

MADAGASCAR - $\hat{\sigma}^{\text {; }}$ Toamasina, botanic garden near entrance to Andasibe National Park; $18^{\circ} 55.58^{\prime}$ S, 48²4.47' E; alt. 1025 m; 16-24 Oct. 2001; M. Irwin and R. Harin'Hala leg.; Malaise trap in tropical forest; MA-01-08B-16; INHS.

\section{Description}

Length of male 5.5-5.7 mm (female unknown). Dorsal coloration pale stramineous, crown with marginal rim brown ventrally. Crown as long as pronotum, anterior margin parabolic, lateral exensions overlapping slightly less than half of eye margin. Hind tibial rows PD, AD and AV with 17, 12 and 15 macrosetae, respectively; tarsomere I with plantar row single, pecten with four platellae. Male pregenital sternite with posterior margin truncate. Valve posterior margin convex. Pygofer lobe short, rounded, without process or emargination. Style apophysis coarsely rugose ventrally through most of length, gradually tapered from base to apex, apex strongly curved dorsomesad, acuminate. Connective caliper-like. Aedeagus with atrium U-shaped in posterior view; shaft slender, straight through most of 
length, somewhat depressed, parallel-sided in lateral and posterior views, apex acuminate, with pair of acuminate lateral processes extended basolaterad, gonopore preapical on posterior surface.

Platyjassella andohahelensis gen. et sp. nov.

urn:1sid:zoobank.org:act:BCC90239-6095-4722-AA4E-097172DD7CB1

Figs 1Q, 7E-G, 16Y-AA

\section{Etymology}

The species name refers to the national park containing the type locality.

\section{Material examined}

\section{Holotype}

MADAGASCAR • đ’; “MADAGASCAR: Tulear Province, Andohahela Nat'1 Park, Ihazofotsy Parcelle III; 24⒋ $4^{\prime}$ S, 4632.17' E; 24 Aug.-3 Sep. 2003, California Acad of Sciences colls: M. Irwin, F. Parker, R. Harin'Hala. elev 80 m malaise trap in dry spiny forest, MA-02-21-30"; CAS.

\section{Paratypes}

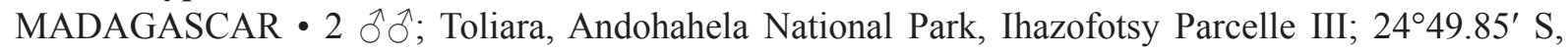
4632.17' E; alt. 80 m; 24 Aug.-3 Sep. 2003; M. Irwin, F. Parker and R. Harin'Hala leg.; Malaise trap; dry spiny forest; MA-02-21-30; CAS $\bullet 1 \hat{\jmath}, 1$ \%; same collection data as for preceding; INHS.

\section{Description}

Length of male $5.7 \mathrm{~mm}$, female $6.7 \mathrm{~mm}$. Color uniformly stramineous, except forewing apex infused with brown pigment. Crown as long as pronotum, anterior margin parabolic, lateral extensions overlapping slightly less than half of eye margin. Hind tibial rows PD, AD and AV with 17, 13 and 15 macrosetae, respectively. Male pregenital sternite no longer than sternite VII, posterior margin truncate. Pygofer with dorsal process constricted at base, broadened, then evenly tapered to sharp point distally, extended posteroventrad, not reaching lobe apex, ventral part of lobe attenuated posterodorsad and terminating in sharp spine. Style apophysis slightly sinuate, slightly broadened near midlength, bearing numerous irregular ventral denticuli, apex curved slightly dorsolaterad and tapered to blunt tip. Connective with anterior margin truncate. Aedeagus with atrium relatively large, rectangular; dorsal apodeme weakly developed; shaft slender, tapered, curved slightly dorsad, dorsal margin depressed, gonopore apical. Female sternite VII with posterior margin broadly angulately emarginate.

Platyjassella attenuata gen. et sp. nov. urn:1sid:zoobank.org:act:391112A8-F178-4593-8F85-2B59CD4DFAED Figs $1 \mathrm{R}, 7 \mathrm{H}-\mathrm{K}$

\section{Etymology}

The species name refers to the attenuated aedeagal shaft.

\section{Material examined}

\section{Holotype}

MADAGASCAR - $\hat{\jmath}$; "MADAGASCAR: Tulear Province, Mikea Forest, NW of Manombo, el 30 m, 6-16 January 2002, 22 $54.22^{\prime} \mathrm{S}, 43^{\circ} 28.53^{\prime}$ E, coll: M. Irwin, R. Harin'Hala, California Acad of Sciences, malaise trap in deciduous dry forest MA-02-18A-09"; CAS.

\section{Description}

Length of male $6.0 \mathrm{~mm}$ (female unknown). Dorsal coloration yellow, crown bordered with white posteriorly, lateral margin of pronotum white, venter without markings. Crown distinctly shorter than 
pronotum, anterior margin broadly rounded, lateral extensions overlapping $\sim 1 / 3$ of eye margin. Hind tibial rows PD, AD and AV with 17, 12 and 14 macrosetae, respectively. Male pregenital sternite with posterior margin truncate. Pygofer lobe broad, without process or emargination, apex obliquely truncate. Style apophysis with ventral denticuli relatively coarse, ventral margin appearing serrate, apex in lateral view obliquely truncate with acute dorsoapical projection. Connective broadly Y-shaped. Aedeagus with atrium narrowly V-shaped in posterior view; shaft very slender, comprssed and belt-like, curved dorsad and slightly twisted, with apex divided into two short projections flanking apical gonopore.

Platyjasella cormorana gen. et sp. nov. urn:Isid:zoobank.org:act:37289504-C79E-4CFB-BAA2-3B2616ABEE78

Figs $1 \mathrm{~S}, 7 \mathrm{~L}-\mathrm{N}$

\section{Etymology}

The species name refers to the shape of the style apex, being similar to the head of a cormorant (a group of common and widespread aquatic birds).

\section{Material examined}

Holotype

MADAGASCAR - O'; "MADAGASCAR: Mahajanga Province, Sofia District, $45 \mathrm{~km}$ S Antsohihy,

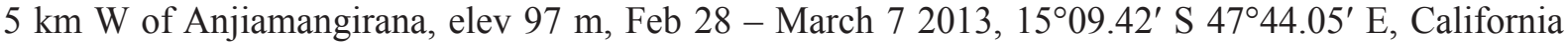
Acad. of Sciences, coll: M. Irwin, R. Harin'Hala, malaise, Analagnambe dry degraded forest MG-61$100 " ;$ CAS.

\section{Description}

Length of male $6.3 \mathrm{~mm}$ (female unknown). Color uniformly stramineous, except anterior margin of head black and forewing apex infused with brown pigment. Crown distinctly shorter than pronotum, anterior margin parabolic, lateral extensions overlapping $\sim 1 / 3$ of eye margin. Hind tibial rows PD, AD and AV with 18, 12 and 13 macrosetae, respectively. Male pregenital sternite slightly longer than sternite VII, posterior margin weakly trilobed. Pygofer with dorsal process evenly tapered, nearly straight, extended posterodorsad, not reaching lobe apex, apex bluntly angulate. Style apophysis avicephaliform, with apex attenuate and extended posterolaterad, conspicuously denticulate ventrolaterally. Connective stem very short and narrow, arms widely divergent, anterior margin concave. Aedeagus with atrium narrowly V-shaped in posterior view, arms weakly divergent; shaft broad basally, tapered toward apex, curved strongly dorsad then nearly straight, with triangular posterolateral preapical process and short apical process extended anterad on left side, right side without processes.

Platyjassella emarginata gen. et sp. nov. urn:lsid:zoobank.org:act:D40BB83D-8E93-40CD-AC65-08FAFD583ED5

Figs 1T, 7O-R

\section{Etymology}

The species name refers to the emarginate male pygofer lobe.

\section{Material examined}

Holotype

MADAGASCAR - $\hat{\jmath}^{7}$; "MADAGASCAR: Province Antananarivo, $46 \mathrm{~km}$ NE of Ankazobe: Ambohitantely, $18^{\circ} 11.88^{\prime}$ S, 47 $16.89^{\prime}$ E, 1-14 November 2004, California Acad of Sciences, coll: M. Irwin, R. Harin'Hala, malaise trap - in sclerophyl forest, elev 700 m MA-27-20"; CAS. 


\section{Description}

Length of male $6.5 \mathrm{~mm}$ (female unknown). Dorsal coloration stramineous, lateral margin of pronotum and costal margin of forewing paler. Crown distinctly shorter than pronotum, anterior margin parabolic, lateral extensions overlapping $\sim \frac{1}{3}$ of eye margin. Hind tibial rows PD, AD and AV with 18,12 and 13 macrosetae, respectively. Male pregenital sternite with posterior margin convex. Pygofer lobe short, without process, with conspicuous preapical posteroventral emargination. Style apophysis with ventral denticuli moderately coarse, ventral margin appearing serrate, apex in lateral view broadened and truncate, with attenuate dorsoapical extension. Connective narrowly Y-shaped, stem longer than arms. Aedeagus with atrium V-shaped in posterior view, shaft simple, tubular, tapered, apex with pair of asymmetrical processes arising from right side, one curved dorsomesad over gonopore, the other extended ventrolaterad, gonopore apical.

Platyjassella immaculata gen. et sp. nov. urn:1sid:zoobank.org:act:6E374C5C-94D1-4199-B5FD-1CB58E449FCF

Figs $1 \mathrm{U}, 7 \mathrm{~S}-\mathrm{U}$

\section{Etymology}

The species name refers to the lack of dark markings in this species.

\section{Material examined}

\section{Holotype}

MADAGASCAR - ô; "MADAGASCAR: Toliara Prov. Parc National d'Andohahela, Forêt de

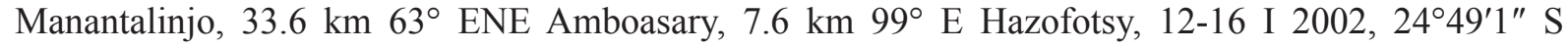
46 36'36" E, coll: Fisher, Griswold et al., California Acad. of Sciences, beating veg spiny forest/thicket elev 150m code: BLF4814"; CAS.

\section{Description}

Length of male $6.7 \mathrm{~mm}$ (female unknown). Dorsal coloration ochraceous yellow, crown bordered with white posteriorly, lateral margin of pronotum white. Crown distinctly shorter than pronotum, anterior margin broadly rounded. Hind tibial rows $\mathrm{PD}, \mathrm{AD}$ and $\mathrm{AV}$ with 16, 12 and 15 macrosetae, respectively. Male pregenital sternite with posterior margin trilobed. Pygofer without process or emargination, lobe tapered distally to narrowly rounded apex. Style apophysis with ventral denticuli relatively fine, apex excavated, scoop-like. Connective broadly Y-shaped. Aedeagus with atrium plate-like, broad, shaft simple, curved dorsad, with pair of short preapical ventral retrorse spines, gonopore preapical on posterior surface.

Platyjassula gen. nov.

urn:lsid:zoobank.org:act:EEF5D5C5-69BB-4A44-9469-A4FBA0C9988F

Figs $2 \mathrm{~A}-\mathrm{D}, 8,17 \mathrm{~A}-\mathrm{C}$

\section{Type species}

Platyjassula isofurca sp. nov.

\section{Diagnosis}

This genus may be distinguished by the following combination of features: body medium-sized; color stramineous with few darker markings on face and legs; vertex overlapping distinctly less than half of anterior margin of eye, crown uniformly shagreen; forewing with supernumerary crossveins distally; hindwing veins $\mathrm{R} 4+5$ and $\mathrm{M} 1+2$ confluent preapically but separate near apex; hind femur macrosetal formula $2+2+1$; style apex divided into two divergent acute points. 


\section{Etymology}

The name, a feminine noun, is a variant of that of the type genus of the tribe.

\section{Description}

HaBitus. Medium-sized platyjassines $(7.0-8.7 \mathrm{~mm})$. Color stramineous, with few darker markings on face, legs and forewing apex; front tibia with dorsum dark brown to black.

HeaD. Crown flattened, uniformly shagreen, anterior margin produced, spatulate, forming hood over dorsal part of face, anterolateral extension of vertex overlapping less than half of eye margin.

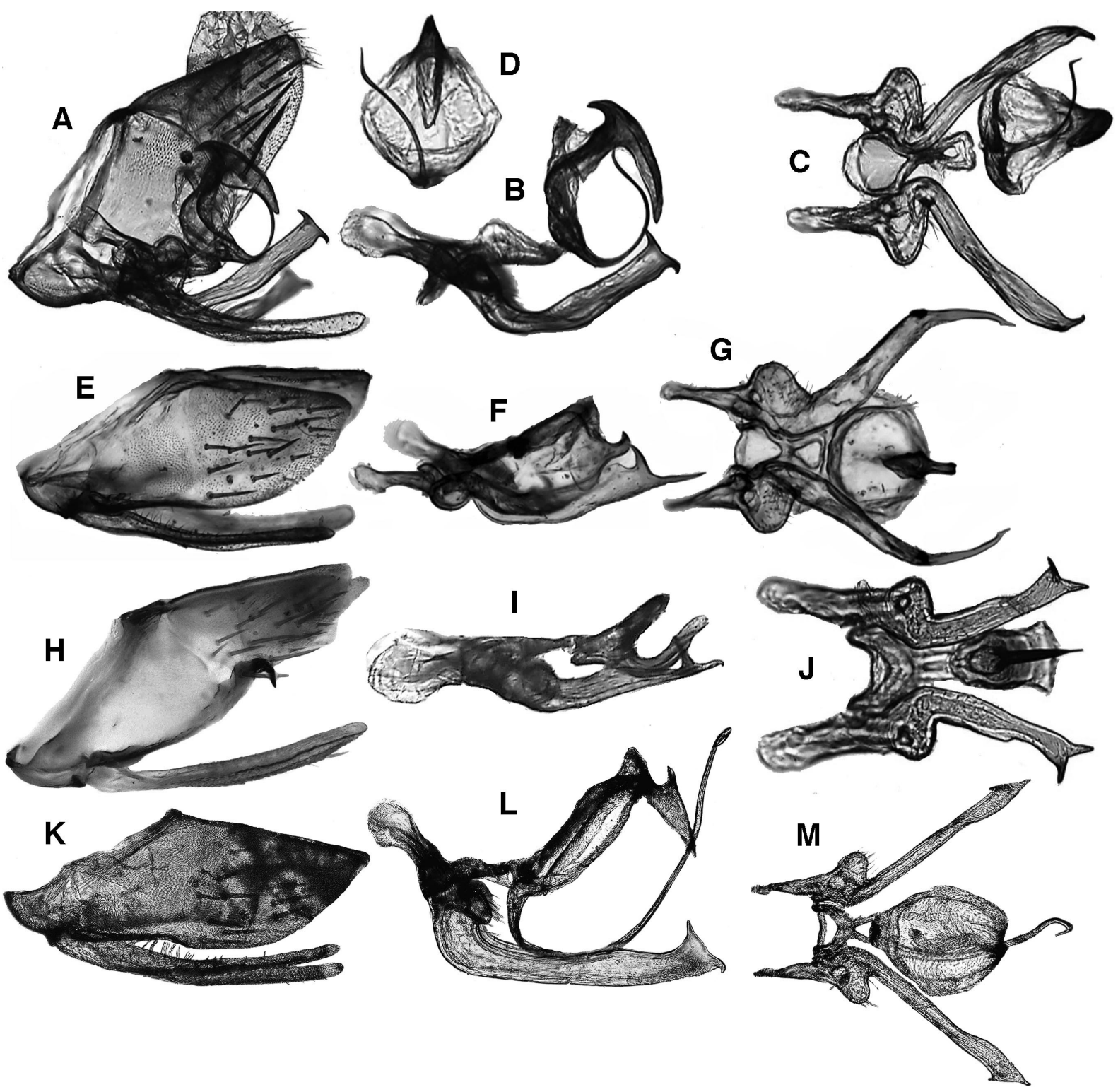

Fig. 8. Platyjassula gen. nov. - A-D. Platyjassula cyclura sp. nov. A. Genital capsule, lateral view. B. Genitalia, lateral view. C. Same, ventral view. D. Aedeagus, posterior view. - E-G. Platyjassula heterofurca sp. nov. E. Genital capsule, lateral view. F. Genitalia, lateral view. G. Same, ventral view. H-J. Platyjassula isofurca sp. nov. H. Genital capsule, lateral view. I. Genitalia, lateral view. J. Same, ventral view. - K-M. Platyjassula mahajangensis sp. nov. K. Genital capsule, lateral view. L. Genitalia, lateral view. M. Same, ventral view. Photos not to scale. 
Frontoclypeus moderately convex, with slight median dorsal depression; antennal ledge transverse, not overlapping frontoclypeus; lateral frontal suture present above antennal ledge but not extended to crown margin; gena slightly emarginate below eye, not completely concealing proepisternum, with weak carina extended from lorum dorsad to antennal pit; lorum small, flat; anteclypeus slightly convex, lateral margins distinctly divergent distally; rostrum slender, not surpassing front trochanters.

Thorax. Pronotum slightly declivous, in profile continuing contour of crown, much wider than head, lateral margins strongly divergent posterad, transverse striations weakly delimited. Forewing with several supernumerary crossveins in distal half, appendix broad and extended to wing apex, inner apical cell relatively short. Hindwing veins $\mathrm{R} 4+5$ and $\mathrm{M} 1+2$ confluent preapically but separate near apex. Front femur row IC with $\sim 10-14$ setae, somewhat irregularly arranged basally; AV with 5 stout setae in basal half, dorsal surface of tibia rounded, PD with 4 widely spaced macrosetae. Hind femur macrosetal formula $2+2+1$, tibial row $\mathrm{AD}$ with one small seta between successive macrosetae; tarsomere I plantar row single and weakly developed, pecten with 4 platellae.

ABDomEn. Male pygofer base band-like, dorsally with median posterior projection; lobe separated from base by membranous vertical cleft, with or without ventral process, with numerous macrosetae in distal half, apex broadly rounded. Subgenital plate with submedial row of macrosetae, dorsolateral margin with irregular row of short, fine setae. Style apophysis slender, smooth, without denticuli, apex divided into two divergent acute points. Connective with stem and arms subequel in length, anterior margin variable. Aedeagus with atrium shield-like in posterior view, shaft compressed, processes, if present, unpaired, gonopore preapical on posterior surface. Female abdominal sternite VII trilobed posteriorly. First valvulae with dorsal sculpturing strigate. Second valvulae broadened to near midlength, then tapered to apex, dorsal margin serrate distally.

\section{Remarks}

This genus closely resembles Platyjassus in size, structure, and coloration, but differs in having supernumerary forewing crossveins, the aedeagus symmetrical or nearly so, and the style apophysis with two acute distal projections.

Key to species of Platyjassula gen. nov. (males)

1. Aedeagus with long, slender, recurved process arising from ventral margin of atrium (Fig. 8B) ...2

- Aedeagus without process arising from atrium separate from shaft (Fig. 8I) ................................3

2. Aedeagus with stem of shaft much shorter than falcate ventroapical process (Fig. 8L)

Platyjassula mahajangensis gen. et sp. nov.

- Aedeagus with stem of shaft approximately of same length as falcate ventroapical process (Fig. $8 \mathrm{~B})$ Platyjassula cyclura gen. et sp. nov.

3. Aedeagus very broad and foot-like in lateral view; apical extensions of style unequal in length (Fig. 8F) ..Platyjassula heterofurca gen. et sp. nov.

- Aedeagus slender in lateral view, not foot-like; apical extensions of style subequal in length (Fig. 8I) Platyjassula isofurca gen. et sp. nov.

Platyjassula cyclura gen. et sp. nov.

urn:1sid:zoobank.org:act:4F4BB98C-94EC-422F-B389-E0801B8D9FF9

Figs $2 \mathrm{~A}, 8 \mathrm{~A}-\mathrm{D}$

\section{Etymology}

The species name, a noun in apposition, was formed by combining the Greek prefix 'cycl-' ('circle') with '-ura' ('tail'), referring to the shape of the aedeagus in lateral view. 


\section{Material examined}

\section{Holotype}

MADAGASCAR • \; "MADAGASCAR: Majunga Ambovomamy Belambo $20 \mathrm{~km}$ NW of Port Berger, 2-19 August 2008, $15^{\circ} 27.07^{\prime} \mathrm{S}, 4^{\circ} 36.80^{\prime}$ E, California Acad of Sciences coll: R. Harin'Hala, M. Irwin, F. Parker, malaise, secondary growth on white sand, elev 33 m, MG-33-58"; CAS.

\section{Description}

Length of male $7.8 \mathrm{~mm}$ (female unknown). Crown anterior margin, lateral margin of pronotum and costal margin of forewing bordered with pale yellow contrasting with darker adjacent areas; dorsal margin of face, dorsal surface of front tibia and spots at anterior apices of femora black. Crown distinctly shorter than pronotum, broadly rounded, only slightly longer medially than next to eye, anterior margin broadly rounded. Hind tibial rows PD, AD and AV with 18, 12 and 13 macrosetae, respectively. Male pygofer without ventral process. Style apophysis smooth, with apical branches diverging at nearly $180^{\circ}$, approximately equal in length, ventromedial branch falcate, dorsolateral branch straight. Aedeagus with atrium disc-like, shaft arising dorsally, with short, stout recurved process bearing gonopore and longer falcate process with excavated anteroventral surface curved ventrad; unpaired long, slender, slightly asymmetrical process arising ventrally from atrium and curved dorsad beneath ventroapical process.

Platyjassula heterofurca gen. et sp. nov. urn:lsid:zoobank.org:act:39E6412C-C4A6-4D21-8CB7-7D4294A1ACFB

Figs $2 \mathrm{~B}, 8 \mathrm{E}-\mathrm{G}$

\section{Etymology}

The species name refers to the different-sized branches of the style apex.

\section{Material examined}

\section{Holotype}

MADAGASCAR - O'; "MADAGASCAR: Mahajanga Prov: Parc National Tsingy de Bemaraha, 2.5

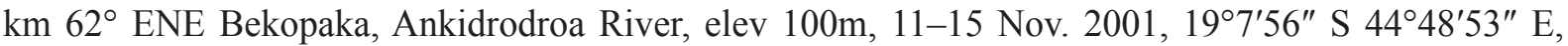
coll: Fisher, Griswold et al. California Acad. of Sciences at light, tropical dry forest on Tsingy, code: BLF4343"; CAS.

\section{Paratype}

MADAGASCAR • 1 đ; Toliara, Berent, $12 \mathrm{~km} \mathrm{NW}$ of Amboasary; 5-15 May 1983; J.S. Noyes and M.C. Day leg.; B.M. 1983-201; BMNH.

\section{Description}

Length of male 7.0-7.2 mm (female unknown). Crown anterior margin, lateral margin of pronotum and costal margin of forewing bordered with pale yellow contrasting with darker adjacent areas; dorsal margin of face and dorsal surface of front tibia dark brown, other legs without dark markings. Crown distinctly shorter than pronotum, broadly rounded, only slightly longer medially than next to eye, anterior margin broadly rounded. Hind tibial rows PD, AD and AV with 18, 12 and 12 macrosetae, respectively. Male pygofer without ventral process. Style apophysis inconspicuously denticulate preapically on ventral surface, dorsal margin with preapical obtuse angle, dorsoapical process extended dorsad and slightly recurved, ventroapical process more than twice as long, straight in lateral view and curved mesad in ventral view. Aedeagus with atrium disc-like, shaft arising from dorsum of atrium, strongly compressed, broad and quadrate in lateral view, with gonopore bearing apical process, short and slightly recurved dorsad. 
Platyjassula isofurca gen. et sp. nov. urn:lsid:zoobank.org:act:2D17FE6A-B73B-4EA4-B002-128D2AC3CEC3

Figs $2 \mathrm{C}, 8 \mathrm{H}-\mathrm{J}$

\section{Etymology}

The species name refers to the similar-sized branches of the style apex.

\section{Material examined}

Holotype

MADAGASCAR - đ̇; "MADAGASCAR: Tulear Province, Andohahela Nat'1 Park, Tsimelahy, Parcelle II, 24⒌21' S, 463․60' E; 28 Jan. - 12 Feb. 2004; California Acad of Sciences colls: M. Irwin, F. Parker, R. Harin'Hala, el 180 m, malaise trap in transitional forest, MA-02-20-53"; CAS.

\section{Paratypes}

MADAGASCAR - Toliara - $1 \delta^{\top}$; Mikea Forest, NW of Manombo; $22^{\circ} 54.80^{\prime} \mathrm{S}, 43^{\circ} 28.93^{\prime} \mathrm{E}$; alt. 37 m; 16-17 Jan. 2002; M. Irwin and R. Harin'Hala leg.; Malaise trap; spiny forest; MA-02-18B-10; CAS 11 ô (abdomen missing); Beza Mahafaly Reserve, Parcelle I near research station; $23^{\circ} 41.19^{\prime}$ S, 4435.46' E; alt. 165 m; 4-11 Dec. 2001; M.E. Irwin, F.D. Parker and R. Harin’Hala leg.; Malaise trap; dry deciduous forest; MA-02-14A-05; CAS 1 1 ; Berenty Reserve, W of Fort Dauphin, spiny forest; 2501'12.5" S, 46²18'25.8" E; 9-24 Nov. 2008; J.R. Cryan and G. Svenson leg.; DNA voucher: Entomologia DZRJ, ENT2298; DZRJ.

\section{Description}

Length of male $7.5 \mathrm{~mm}$ (female unknown). Crown, pronotum and scutellum uniformly pale stramineous, forewing somewhat darker. Face with antennal ledges orange, upper margin brown, front tibia orange anteriorly, dark brown posteriorly. Crown distinctly shorter than pronotum, anterior margin parabolically rounded. Hind tibial rows $\mathrm{PD}, \mathrm{AD}$ and $\mathrm{AV}$ with 18, 14 and 13 macrosetae, respectively. Male pygofer ventral margin with stout, falcate appendage arising near midlength but not extended to apex of lobe. Subgenital plate with submedial row of 3-4 macrosetae. Style with branches of apophysis approximately equal in size, diverging at $>90^{\circ}$ angle, lateral branch extended dorsolaterad. Aedeagus with atrium shield-like in posterior view, U-shaped in lateral view with shaft approximately as long as atrium, portion distad of gonopore strongly compressed, rounded in lateral view.

Platyjassula mahajangensis gen. et sp. nov. urn:1sid:zoobank.org:act:B49E9D41-6090-48CB-8850-424FEC99B7C8

Figs 2D, $8 \mathrm{~K}-\mathrm{M}, 17 \mathrm{~A}-\mathrm{C}$

\section{Etymology}

The species name is derived from the province of the type locality.

\section{Material examined}

\section{Holotype}

MADAGASCAR - ô; "MADAGASCAR: Province de Mahajanga, Parc National d'Ankarafantsika, Ampijoroa Station Forestière, $40 \mathrm{~km} \mathrm{306^{ \circ }}$ NW Andranofasika, elev 130m, 26 March - 1 April 2001, $16^{\circ} 19^{\prime} 15^{\prime \prime} \mathrm{S} 46^{\circ} 48^{\prime} 38^{\prime \prime}$ E, coll. Fisher, Griswold et al. California Acad. of Sciences, malaise trap in tropical dry forest, coll. code: BLF3520"; CAS.

\section{Paratypes}

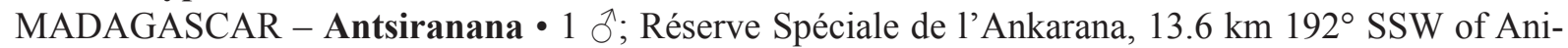
vorano Nord; 1251'49" S, 49¹3'33" E; alt. 210 m; 16-20 Feb. 2001; Fisher, Griswold et al. leg.; 
Malaise trap; tropical dry forest; coll. code: BLF3011; CAS • 1 万े; Orangea, $3 \mathrm{~km}$ E of Ramena, near fort; $12^{\circ} 14^{\prime} 49^{\prime \prime}$ S, 49²2'17" E; alt. 65 m; 23-27 Jan. 2001; M.E. Irwin, E.I. Schlinger and R. Harin'Hala leg.; Malaise trap; littoral forest on sand; MA-01-05-02; INHS • 1 \%; same collection data as for preceding; CAS.

\section{Description}

Length of male 7.1-7.5 mm, female $8.7 \mathrm{~mm}$. Crown anterior margin, lateral margin of pronotum and costal margin of forewing bordered with pale yellow contrasting with darker adjacent areas; dorsal margin of face and dorsal surface of front tibia dark brown, other legs without dark markings. Crown distinctly shorter than pronotum, broadly rounded, only slightly longer medially than next to eye, anterior margin broadly rounded. Hind tibial rows PD, AD and AV with 19, 12 and 10 macrosetae, respectively. Male pygofer without ventral process. Style apophysis with dense patch of denticuli preapically on ventrolateral surface; aedeagal shaft with gonopore-bearing apical process very short and ventral branch also shorter and strongly asymmetrical, unpaired ventral process surpassing shaft and strongly hooked apically. Aedeagus with atrium disc-like, shaft arising dorsally with short, stout recurved process bearing gonopore and longer falcate process with excavated anteroventral surface curved ventrad; unpaired long, slender, slightly asymmetrical process arising ventrally from atrium and curved dorsad. Female abdominal sternite VII with pair of short, narrow median lobes. Second valvulae with dorsal margin rising to distinct medial peak, then descending posterad to acute apex, distal fourth coarsely serrate with teeth slightly offset between sides.

Platyjassus Evans, 1953

Figs 2E-P, 9-11, 17D-L, 22

\section{Type species}

Platyjassus viridis Evans, 1953, by original monotypy.

\section{Diagnosis}

This genus may be distinguished by the following combination of features: body medium-sized; color pale stramineous without distinct spots or stripes; vertex overlapping $>1 / 2$ of anterolateral margin of eye, crown uniformly shagreen; forewing without supernumerary crossveins; hindwing veins R $4+5$ and M1+2 confluent preapically but separate near apex; hind femur macrosetal formula $2+2+1$; style apex tapered or foot-like; aedeagus usually with single asymmetrical process arising from atrium.

\section{Description}

HaBitus. Medium-sized platyjassines $(6.8-9.3 \mathrm{~mm})$. Color stramineous, with darker pigment at apex of forewing and variably present on venter and legs.

Head. Crown flattened, uniformly shagreen, anterior margin strongly produced, spatulate, forming hood over dorsal part of face, lateral extension of vertex overlapping at least half of eye margin; ocelli anteromesad of eyes. Frontoclypeus moderately convex, with slight median dorsal depression; antennal ledge transverse, strongly overlapping frontoclypeus; lateral frontal suture present above antennal ledge but not extended to crown margin; gena slightly emarginate below eye but completely concealing proepisternum; lorum small, flat; anteclypeus slightly convex, lateral margins only slightly divergent distally; rostrum slender, not surpassing front trochanters.

Thorax. Pronotum slightly declivous, in profile continuing contour of crown, much wider than head, lateral margins strongly divergent posterad, transverse striations weakly delimited. Forewing without supernumerary crossveins, appendix broad and extended to wing apex, inner apical cell relatively short. Hindwing veins $\mathrm{R} 4+5$ and $\mathrm{M} 1+2$ confluent preapically but separate near apex. Front femur row IC with 
setae in single row and relatively widely spaced; AV with single row of stout setae in basal half, dorsal surface of tibia rounded, PD with 4 widely spaced macrosetae. Hind femur macrosetal formula $2+2+1$, tibial row $\mathrm{AD}$ with one or more smaller setae between successive macrosetae; tarsomere I plantar row single and weakly developed, pecten with 4 platellae.

ABdomen. Male pregenital sternite distinctly longer than sternite VII, posterior margin truncate. Male pygofer base band-like, dorsally with median posterior projection; lobe separated from base by membranous vertical cleft, with numerous macrosetae in distal half, apex tapered to point (rounded in

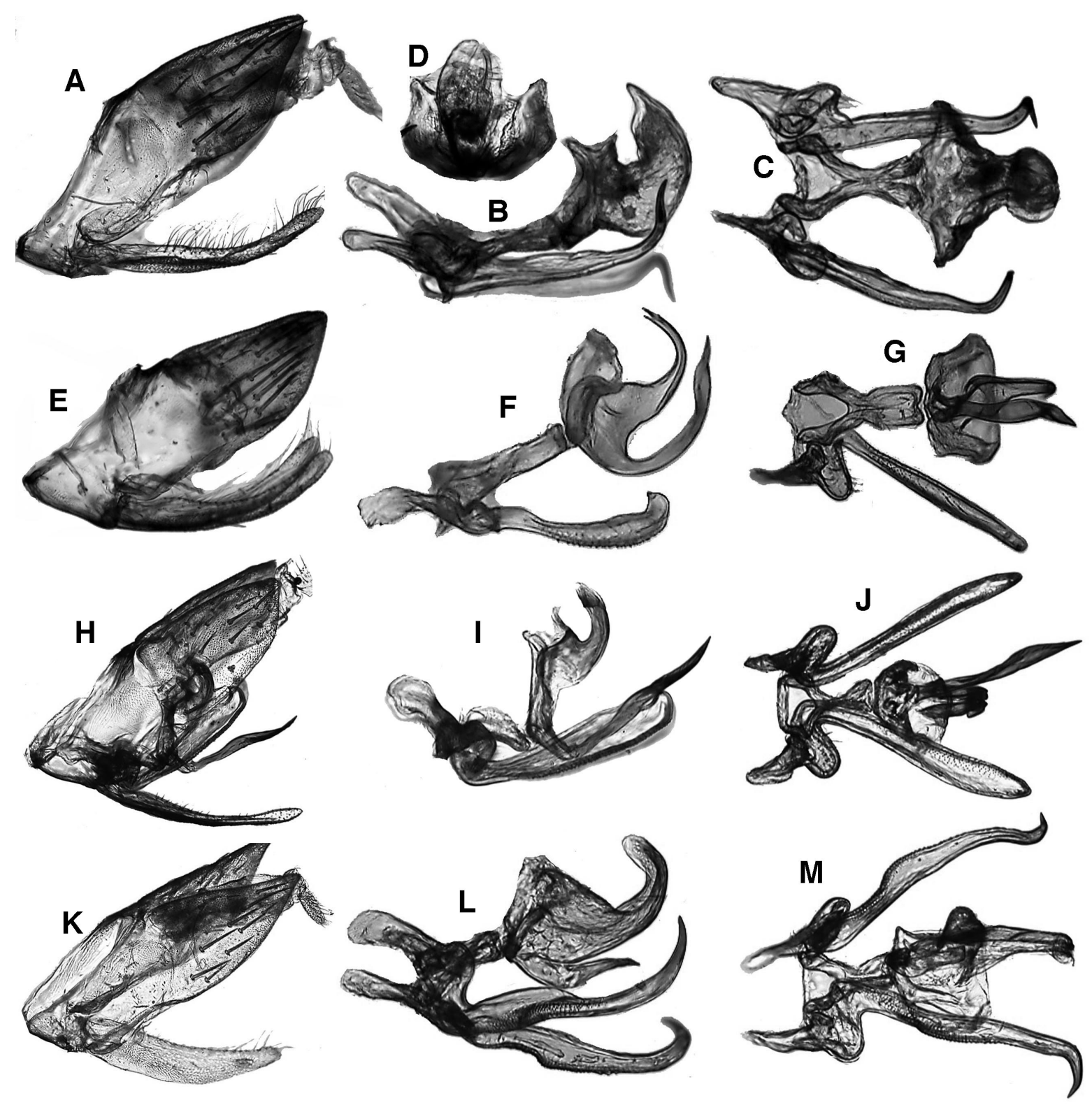

Fig. 9. Platyjassus Evans, 1953. - A-D. Platyjassus asymmetricus sp. nov. A. Genital capsule, lateral view. B. Genitalia, lateral view. C. Same, ventral view. D. Aedeagus, posterior view. - E-G. Platyjassus fisheri sp. nov. E. Genital capsule, lateral view. F. Genitalia, lateral view. G. Same, ventral view. H-J. Platyjassus griswoldi sp. nov. H. Genital capsule, lateral view. I. Genitalia, lateral view. J. Same, ventral view. - K-M. Platyjassus harinhalai sp. nov. K. Genital capsule, lateral view. L. Genitalia, lateral view. M. Same, ventral view. Photos not to scale. 
P. symmetricus sp. nov.), processes and spines absent, ventral margin without distinct group of fine setae. Subgenital plate without macrosetae, dorsolateral margin with row of long, fine setae. Style apophysis slender, usually with ventral denticuli, apex curved dorsomesad. Aedeagus with shaft simple, gonopore at or near apex; one asymmetrical process present, usually arising separately from venter of atrium (except in P. asymmetricus sp. nov.); shaft rarely with paired processes (P. symmetricus sp. nov.). Female abdominal sternite VII with posterior margin varying in shape among species. First valvulae with dorsal sculpturing strigate. Second valvulae usually broadened toward midlength, then tapered, dorsal margin serrate distally.

\section{Remarks}

The definition of the genus is here narrowed to include only the type species, originally described by Evans (1953) and redescribed and illustrated by Linnavuori \& Quartau (1975), plus 11 new species that are very similar in external appearance but have distinctive male genitalia. Other species placed by Evans (1959) in this genus are here transferred to Pallijassus gen. nov. and Plerujassus gen. nov. Platyjassus appears to be most closely related to Platyjassula, but differs from the latter in lacking supernumerary crossveins in the forewing, in having the aedeagus usually distinctly asymmetrical and in having the style apex with a single point or foot-like rather than with two acuminate projections.

\section{Key to species of Platyjassus Evans, 1953 (males)}

1. Forewing with large red spot covering preapical section (Fig. 2N)

Platyjassus pictipennis sp. nov.

- Forewing without red spot, uniformly stramineous except for fuscous areas in apical cells .....2

2. Style without distinct preapical constriction, evenly tapered throughout length or tapered only at apex, at most with slight dorsal preapical concavity (Fig. 9B, F, I, L)

- Style apophysis with distinct preapical constriction and narrow distal extension (Figs 10E, 11A)

3. Style apophysis tapered through most of length to acuminate apex (Fig. 9B)

- Style apophysis approximately parallel-sided or expanded through most of length, apex abruptly tapered (Fig. 9F)

4. Aedeagus without atrial processes, shaft globular, with slender prepical process on right side (Fig. 9D) Platyjassus asymmetricus sp. nov.

- Aedeagus with process arising from atrium

5. Aedeagal shaft with pair of short, symmetrical lateral processes preapically (Fig. 10L)

Platyjassus symmetricus sp. nov.

- Aedeagal shaft without processes

6. Aedeagus with basal process very slender and short (Fig. 10N); style apophysis with distinct dorsal lobe near base (Fig. 10N)

Platyjassus vestigius sp. nov.

- Aedeagus with basal process robust; style apophysis without distinct dorsal lobe near base (Fig. 9L) Platyjassus harinhalai sp. nov.

7. Aedeagus with basal process much longer than shaft, divergent from shaft in lateral view (Fig. 9I)

Platyjassus griswoldi sp. nov.

- Aedeagus with basal process subequal to shaft in length, convergent toward shaft in lateral view (Fig. 9F)

Platyjassus fisheri sp. nov. 
8. Basal process of aedeagus with spine-like preapical median branch (Fig. 10C)

Platyjassus irwini sp. nov.

- Basal process of aedeagus without preapical branch

9. Basal process of aedeagus closely adjacent to or overlapping shaft in ventral view (Fig. 10F); style apex foot-like, with acutely pointed ventral heel and recurved dorsal toe (Fig. 10E)

Platyjassus pedistylus sp. nov.

- Basal process of aedeagus well separated from shaft in ventral view (Fig. 11C); style apex not foot-like, with single acute dorsal point (Fig. 11A) (viridis complex) ...10

10. Ventral preapical lobe of style obtusely rounded, not angulate (Fig. 11G)

..Platyjassus viridis Evans, 1953

- Ventral prepical lobe of style apophysis forming acute or right angled lobe in lateral view (Fig. $11 \mathrm{~A}, \mathrm{D})$ .11

11. Ventral preapical lobe of style apophysis distinctly acute (Fig. 11A)

- Ventral preapical lobe of style apophysis forming right angle (Fig. 11D)

Platyjassus acutus sp. nov.

Platyjassus pennyi sp. nov.

Platyjassus asymmetricus sp. nov.

urn:lsid:zoobank.org:act:D084D845-FFED-4843-9376-0B9B1747F1D8

Figs 2H, 9A-D

\section{Etymology}

The species name refers to the asymmetrical aedeagal shaft.

\section{Material examined}

Holotype

MADAGASCAR - ơ; "MADAGASCAR: Province Fianarantsoa, Parc National Ranomafana, radio tower at forest edge, elev $1130 \mathrm{~m}, 14-21$ Jan. $2002,21^{\circ} 15.05^{\prime} \mathrm{S}, 47^{\circ} 24.43^{\prime} \mathrm{E}$, coll: M. Irwin, R. Harin'Hala, California Acad of Sciences, malaise, mixed tropical forest, MA-02-09B-12"; CAS.

\section{Description}

Length of male $7.9 \mathrm{~mm}$ (female unknown). Dull stramineous throughout, crown with marginal rim infuscate. Crown distinctly shorter than pronotum, anterior margin parabolic. Hind tibial rows PD, $\mathrm{AD}$ and $\mathrm{AV}$ with 19, 14 and 10 macrosetae, respectively. Style apophysis slender throughout, slightly sinuate, apex strongly hooked dorsomesad and acuminate, ventral denticuli small and inconspicuous. Connective anterior margin weakly trilobed. Aedeagus with shaft arising from middle of broad, shieldlike atrium, broadly tubular, bent dorsad and tapered in lateral view, in posterior view with apex deeply divided longitudinally, with left section much wider than spine-like right section.

\section{Platyjassus fisheri sp. nov. urn:lsid:zoobank.org:act:4274872C-7D6E-4413-9CEF-D37F17EF10A7} Figs 2I, 9E-G, 17D-F

\section{Etymology}

The species is named for Dr. Brian Fisher, noted ant expert and one of the collectors of the type series. 


\section{Material examined}

\section{Holotype}

MADAGASCAR • ${ }^{\lambda}$; "MADAGASCAR: Antsiranana Prov., Parc National de Marojejy Manantenina River, $27.6 \mathrm{~km} 35^{\circ} \mathrm{NE}$ Andapa, $9.6 \mathrm{~km} 327^{\circ} \mathrm{NNW}$ Manantenina, 11-14 Dec 2005, 14${ }^{\circ} 26^{\prime} 06^{\prime \prime} \mathrm{S}$ 049 45'36" E, California Academy of Sciences coll. B.L. Fisher et al., elev 775m, malaise trap, rainforest, collection code: BLF13383"; CAS.

\section{Paratypes}

MADAGASCAR - Antsiranana - 2 $\widehat{\jmath}$; Parc National Montagne d'Ambre, $12.2 \mathrm{~km} 211^{\circ} \mathrm{SSW}$ of Joffreville; 12³5'47" S, 4909'34" E; alt. 1300 m; 2-7 Feb. 2001; Fisher, Griswold et al. leg.; Malaise

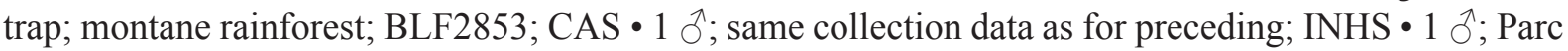
National Montagne d'Ambre; 12³0'52" S, 49¹0'53" E; alt. 960 m; 26-29 Jan. 2001; M.E. Irwin, E.I. Schlinger and R. Harin'Hala leg.; Malaise trap; MA-01-01A-02; CAS • 1 \&; Parc National Montagne d'Ambre; 12³1'13" S, 49¹0'45" E; alt. 1125 m; 29 Jan.-11 Feb. 2001; M. Irwin and R. Harin'Hala leg.; Malaise trap; MA-01-01D-03; CAS.

\section{Description}

Length of male $6.8 \mathrm{~mm}$, female $8.8 \mathrm{~mm}$. Dorsum ochraceous, venter pale stramineous, marginal rim of crown brown. Head with crown as long as pronotum. Hind tibial rows PD, AD and AV with 16, 13 and 14 macrosetae, respectively. Style apophysis in lateral view broadened from base to distal fourth, then gradually tapered, apex acute, denticuli densely distributed over basal two thirds ventrally, curved dorsad in lateral view, straight and extended posterolaterad in ventral view. Connective with anterior margin angulately produced. Aedeagus with preatrium broadly quadrate in posterior view, shaft strongly compressed basally, tubular distally, tapered and evenly curved dorsad in lateral view, gonopore apical; ventral process nearly as long as shaft, depressed and twisted asymmetrically, curved dorsad and tapered to acute tip, well separated from shaft throughout length. Female abdominal sternite VII with posterior margin truncate, with slight median notch. Second valvulae with dorsal margin concave in basal half, rising to bluntly angulate peak near midlength, then extended straight to acute apex, distal third irregularly serrate, with teeth offset between sides.

Platyjassus griswoldi sp. nov. urn:1sid:zoobank.org:act:A8A4D3F9-B15A-4E10-9DB6-8FAF2CB02E86

Figs 2J, 9H-J, 17G-I

\section{Etymology}

This species is named for Dr. Charles Griswold, noted spider expert and one of the collectors of the type series.

\section{Material examined}

Holotype

MADAGASCAR - O'; "MADAGASCAR: Mahajanga Province, Mahavavy River, $6.2 \mathrm{~km} 145^{\circ} \mathrm{SE}$ Mitsinjo, elev 20m, 1-5 Dec 2002, 16 $03^{\circ} 06^{\prime S}$, 45 54'30" E, coll. Fisher, Griswold et al. California Acad. of Sciences collected at light - in gallery forest, code: BLF6933"; CAS.

\section{Paratypes}

MADAGASCAR - $1 \mathrm{O}^{\top}$; Mahajanga, Mahavavy River, $6.2 \mathrm{~km} 145^{\circ}$ SE of Mitsinjo; $16^{\circ} 03^{\prime} 06$ "S, $45^{\circ} 54^{\prime} 30^{\prime \prime}$ E; alt. 20 m; 1-5 Dec. 2002; Fisher, Griswold et al. leg.; collected at light; gallery forest; coll. code: BLF6933; INHS • 1 +; same collection data as for preceding; CAS.

\section{Other material}

MADAGASCAR - Antananarivo 11 ¿ $3 \mathrm{~km} 41^{\circ} \mathrm{NE}$ of Andranomay, $11.5 \mathrm{~km} 147^{\circ} \mathrm{SSE}$ of Anjozorobe; $18^{\circ} 28^{\prime} 24^{\prime \prime} \mathrm{S}, 47^{\circ} 57^{\prime} 36^{\prime \prime}$ E; alt. 1300m; 5-13 Dec. 2000; Fisher, Griswold et al. leg.; Malaise trap in 
montane rainforest; coll. code: BLF2375; CAS. - Mahajanga • 1 đ̇; Réserve d'Ankoririka, $10.6 \mathrm{~km}$ $13^{\circ} \mathrm{NE}$ of Tsaramandroso; $16^{\circ} 16^{\prime} 02^{\prime \prime} \mathrm{S}, 46^{\circ} 02^{\prime} 55^{\prime \prime} \mathrm{E}$; alt. 210 m; 9-14 Apr. 2001; Fisher, Griswold et al. leg.; Malaise trap; tropical dry forest; coll. code: BLF3665; INHS.

\section{Description}

Length of male $7.5 \mathrm{~mm}$, female $8.8 \mathrm{~mm}$. Dorsum bright yellow except anterior margin of crown and lateral margin of pronotum white. Crown approximately as long as pronotum, anterior margin parabolic. Hind tibial rows PD, AD and AV with 18-19, 13-14 and 11-12 macrosetae, respectively. Style apophysis densely denticulate ventrally, broadened to distal two thirds in lateral view, then gradually narrowed, abruptly curved dorsad and tapered to acute apex. Connective anterior margin truncate. Aedeagus with shaft symmetrical, relatively short, curved dorsad, with pair of angulate lateroapical flanges, gonopore apical on posterior surface; basal process arising from ventral end of atrium, well separated from shaft, extended posteroventrad for short distance, then bent at right angle and extended posterodorsad, distal part asymmetrically twisted and blade-like, apex acuminate. Female abdominal sternite VII with posterior margin weakly trilobed. Second valvulae strongly and evenly broadened from base to near midlength; dorsal margin rising to bluntly angulate peak, then descending evenly to acute apex, distal third finely serrate with teeth slightly offset between sides.

\section{Remarks}

The males from Antananarivo Province and Réserve d'Ankoririka (Majajanga) are excluded from the type series because they exhibit variation in the aedeagus that may eventually prove to be interspecific. The former has the aedeagus with the shaft slightly longer and more slender than that of the holotype, with the apex constricted distad of the lateroapical processes in posterior view and the basal appendage broadened preapically. The latter has the preapical processes of the aedeagus relatively small.

$$
\begin{aligned}
& \text { Platyjassus harinhalai sp. nov. } \\
& \text { urn:1sid:zoobank.org:act:DDCC86DD-3BCA-4529-86B1-B72761E6ACAA } \\
& \text { Figs 2K, 9K-M }
\end{aligned}
$$

\section{Etymology}

This species is named in honor of Rinha Harin'Hala, the collector of the type series, who maintained several of the Malaise traps in Madagascar for the bioinventory project, yielding numerous specimens of additional species of Platyjassini.

\section{Material examined}

\section{Holotype}

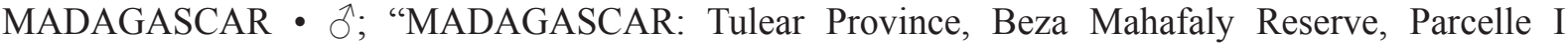

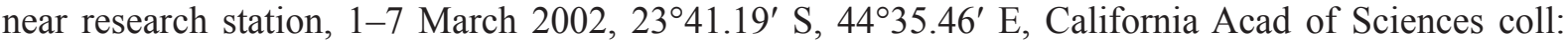
R. Harin'Hala, malaise trap in dry deciduous forest, elev 165 m, MA-02-14A-18"; CAS.

\section{Paratype}

MADAGASCAR - + ; Toliara, Beza Mahafaly Reserve, Parcelle I near research station; $23^{\circ} 41.19^{\prime}$ S, 44³5.46' E; alt. 165 m; 1-7 Mar. 2002; R. Harin'Hala leg.; Malaise trap; dry deciduous forest; MA-0214A-18; CAS.

\section{Description}

Length of male $6.8 \mathrm{~mm}$, female $7.1 \mathrm{~mm}$. Dorsum dull stramineous, venter paler. Head with crown slightly shorter (male) to slightly longer (female) than pronotum. Hind tibial rows PD, AD and AV with 18-21, 16 and 14-15 macrosetae, respectively. Connective with anterior margin truncate. Style apophysis densely and finely denticulate in basal half, evenly curved dorsolaterad and tapered to acute 
point distally. Aedeagus with shaft arising ventrally on atrium, with broad asymmetrical basolateral lobe, distal part curved dorsad, tapered to rounded apex, gonopore apical; basal process short, arising adjacent to shaft base, extended along shaft, then slightly divergent from shaft in distal half, tapered to acute apex, reaching apex of basolateral lobe of shaft. Female sternite VII with posterior margin very slightly emarginate.

Platyjassus irwini sp. nov. urn:1sid:zoobank.org:act:9273F8FA-6F6A-408E-9FBC-49653477D4B2

Figs $2 \mathrm{~L}, 10 \mathrm{~A}-\mathrm{C}$

\section{Etymology}

This species is named for Dr. Michael E. Irwin, noted dipterist and collector of the holotype.

\section{Material examined}

\section{Holotype}

MADAGASCAR - ${ }^{\text {; }}$; "MADAGASCAR: Province Antananarivo, $46 \mathrm{~km}$ NE of Ankazobe: Ambohitantely, $18^{\circ} 11.88^{\prime}$ S, 47 $16.89^{\prime}$ E, 16-27 January 2005, California Acad of Sciences coll: M. Irwin, R. Harin'Hala, malaise trap - in sclerophyl forest, elev 700 m MA-27-25"; CAS.

\section{Description}

Length of male $7.1 \mathrm{~mm}$ (female unknown). Dorsum mostly ochraceous; head, anterior part of pronotum and scutellum pale stramineous; anterior rim of crown light brown. Crown distinctly shorter than pronotum, anterior margin parabolic. Hind tibial rows $\mathrm{PD}, \mathrm{AD}$ and $\mathrm{AV}$ with 19, 14 and 13 macrosetae, respectively. Style coarsely denticulate ventrally, expanded from base to near apex, then abruptly tapered, apex expanded and foot-like, curved dorsomesad. Connective with anterior margin convex. Aedeagus with atrium quadrate in posterior view, shaft depressed and evenly curved dorsad, gonopore preapical on posterior surface; basal process arising from ventral end of atrium and curved dorsad, asymmetrically curved in ventral view, with thin preapical process curved ventromesad, apex blade-like, extended slightly beyond shaft.

\section{Platyjassus pedistylus sp. nov. urn:1sid:zoobank.org:act:42D8B898-D5E7-4CFB-AC58-1448BC26D874}

Figs 2M, 10D-F, 17J-L

\section{Etymology}

The species name, a noun in apposition, refers to the foot-like style apex.

\section{Material examined}

\section{Holotype}

MADAGASCAR - ơ; "MADAGASCAR: Fianarantsoa, Parc National Ranomafana, Belle Vue at

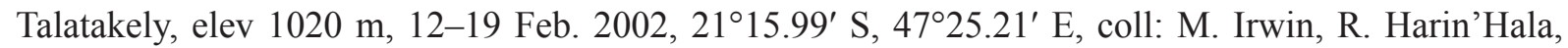
California Acad of Sciences, malaise, secondary tropical forest, MA-02-09C-16"; CAS.

\section{Paratypes}

MADAGASCAR - Fianarantsoa $-2 \widehat{\partial} \delta^{\lambda}$ P Parc National Ranomafana, Vohiparara, at broken bridge; $21^{\circ} 13.57^{\prime}$ S, 47 $22.19^{\prime}$ E; alt. 1110 m; 4-12 Feb. 2002; M. Irwin and R. Harin'Hala leg.; Malaise trap; high altitude rainforest; MA-02-09A-15; CAS 1 万ै; Parc National Ranomafana, Vohiparara, at broken bridge; $21^{\circ} 13.57^{\prime} \mathrm{S}, 47^{\circ} 22.19^{\prime} \mathrm{E}$; alt. $1110 \mathrm{~m}$; 19-26 Feb. 2002; MA-02-09A-17; CAS • $1 \mathrm{O}^{\top}$; Ranomafana JIRAMA water works, near river; $21^{\circ} 14.91^{\prime} \mathrm{S}, 47^{\circ} 27.13^{\prime} \mathrm{E}$; alt. $690 \mathrm{~m}$; 21-28 Jan. 2002; M. Irwin and 
R. Harin'Hala leg.; Malaise trap; MA-02-09D-13; INHS • 1 ô; Parc National Ranomafana, Belle Vue at Talatakely; $21^{\circ} 15.99^{\prime}$ S, 47²5.21' E; alt. 1020 m; 22-28 Nov. 2001; M. Irwin and R. Harin'Hala leg.; Malaise trap; secondary tropical forest; MA-02-09C-04; CAS 11 गे; Parc National Ranomafana, Belle Vue at Talatakely; $21^{\circ} 15.99^{\prime} \mathrm{S}, 47^{\circ} 25.21^{\prime} \mathrm{E}$; alt. $1020 \mathrm{~m}$; 21-28 Jan. 2002; MA-02-09C-13; CAS • 1 ð’; Parc National Ranomafana, Belle Vue at Talatakely; 21 ${ }^{\circ} 15.99^{\prime}$ S, 47 $25.21^{\prime}$ E; alt. 1020 m; 31 Mar.-

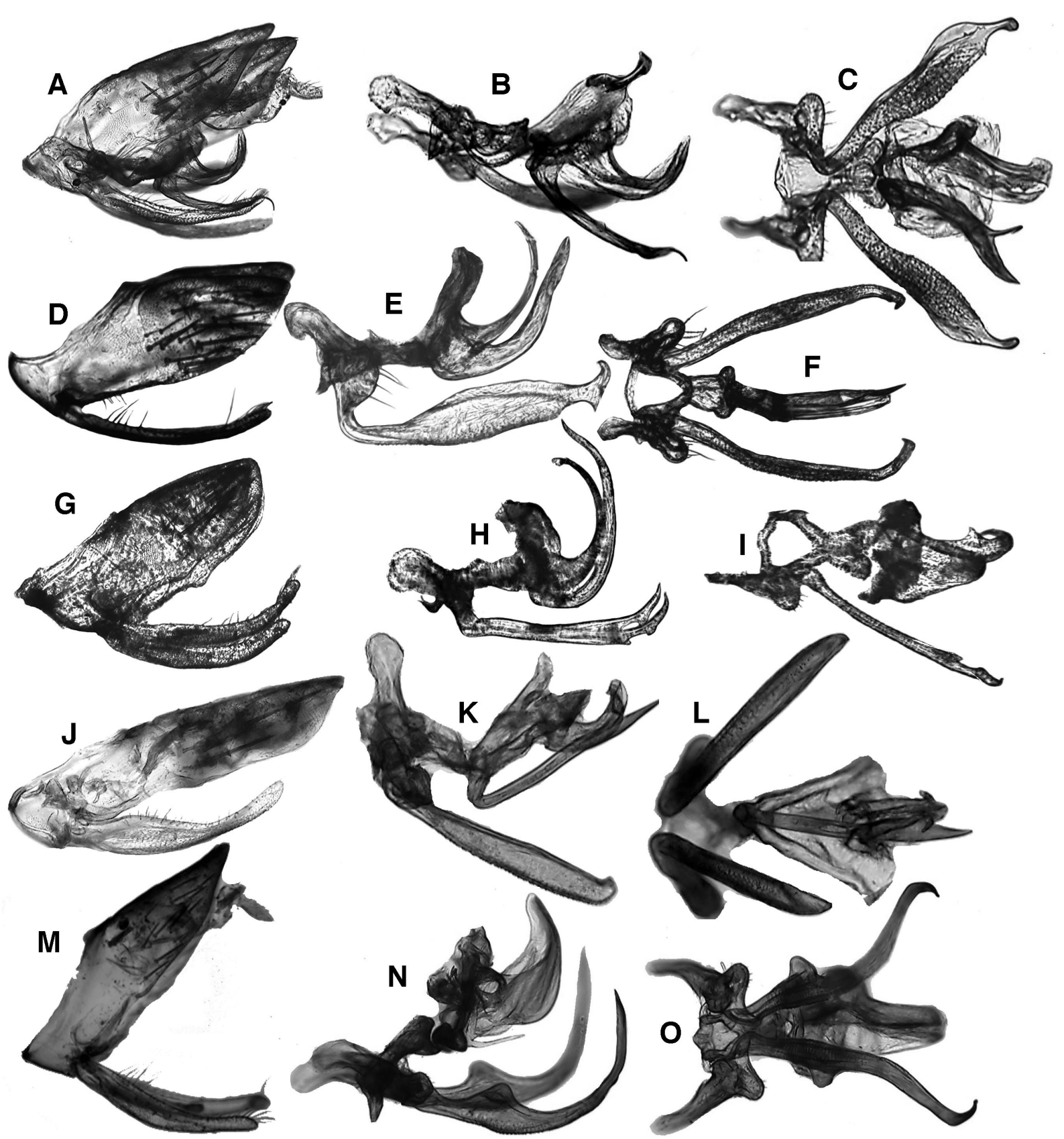

Fig. 10. Platyjassus Evans, 1953. - A-C. Platyjassus irwini sp. nov. A. Genital capsule, lateral view. B. Genitalia, lateral view. C. Same, ventral view. -D-F. Platyjassus pedistylus sp. nov. D. Genital capsule, lateral view. E. Genitalia, lateral view. F. Same, ventral view. - G-I. Platyjassus pictipennis sp. nov. G. Genital capsule, lateral view. H. Genitalia, lateral view. I. Same, ventral view. - J-L. Platyjassus symmetricus sp. nov. J. Genital capsule, lateral view. K. Genitalia, lateral view. L. Same, ventral view. - M-O. Platyjassus vestigius sp. nov. M. Genital capsule, lateral view. N. Genitalia, lateral view. O. Same, ventral view. Photos not to scale. 
7 Apr. 2002; MA-02-09C-23; INHS • 1 ภे, 1 + ; Parc National Ranomafana, Belle Vue at Talatakely; $21^{\circ} 15.99^{\prime} \mathrm{S}, 47^{\circ} 25.21^{\prime} \mathrm{E}$; alt. 1020 m; 28 Apr.-5 May 2002; MA-02-09C-27; CAS.

\section{Description}

Length of male $7.2-9.3 \mathrm{~mm}$, female $8.9 \mathrm{~mm}$. Dorsum uniformly pale stramineous, except marginal rim of crown black. Crown distinctly shorter than pronotum, anterior margin broadly rounded. Hind tibial rows PD, AD and AV with 17-18, 12 and 12-13 macrosetae, respectively. Style apophysis in lateral view broad and ventrally denticulate through most of length, abruptly constricted prepically, with footlike apical extension bearing apically recurved dorsal toe and acutely angulate ventral heel. Connective with anterior margin slightly convex. Aedeagus with atrium in posterior view narrowly quadrate, shaft simple, very slender and tubular; basal process broader than but nearly of same length as shaft, closely parallel to shaft through most of length. Female abdominal sternite VII with posterior margin trilobed, lateral lobes narrower than medial lobe. Second valvulae relatively slender, only slightly broadened toward midlength, distal fourth of dorsal margin coarsely serrate, with teeth offset between sides.

Platyjassus pictipennis sp. nov.

urn:1sid:zoobank.org:act:C8B2B310-A10C-444E-8D53-E2D8564BF83A

Figs 2N, 10G-I

\section{Etymology}

The species name combines 'pict' ('paint') with 'pennis' ('wing') and refers to the large reddish spot on the forewing.

\section{Material examined}

Holotype

MADAGASCAR • ${ }^{\top}$; "MADAGASCAR: Mahajanga Province, Parc National de Namoroka, $16.9 \mathrm{~km}$

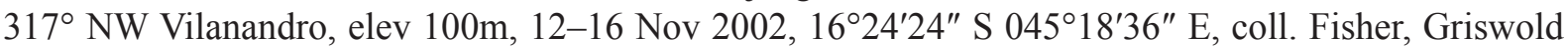
et al., California Acad. of Sciences, yellow pan trap - in tropical dry forest coll. code: BLF6586"; CAS.

\section{Paratype}

MADAGASCAR - ${ }^{\lambda}$; Antsiranana, Diana Region, Orangea dry forest, Ramena, Baie de Dune, $900 \mathrm{~m} \mathrm{E}$ of Camp Minier; $12^{\circ} 13.97^{\prime}$ S, 49²1.99' E; alt. 152 m; 5-12 Jul. 2011; M. Irwin and R. Harin'Hala leg.; Malaise trap; dry forest; MG-62-30; INHS.

\section{Description}

Length of male $6.8 \mathrm{~mm}$ (female unknown). Dorsum nearly uniformly yellow, except apical third of forewing pink and apical cells infuscate distally. Crown longer than pronotum, anterior margin parabolic. Hind tibial rows PD, AD and AV with 21, 15 and 12 macrosetae, respectively. Style apophysis in lateral view slender through most of length, abruptly narrowed preapically, with small but prominent ventral lobe, distal extension foot-like, with short, rounded heel and attenuate toe curved dorsad. Connective anterior margin broadly obtuse. Aedeagus with shaft depressed, belt-like curved strongly dorsad, apex somewhat asymmetrical in posterior view, basal process arising near shaft base, curved dorsad and closely parallel to shaft through most of length, apex extended beyond shaft apex, attenuate and slightly sinuate in lateral view.

Platyjassus symmetricus sp. nov.

urn:1sid:zoobank.org:act:CE644CE6-52B0-4AB9-BAFE-D4326B8E5644

Figs $2 \mathrm{O}, 10 \mathrm{~J}-\mathrm{L}$

\section{Etymology}

The species name refers to the nearly symmetrical aedeagus. 


\author{
Material examined \\ Holotype \\ MADAGASCAR • O'; “Andobo, 190 m, foret Antsingy det Antsalova, II-57 P. Griv.; INSTITUT \\ SCIENTIFIQUE MADAGASCAR”; MNHN.
}

\title{
Description
}

Length of male $7.8 \mathrm{~mm}$ (female unknown). Pale ochraceous throughout. Crown shorter than pronotum, anteror margin parabolically produced. Hind tibial rows PD, AD and AV with 18,13 and $\sim 12$ macrosetae, respectively. Male pygofer lobe elongate, apex obliquely truncate. Style apophysis robust, broadened and straight through most of length, densely denticulate ventrally, apex abruptly but slightly curved dorsad and terminating in acute point. Aedeagus with atrium V-shaped in posterior view, shaft arising dorsally, relatively short, tubular, evenly curved dorsad, with pair of short, recurved preapical lateral processes just basad of apical gonopore; basal process arising from ventral end of atrium well separated from shaft, nearly symmetrical, sharply bent dorsad near base, thence nearly straight, slightly broadened preapically in ventral view, then gradually tapered to acuminate apex, slightly surpassing shaft.

\section{Remarks}

According to the previously attached determination label, the holotype designated here was identified as "Platyjassus viridis" by J.W. Evans in 1958, but its genitalia do not match those of the specimen identified as that species and illustrated by Linnavuori \& Quartau (1975). Study of other material identified by Evans indicates that his concept of $P$. viridis included several species that are similar in external appearance but readily distinguishable by the male genitalia.

Platyjassus vestigius sp. nov.

urn:lsid:zoobank.org:act:6CAD874B-19B2-4F64-9C7D-52333A022AF7

Figs $2 \mathrm{P}, 10 \mathrm{M}-\mathrm{O}$

\section{Etymology}

The species name refers to the strongly reduced basal process of the aedeagus.

\section{Material examined}

\section{Holotype}

MADAGASCAR - o; "MADAGASCAR: Province Fianarantsoa, Parc National Ranomafana, Vohiparara, at broken bridge, el $1110 \mathrm{~m}, 15-25$ July $2002,21^{\circ} 13.57^{\prime} \mathrm{S}, 4^{\circ} 22.19^{\prime} \mathrm{E}$, coll: M. Irwin, R. Harin'Hala, California Acad of Sciences, malaise trap in high altitude rainforest, MA-02-09A-35"; CAS.

\section{Description}

Length of male $7.8 \mathrm{~mm}$ (female unknown). Pale stramineous throughout, crown with marginal rim infuscated. Crown slightly shorter than pronotum, anterior margin parabolic. Hind tibial rows PD, AD and AV with 21, 14 and 12 macrosetae, respectively. Style apophysis in lateral view with prominent subbasal lobe, distal part evenly curved dorsad and attenuate, in ventral view hooked mesad at apex, ventral denticuli concentrated in area ventrad of hump. Connective with anterior margin angulately produced. Aedeagus with gonopore-bearing shaft large, curved dorsad and tapered in lateral view, with median longitudinal cleft in distal half, right half weakly sclerotized; basal process short, slender and attenuate, extended below shaft and not reaching shaft midlength. 


\section{Platyjassus viridis species complex}

Figs $2 \mathrm{E}-\mathrm{G}, 11$

\section{Remarks}

The following three species constitute a distinctive group that includes the type species of the genus. The group is characterized by the relatively short broad crown with infuscate marginal rim and the following combination of features of the male genitalia: style apophysis broadened and conspicuously denticulate from the base to near apex, abruptly constricted preapically, with apical extension narrow at base but broadened, rounded ventrally and angulate dorsally at apex; aedeagus with atrium quadrate in posterior view; shaft simple and evenly curved dorsad, with gonopore apical, apex blunt in posterior view; single asymmetrical basal process arising from atrium well to right of shaft, not overlapping shaft in ventral view, approximately as large as shaft, undulate apically and terminating in acuminate tip. The shaft and process of the aedeagus vary in orientation and degree of curvature among specimens of the same species. Nevertheless, the following three species of the group may be separated by the shape of the style apophysis, particularly the ventral preapical angle in broadest aspect.

\section{Platyjassus acutus sp. nov.}

urn:1sid:zoobank.org:act:391BC100-F0F3-4131-99E3-D2E9DAF9723A

Figs $2 \mathrm{E}, 11 \mathrm{~A}-\mathrm{C}$

\section{Etymology}

The species name refers to the acute preapical ventral projection on the style apophysis.
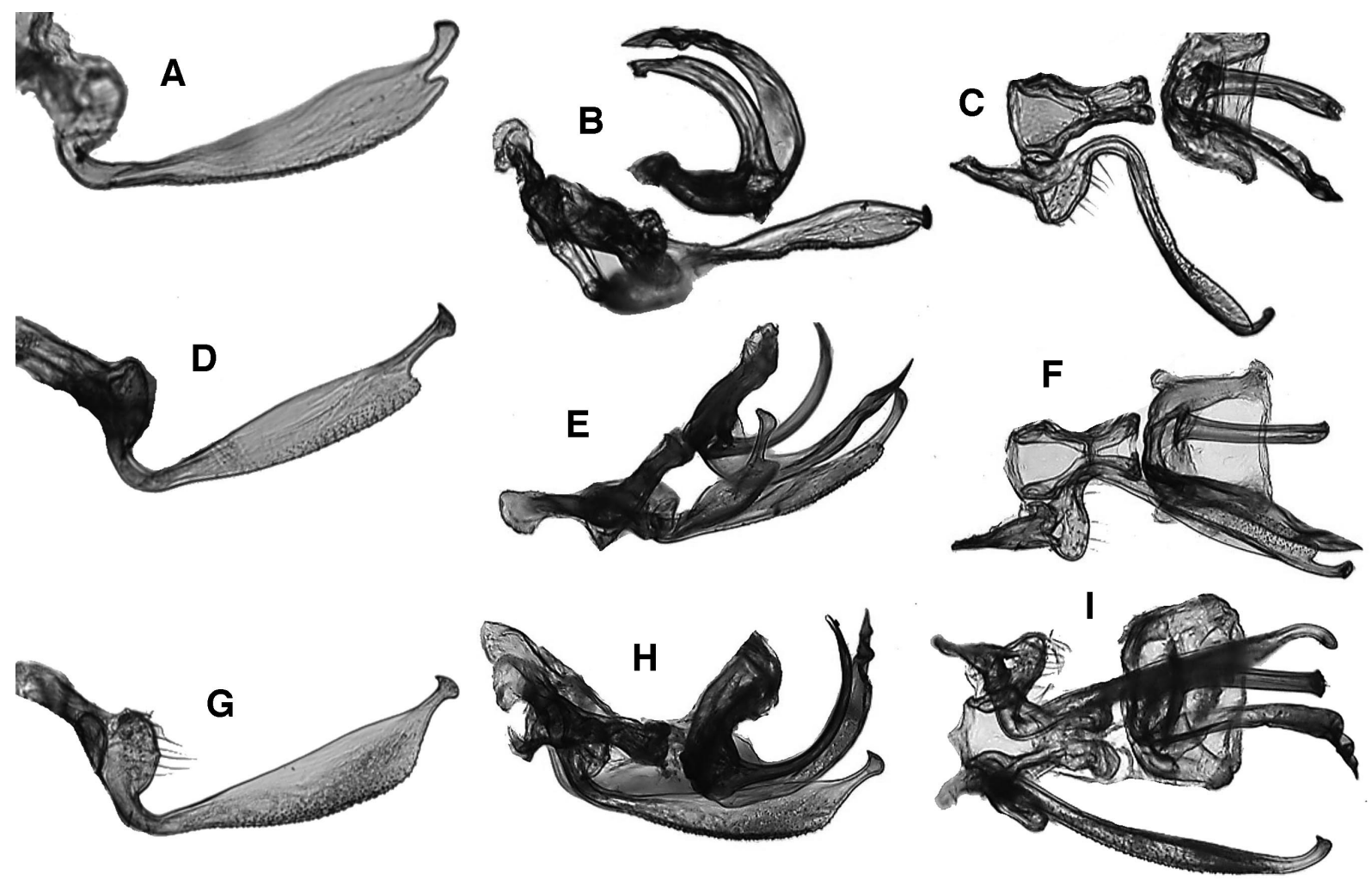

Fig. 11. Platyjassus viridis complex. - A-C. Platyjassus acutus sp. nov. A. Style, broad aspect. B. Genitalia, lateral view. C. Same, ventral view. - D-F. Platyjassus pennyi sp. nov. D. Style, broad aspect. E. Genitalia, lateral view. F. Same, ventral view. - G-I. Platyjassus viridis Evans, 1959. G. Style, broad aspect. H. Genitalia, lateral view. I. Same, ventral view. Photos not to scale. 


\section{Material examined}

\section{Holotype}

MADAGASCAR • 3 ; "MADAGASCAR: Province Fianarantsoa, Parc National Ranomafana, radio tower at forest edge, elev $1130 \mathrm{~m}, 24$ June -8 July 2004, $21^{\circ} 15.05^{\prime} \mathrm{S}, 47^{\circ} 24.43^{\prime} \mathrm{E}$, coll: M. Irwin, R. Harin'Hala, California Acad of Sciences, malaise, mixed tropical forest MA-02-09B-95"; CAS.

\section{Paratypes}

MADAGASCAR - Fianarantsoa - 1 ते; Parc National Ranomafana, radio tower at forest edge; $21^{\circ} 15.05^{\prime} \mathrm{S}, 47^{\circ} 24.43^{\prime} \mathrm{E}$; alt. $1130 \mathrm{~m}$; 24 Jun.-8 Jul. 2004; M. Irwin and R. Harin'Hala leg.; Malaise trap; mixed tropical forest; MA-02-09B-95; SMK DNA voucher: MIAS1; INHS • 1 ; ; Parc National Ranomafana, radio tower at forest edge; $21^{\circ} 15.05^{\prime} \mathrm{S}, 47^{\circ} 24.43^{\prime} \mathrm{E}$; alt. $1130 \mathrm{~m}$; 17-27 Jul. 2003; M. Irwin and R. Harin'Halal leg.; Malaise trap; mixed tropical forest; MA-02-09B-67; CAS • 1 §ै; same collection data as for preceding; INHS.

\section{Description}

Length of male $7.3 \mathrm{~mm}$ (female unknown). Anterior margin of head and costal margin of forewing dark brown. Hind tibial rows PD, AD and AV with 17-18, 12-13, and 12 macrosetae, respectively. Style apophysis somewhat broadened from base to near apex, then strongly constricted, with posteroventral margin forming acute angle, distal extension with stem moderately long, hooked mesad, apex broadened and less than half as wide as section just basad of constriction.

\section{Remarks}

This species corresponds to the OTU labeled as "Platyjassus sp." in the phylogenetic analysis of Krishnankutty et al. (2016).

$$
\begin{gathered}
\text { Platyjassus pennyi sp. nov. } \\
\text { urn:1sid:zoobank.org:act:1A9AE459-BCDD-47C2-9E41-65E419FD490F } \\
\text { Figs 2F, 11D-F }
\end{gathered}
$$

\section{Etymology}

This species is dedicated to the memory of Norman B. Penny, former manager of the California Academy of Science insect collection, who provided access to a large proportion of the specimens incorporated into this study.

\section{Material examined}

Holotype

MADAGASCAR - $\jmath^{\text {; }}$ "MADAGASCAR: Province Fianarantsoa, Parc National Ranomafana, Vohiparara, at broken bridge, el $1110 \mathrm{~m}, 4-12$ February $2002,21^{\circ} 13.57^{\prime} \mathrm{S}, 47^{\circ} 22.19^{\prime} \mathrm{E}$, coll: M. Irwin, R. Harin'Hala, California Acad of Sciences, malaise trap in high altitude rainforest, MA-02-09A-15"; CAS.

\section{Paratype}

MADAGASCAR - ô; Fianarantsoa, Parc National Ranomafana, radio tower, at forest edge; $21^{\circ} 15.05^{\prime} \mathrm{S}, 47^{\circ} 24.43^{\prime}$ E; alt. 1130 m; 15-21 Dec. 2001; M. Irwin and R. Harin'Hala leg.; Malaise trap; mixed tropical forest; MA-02-09B-07; INHS.

\section{Description}

Length of male 6.9-7.1 mm (female unknown). Dorsum dull stramineous, crown marginal rim infuscate. Pronotum with pair of faint sublateral marginal brown stripes. Crown slightly shorter than pronotum, 
anterior margin parabolically rounded. Hind tibial rows PD, AD, and AV with 19, 12 and 12 macrosetae, respectively. Style apophysis somewhat broadened from base to near apex, then strongly constricted, with posteroventral margin forming approximately $90^{\circ}$ angle, distal extension with stem relatively long, hooked mesad, apex broadened and approximately half as wide as section just basad of constriction.

Platyjassus viridis Evans, 1953

Figs 2G, 11G-I, 22

Platyjassus viridis Evans, 1953: 114.

\section{Material examined}

\section{Holotype}

MADAGASCAR • ㅇ (Fig. 22); "Inst. Scient. Madagascar Mt. Tsaratanana, 1500m. forêt de mousses X-49 RP[aulian], Platyjassus viridis Ev. J. W. Evans det., 1952, Museum Paris MNHN(EH) 2362"; MNHN(EH) 2362.

\section{Other material}

MADAGASCAR - Antananarivo - 1 今ं; $46 \mathrm{~km}$ NE of Ankazobe, Ambohitantely; $18^{\circ} 11.88^{\prime} \mathrm{S}$, 47¹6.89' E; alt. 700 m; 1-14 Nov. 2004; M. Irwin and R. Harin'Hala leg.; Malaise trap; sclerophyll forest; MA-27-20; CAS • 1 ð̊; $46 \mathrm{~km} \mathrm{NE}$ of Ankazobe, Ambohitantely; $18^{\circ} 11.88^{\prime} \mathrm{S}, 47^{\circ} 16.89^{\prime} \mathrm{E}$; alt. 700 m; 22-29 Nov. 2003; MA27-07; CAS. - Fianarantsoa - 1 §; Parc National Ranomafana, Vohiparara, at broken bridge; $21^{\circ} 13.57^{\prime} \mathrm{S}, 47^{\circ} 22.19^{\prime} \mathrm{E}$; alt. $1110 \mathrm{~m}, 14-21 \mathrm{Jan}$. 2002; M. Irwin and

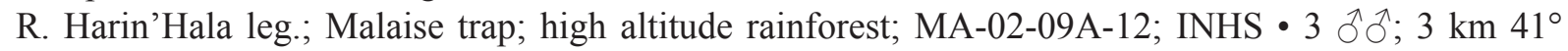
NE of Andranomay, $11.5 \mathrm{~km} 147^{\circ} \mathrm{SSE}$ of Anjozorobe; $18^{\circ} 28^{\prime} 24^{\prime \prime} \mathrm{S}, 47^{\circ} 57^{\prime} 36^{\prime \prime} \mathrm{E}$; alt. $1300 \mathrm{~m}$; 5-13 Dec. 2000; Fisher, Griswold et al. leg.; Malaise trap; montane rainforest; coll. code: BLF2372; CAS • $1 \mathrm{~d}^{\prime}$; Parc National Ranomafana, Belle Vue at Talatakely; $21^{\circ} 15.99^{\prime} \mathrm{S}, 47^{\circ} 25.21^{\prime} \mathrm{E}$; alt. $1020 \mathrm{~m}$; 22-28 Nov. 2001; M. Irwin and R. Harin'Hala leg.; Malaise trap; secondary tropical forest; MA-02-09C-04;

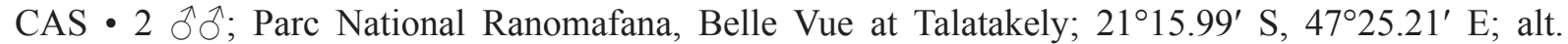
1020 m; 21-28 Jan. 2002; MA-02-09C-13; CAS • 1 今; Parc National Ranomafana, Belle Vue at Talatakely; $21^{\circ} 15.99^{\prime} \mathrm{S}, 4^{\circ} 25.21^{\prime} \mathrm{E}$; alt. $1020 \mathrm{~m}$; 12-19 Feb. 2002; MA-02-09C-16; CAS • 1 '̊; Parc National Ranomafana, Belle Vue at Talatakely; $21^{\circ} 15.99^{\prime} \mathrm{S}, 47^{\circ} 25.21^{\prime} \mathrm{E}$; alt. $1020 \mathrm{~m}$; 14-23 Apr. 2002; MA-02-09C-25; CAS • 1 ô; Parc National Ranomafana, radio tower, at forest edge; $21^{\circ} 15.05^{\prime} \mathrm{S}$, 472․43' E; alt. 1130 m; 15-27 Apr. 2003; M. Irwin and R. Harin'Hala leg.; Malaise trap; mixed tropical forest; MA-02-09B-58; INHS. - Mahajanga - 1 §̧; Andobo, forêt Antsingy; alt. 190 m; "det Antsalova, II-57 P. Griv., alt. 190 m; MNHN(EN) 16105, identified by Evans"; MNHN.

\section{Description}

Length of male 7.5-7.9 mm (female unknown). Crown with anterior margin parabolically rounded. Hind tibial rows $\mathrm{PD}, \mathrm{AD}$ and $\mathrm{AV}$ with 18, 12 and 13 macrosetae, respectively. Style apophysis broadened from base to near apex, then strongly constricted, with posteroventral margin rounded and forming obtuse angle, distal extension with stem relatively long, apex broadened but distinctly less than half as wide as section just basad of constriction.

\section{Remarks}

Study of several specimens identified by J. W. Evans as "Platyjassus viridis" indicates that his concept of the species included several species that are similar in external appearance but readily distinguishable by the male genitalia. The species concept adopted here follows that of Linnavuori \& Quartau (1975), who first illustrated the male genitalia of $P$. viridis, presumably based on study of Evans' type material. We were unable to locate the two male paratypes at MNHN. Other specimens identified by Evans in the BMNH collection do not bear paratype labels and either represent other species or their identities cannot be conirmed.. 


\author{
Plerujassus gen. nov. \\ urn:1sid:zoobank.org:act:F7ABBEAF-8CDB-4D0F-BBE4-547CBC183259 \\ Figs $3 \mathrm{~A}-\mathrm{B}, 12 \mathrm{~A}-\mathrm{F}, 19$
}

\title{
Type species
}

Platyjassus appendiculatus Evans, 1959.

\section{Etymology}

The genus name, a masculine noun, combines the Latin 'plerus' ('many' or 'most') with '-jassus', a common suffix used for genera of Iassinae, and refers to the densely reticulate forewing venation.

\section{Diagnosis}

This genus may be distinguished by the following combination of features: body robust; dorsum stramineous to brown, without distinct spots or stripes; vertex slightly overlapping anterolateral margin of eye, crown transversely striate anteriorly and with anterior margin upturned; frontoclypeus transversely rugose/striate; forewing densely reticulate; hindwing veins $\mathrm{R} 4+5$ and $\mathrm{M} 1+2$ confluent preapically but separate near apex; hind femur macrosetal formula $2+2+1+1+1$; style serrate ventrally; aedeagus with pair of distally directed lateral preapical spines.

\section{Description}

HABITUs. Large platyjassines (8.9-10.5 mm). Color stramineous to dark brown.

HEAD. Crown depressed, with numerous irregular transverse striations well delimited throughout length, anterior margin weakly produced, slightly upturned, subparallel to posterior margin, well delimited but only slightly produced over dorsal part of face, vertex only slightly overlapping eye margin; ocelli anteromesad of eyes, relatively large and close to eyes. Frontoclypeus moderately convex, transversely rugose, without median dorsal depression; antennal ledge oblique, strongly overlapping frontoclypeus; lateral frontal suture present above antennal ledge but not extended to crown margin; gena slightly emarginate below eye, proepisternum slightly exposed; lorum small, flat; anteclypeus weakly convex, lateral margins slightly divergent distally; rostrum slender, extended to middle coxae.

Thorax. Pronotum strongly declivous, in profile continuing contour of crown, much wider than head, lateral margins strongly divergent posterad, transversely striate. Forewing venation densely reticulate throughout, appendix broad and extended to wing apex, inner apical cell divided into many small cells. Hindwing veins R4 +5 and M1 +2 confluent preapically but separate near apex. Front femur row IC with setae in irregular row; AV irregular row of stout setae in basal half, dorsal surface of tibia rounded, $\mathrm{PD}$ and $\mathrm{AD}$ macrosetae only partially differentiated. Hind femur macrosetal formula $2+2+1+1+1$, tibial rows $\mathrm{PD}, \mathrm{AD}$ and $\mathrm{AV}$ with $\sim 29,12$ and 24 macrosetae, respectively, $\mathrm{AD}$ and $\mathrm{PD}$ with one or more smaller setae between successive macrosetae; tarsomere I with two plantar rows, pecten with 4 platellae.

ABDomen. Male pregenital sternite slightly longer than sternite VII, posterior margin truncate. Pygofer base band-like, dorsally with median posterior projection; lobe separated from base by membranous vertical cleft, with numerous macrosetae in distal half, apex rounded, processes and spines absent, ventral margin without distinct group of fine setae. Subgenital plate with median longitudinal row of macrosetae, dorsolateral margin with row of long, fine setae extended entire length. Style apophysis slender throughout length, basal half serrate ventrally, with serrations formed by row of oblique transverse ventral ridges, apex tapered to acute point. Connective with stem much longer than arms, arms connected ventrally by scoop-like extension. Aedeagus with atrium shield-like; shaft long, recurved dorsad, with pair of lateral flanges bearing lateral band of minute, stout setae; apex with pair of lateral spines directed distad; gonopore apical. Female unknown. 


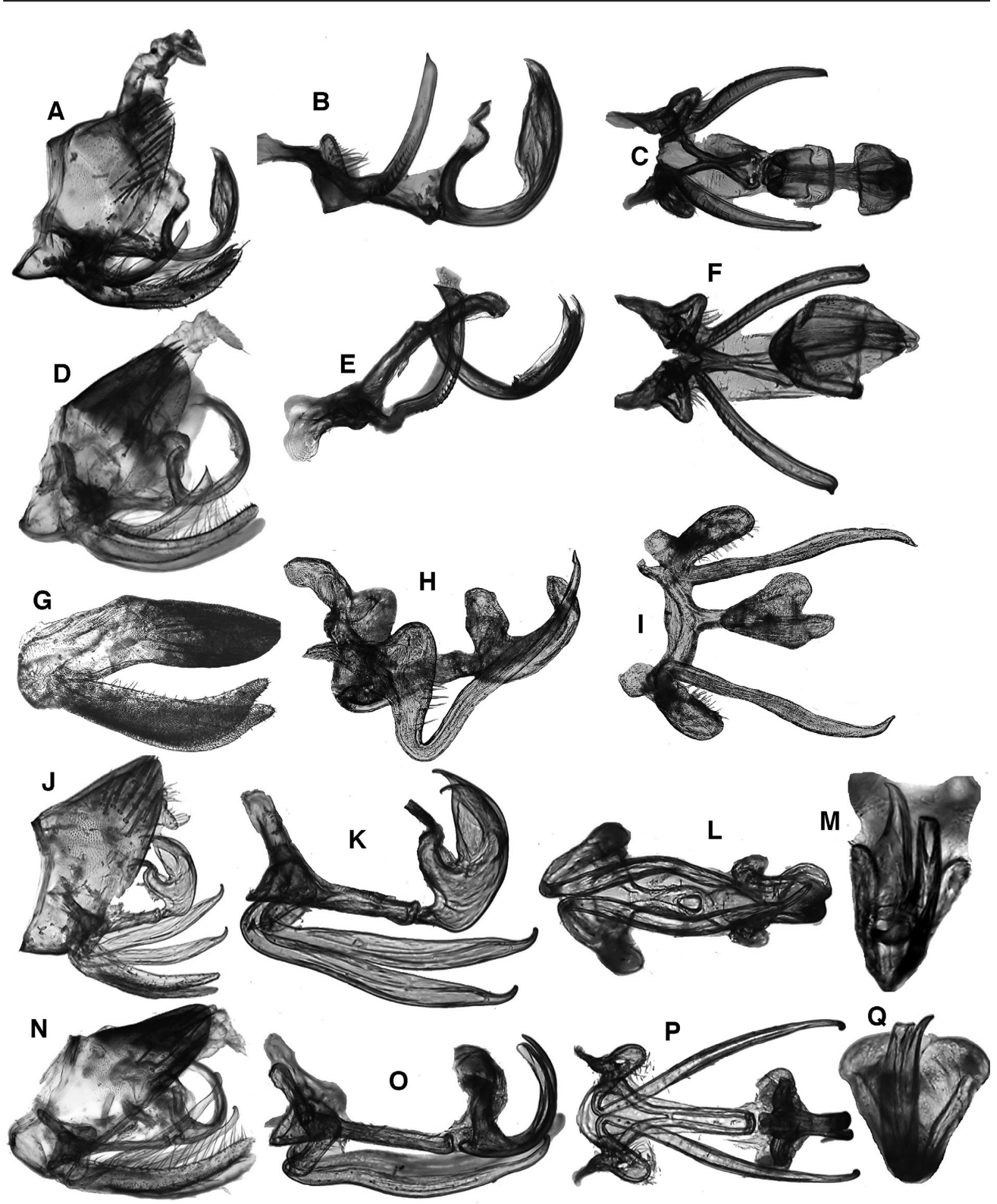

Fig. 12. Plerujassus gen. nov., Plexijassus gen. nov. and Pseudocurtara gen. nov. - A-C. Plerujassus appendiculatus (Evans, 1959). A. Genital capsule, lateral view. B. Genitalia, lateral view. C. Same, ventral view. - D-F. Plerujassus brunnescens sp. nov. D. Genital capsule, lateral view. E. Genitalia, lateral view. F. Same, ventral view. - G-I. Plexijassus caliginosus sp. nov. G. Genital capsule, lateral view. H. Genitalia, lateral view. I. Same, ventral view. - J-M. Pseudocurtara minima sp. nov. J. Genital capsule, lateral view. K. Genitalia, lateral view. L. Same, ventral view. M. Aedeagus, posterior view. - N-Q. Pseudocurtara nigripicta sp. nov. N. Genital capsule, lateral view. O. Genitalia, lateral view. P. Same, ventral view. Q. Aedeagus, posterior view. Photos not to scale. 


\section{Remarks}

This genus is erected to include P. appendiculatus, described in Platyjassus by Evans (1959) and an additional new species. It differs from Platyjassus in having transverse striations anteriorly on the crown and forewing venation densely reticulate.

Key to species of Plerujassus gen. nov. (males)

1. Color mostly dark brown (Fig. 3B); male style apophysis distinctly broadened apically (Fig. 12E) .Plerujassus brunnescens gen. et sp. nov.

- Color stramineous, without darker markings (Fig. 3A); male style apophysis not distinctly broadened apically (Fig. 12B) Plerujassus appendiculatus (Evans, 1959)

Plerujassus appendiculatus (Evans, 1959) comb. nov.

Figs 3A, 12A-C, 19

Platyjassus appendiculatus Evans, 1959: 501.

\section{Material examined}

\section{Holotype}

MADAGASCAR • đ (Fig. 19); “Type [circle red label], Morondava fôret sud de Befasy I-56 R.P[aulian] Institut scientifique MADAGASCAR, Museum Paris MNHN(EH) 2354", "Platyjassus appendiculatus Evans [J]. W. Evans det., 1958, ABDOMEN \DISSECTED BY $\backslash$ O. EVANGELISTA $\backslash ð \backslash$ O. Evangelista det. '17”; $\mathrm{MNHN}(\mathrm{EH}) 2354$.

\section{Paratype}

MADAGASCAR • O’; "Morondava fôret sud de Befasy, I-56”; R. Paulian leg.; BMNH.

\section{Other material}

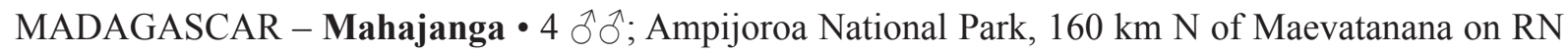
04; 16 $19.16^{\prime}$ S, $46^{\circ} 48.80^{\prime}$ E; alt. 43 m; 20-30 Nov. 2003; M. Irwin and R. Harin'Hala leg.; Malaise trap; deciduous forest; MA-25-24; CAS 1 1 ; same collecction data as for preceding; INHS 11 ; ; Ampijoroa National Park, $160 \mathrm{~km} \mathrm{~N}$ of Maevatanana on RN 04; $16^{\circ} 19.16^{\prime} \mathrm{S}, 46^{\circ} 48.80^{\prime} \mathrm{E}$; alt. $43 \mathrm{~m}$; 9-20 Nov. 2003; SMK DNA voucher: MIAS15; INHS.

\section{Description}

Length of male 9.5-10.5 mm (female unknown). Color stramineous, without darker markings. Style apophysis not broadened preapically, parallel-sided to acutely tapered apex. Aedeagus with lateral ridges of atrium not distinctly more sclerotized than medial part; shaft without digitiform processes mesad of lateral spines at apex.

\section{Remarks}

This species corresponds to the OTU labeled "Platyjassini gen. n. 1, sp. 3" in the phylogeny of Krishnankutty et al. (2016).

Plerujassus brunnescens gen. et sp. nov. urn:Isid:zoobank.org:act:7760A594-2602-43F8-8760-4C668FB3B048

Figs 3B, 12D-F

\section{Etymology}

The species name refers to the overall brownish coloration. 


\section{Material examined}

Holotype

MADAGASCAR • O'; "MADAGASCAR: Majunga, Ampijoroa National Park $160 \mathrm{~km} \mathrm{~N}$ of Maevatanana on RN 04 elev 43 m, 2-14 January 2005, 16²19.16' S, 46 ${ }^{\circ} 48.80^{\prime}$ E, California Acad of Sciences, coll: M. Irwin, R. Harin'Hala, malaise trap in deciduous forest MA-25-40”; CAS.

\section{Paratype}

MADAGASCAR - 1 đ; Mahajanga Province, Ampijoroa National Park, $160 \mathrm{~km}$ N of Maevatanana on RN 04; $16^{\circ} 19.16^{\prime}$ S, 4648.80' E; alt. 43 m; 2-14 Jan. 2005; M. Irwin and R. Harin'Hala leg.; Malaise trap; deciduous forest; MA-25-40; SMK DNA voucher: MIAS17; INHS.

\section{Description}

Length of male $8.9 \mathrm{~mm}$ (female unknown). Color mostly dark brown with some paler mottling. Style apophysis slightly but distinctly broadened preapically. Aedeagus with lateral ridges of atrium much more strongly sclerotized than medial part; shaft with pair of small digitiform processes mesad of longer lateral spines at apex.

\section{Remarks}

This species corresponds to the OTU labeled "Platyjassini gen. n. 1, sp. 1" in the phylogeny of Krishnankutty et al. (2016).

Plexijassus gen. nov. urn:1sid:zoobank.org:act:E7AFC122-8C2D-4036-AF45-018107F94856

Figs $3 \mathrm{C}, 12 \mathrm{G}-\mathrm{I}, 17 \mathrm{M}-\mathrm{O}$

\section{Type species}

Plexijassus caliginosus sp. nov.

\section{Diagnosis}

This genus may be distinguished by the following combination of features: body medium-sized; dorsum dark brown to black; vertex overlapping $>1 / 2$ of anterolateral margin of eye, crown irregularly rugose; forewing with supernumerary branches of $\mathrm{R}$ extended to costal margin; hindwing veins $\mathrm{R} 4+5$ and $\mathrm{M} 1+2$ completely confluent apically; hind femur macrosetal formula $2+2+1+1$; style slender, without denticuli; aedeagus without processes.

\section{Etymology}

The genus name, a masculine noun, refers to the plexus of veins near the apex of the forewing costal margin.

\section{Description}

Haвitus. Medium-sized platyjassines (7.4-8.4 mm). Dorsum uniformly dark brown, venter stramineous.

HEAD. Crown flattened, much longer than pronotum, with numerous irregular transverse rugulae, becoming less prominent posteriorly, anterior margin strongly produced, spatulate, forming hood over dorsal part of face, vertex strongly overlapping eye margin; ocelli anteromesad of eyes, relatively distant from eyes and from anterior margin of crown. Frontoclypeus moderately convex, without punctations, without median dorsal depression; antennal ledge absent, apparently coinciding with anterior margin of 
head; lateral frontal suture extended anterad beyond antennal to crown margin; gena relatively narrow, slightly emarginate below eye, proepisternum partially exposed; lorum small, flat; anteclypeus convex, lateral margins evenly divergent distally; rostrum slender, not surpassing front trochanters.

Thorax. Pronotum slightly declivous, in profile continuing contour of crown, much wider than head, lateral margins strongly divergent posterad, transverse striations distinct. Forewing with costal area unusually broad distally, vein $\mathrm{R}$ with several supernumerary branches, appendix broad and extended to wing apex, inner apical cell elongate, slender. Hindwing veins $\mathrm{R} 4+5$ and $\mathrm{M} 1+2$ completely confluent distally. Front femur row IC with setae in single row; AV with single row of stout setae in basal half, dorsal surface of tibia rounded, PD and AD macrosetae only partially differentiated. Hind femur macrosetal formula $2+2+1+1$, tibial rows $\mathrm{PD}, \mathrm{AD}$ and $\mathrm{AV}$ with 25,15 , and 17 macrosetae, respectively, row $\mathrm{AD}$ with one or more smaller setae between successive macrosetae; tarsomere I with two plantar rows, pecten with 4 platellae.

AвDOMEN. Male pregenital sternite distinctly longer than sternite VII, posterior margin truncate. Pygofer base band-like, dorsally with median posterior projection; lobe fused to base, membranous cleft absent, with numerous macrosetae in distal half, apex narrowly rounded, processes and spines absent, ventral margin without distinct group of fine setae. Subgenital plate relatively broad and strongly depressed, with median longitudinal row of few macrosetae, dorsolateral margin with few sparse, short setae. Style apophysis slender, without conspicuous denticuli. Connective Y-shaped, with anterior arms widely divergent. Aedeagus simple, without processes. Female abdominal sternite VII with posterior margin weakly trilobed. First valvulae broad, dorsal sculpturing strigate. Second valvulae strongly broadened near base, then tapered to acute apex, dorsal margin serrate, with numerous blunt-tipped teeth alternating between sides.

\section{Remarks}

This genus is similar to Pulchrijassus gen. nov. but differs in having the dorsal coloration uniformly dark brown or black and in lacking extra crossveins between forewing veins $\mathrm{R}, \mathrm{M}$ and $\mathrm{CuA}$.

$$
\begin{aligned}
& \text { Plexijassus caliginosus gen. et sp. nov. } \\
& \text { urn:1sid:zoobank.org:act:17FEDD09-707C-45B1-87D6-65F6F9BCD2A3 }
\end{aligned}
$$

Figs $3 \mathrm{C}, 12 \mathrm{G}-\mathrm{I}, 17 \mathrm{M}-\mathrm{O}$

\section{Etymology}

The species name is derived from the Latin 'caligino' ('dark') and refers to the dark overall coloration.

\section{Material examined}

\section{Holotype}

MADAGASCAR - O'; "MADAGASCAR: Province Fianarantsoa, Parc National Ranomafana, radio tower, at forest edge, elev $1130 \mathrm{~m}, 15-27$ April 2003, 21 ${ }^{\circ} 15.05^{\prime} \mathrm{S}, 47^{\circ} 24.43^{\prime} \mathrm{E}$, coll: M. Irwin, R. Harin'Hala, California Acad of Sciences, malaise, mixed tropical forest, MA-02-09B-58"; CAS.

\section{Paratypes}

MADAGASCAR - Fianarantsoa - 1 $\delta^{\lambda}$; Parc National Ranomafana, radio tower, at forest edge; $21^{\circ} 15.05^{\prime}$ S, $47^{\circ} 24.43^{\prime}$ E; alt. 1130 m; 15-27 Apr. 2003; M. Irwin and R. Harin'Hala leg.; Malaise trap; mixed tropical forest; MA-02-09B-58; CAS - 1 q; same collection data as for preceding; 9-26 Feb.

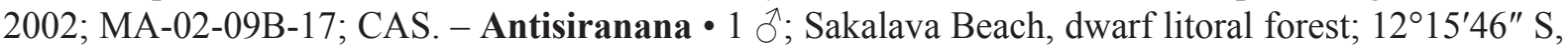
49 23'31" E; alt. 10m; 13-16 May 2001; M. Irwin and R. Harin'Hala leg.; Malaise trap across sandy trail; MA01-048[?]-09; SMK DNA voucher: MIAS2; INHS. 


\section{Description}

Length of male $7.4 \mathrm{~mm}$, female $8.4 \mathrm{~mm}$. Coloration and structure as described for genus. Style apophysis slightly broadened near midlength in lateral view, slightly sinuate, apex attenuate, gradually curved mesad distally. Connective with slight median anterior convexity, stem shorter than arms. Aedeagus with shaft U-shaped, tubular, tapered from base to bluntly pointed apex in lateral view. Female as described for genus.

\section{Remarks}

This species corresponds to the OTU labeled "Platyjassus sp. n. 1" in the phylogeny of Krishnankutty et al. (2016).

Pseudocurtara gen. nov. urn:1sid:zoobank.org:act:859280F7-5DE5-4E92-AEBB-1AC01EC36449

$3 \mathrm{D}, 12 \mathrm{~J}-\mathrm{Q}, 13 \mathrm{~A}-\mathrm{C}, 17 \mathrm{P}-\mathrm{U}$

\section{Type species}

Pseudocurtara quadrata sp. nov.

\section{Etymology}

The genus name, a feminine noun, combines 'pseudo-' ('false') with Curtara, a superficially similar New World leafhopper genus belonging to the tribe Gyponini.

\section{Diagnosis}

This genus may be distinguished by the following combination of features: body medium-sized; dorsum stramineous, with black spots and sometimes additional dark or red markings on crown, pronotum and forewing; vertex not overlapping anterolateral margin of eye, crown transversely striate; forewing with supernumerary crossveins in clavus and corium; hindwing veins $\mathrm{R} 4+5$ and $\mathrm{M} 1+2$ confluent preapically but separate near apex; hind femur macrosetal formula $2+2+1$; style without denticuli; aedeagus shaft with paired or unpaired preapical processes.

\section{Description}

HaBitus. Medium-sized platyjassines (5.8-9.2 mm). Color stramineous, with symmetrical dark brown markings on dorsum.

Head. Crown declivous, slightly convex, with numerous well delimited transverse striations over entire length, anterior and posterior margins parallel, anterior margin well delimited by pair of parallel transverse carinae, not spatulate, forming only slight ledge over dorsal part of face, vertex without anterolateral extension over eye; ocelli mesad of anteromesal corners of eyes, closer to midline than to eyes. Frontoclypeus moderately convex, with median dorsal depression, transversely rugulose; antennal ledge oblique, not overlapping frontoclypeus; lateral frontal suture extended to crown margin above antennal ledge; gena slightly emarginate below eye and relatively broad more ventrad, completely concealing proepisternum; lorum small, flat; anteclypeus slightly convex, lateral margin strongly divergent distally; rostrum broad, extended to middle coxae.

THORaX. Pronotum strongly declivous, in profile continuing contour of crown, much wider than head, lateral margins strongly divergent posteriorly, transverse striations well delimited. Forewing with numerous supernumerary crossveins in clavus and in distal half of corium, appendix broad and extended to wing apex, inner apical cell relatively long. Hindwing veins $\mathrm{R} 4+5$ and M1+2 confluent preapically, then separate near apex. Front femur rows IC and AV well delimited, with stout setae of similar sizes, 
somewhat irregular; dorsal surface of tibia flattened and with few macrosetae between PD and AD. Hind femur macrosetal formula $2+2+1$, tibial row $\mathrm{AD}$ without smaller setae between successive macrosetae; tarsomere I plantar row double, pecten with 4 platellae.

AbDomen. Male pregenital sternite distinctly longer than sternite VII, posterior margin truncate. Male pygofer base band-like, dorsally without median posterior projection; lobe separated from base by membranous cleft, with numerous macrosetae in distal half, processes and spines absent, ventral margin without distinct group of fine setae. Subgenital plate with median longitudinal row or band of macrosetae, dorsolateral margin with band of long, fine setae. Style apophysis slender, without ventral denticuli, apex curved dorsomesad. Connective stem long, arms weakly developed, anterior margin convex. Aedeagus with atrium V-shaped in posterior view, shaft simple, unpaired basal or preapical process present. Female with ovipositor shorter than pygofer; first valvula broad, with dorsal sculpturing reticulate; second valvulae broad, with distal teeth alternating between left and right blade.

\section{Remarks}

This genus differs from other Platyjassini, and is similar to the following two genera, in having the crown relatively short, with well-delimited transverse striations, the vertex without anterolateral extensions overlapping the eyes and the ocelli between rather than anterad of the eyes. It differs from Pseudomarganana gen. nov. and Pseudocyrta gen. nov. in having the forewing venation reticulate.

\section{Key to species of Pseudocurtara gen. nov. (males)}

1. Pronotum posterior margin bordered with dark brown (Fig. 3D); aedeagal process arising on left side of shaft (Fig. 12M) .Pseudocurtara minima gen. et sp. nov.

- Pronotum posterior margin not bordered with brown; aedeagal process arising on right side of shaft

2. Pronotum with large, paired black submedial maculae, forewing heavily marked with bright red (Fig. 3E); aedeagus in lateral view without quadrate ventral lobe (Fig. 12O)

.Pseudocurtara nigripicta gen. et sp. nov.

- Pronotum without large, paired black submedial maculae, forewing without bright red pigmentation (Fig. 3F); aedeagus in lateral view with prominent quadrate ventral lobe (Fig. 13B) ..

.Pseudocurtara quadrata gen. et sp. nov.

$$
\begin{gathered}
\text { Pseudocurtara minima gen. et sp. nov. } \\
\text { urn:Isid:zoobank.org:act:22049B26-9463-4441-B0A2-D805362628E7 }
\end{gathered}
$$

Figs 3D, 12J-M, 17P-R

\section{Etymology}

The species name refers to the small size of this species.

\section{Material examined}

\section{Holotype}

MADAGASCAR - ठ; "MADAGASCAR: Antsiranana Province, Vohemar Dist., SAVA region, Andranotsimaty, dry forest, $9 \mathrm{~km}$ NE Daraina, 29 Sept -6 Oct 2011, 13 $10.17^{\prime} \mathrm{S} 49^{\circ} 42.04^{\prime} \mathrm{E}$, California Acad. of Sciences, coll: M.Irwin, R.Harin'Hala, malaise, dry dense forest, elev 90 m, MG-57-43"; CAS.

\section{Paratypes}

MADAGASCAR - Antsiranana 1 đ̧; Vohemar Dist., SAVA region, Andranotsimaty, dry forest, 9 km NE of Daraina; $13^{\circ} 10.17^{\prime}$ S, 49 $42.04^{\prime}$ E; alt. 90 m; 18-26 Oct. 2012; M.Irwin and R.Harin'Hala leg.; Malaise trap; dry dense forest; MG-57-55; INHS. - Antananarivo • 1 q; 46 km NE of Ankazobe, 
Ambohitantely; $18^{\circ} 11.88^{\prime}$ S, 47 $7^{\circ} 16.89^{\prime}$ E; alt. 700 m; 6-18 Feb. 2005; M. Irwin and R. Harin’Hala leg.; Malaise trap; sclerophyll forest; MA-27-27; SMK DNA voucher: MIAS13; CAS.

\section{Description}

Length of male $5.8 \mathrm{~mm}$, female $7.6 \mathrm{~mm}$. Dorsum yellow with symmetrical dark markings; face yellow with pair of small brown spots on lora; pronotum with several symmetrically arranged black spots anteriorly, posterior margin brown; mesonotum with triangles bordered with brown and with pair of black submedial spots; forewing costal area with yellow opaque sclerotization in basal half, remainder hyaline, veins ochraceous to dark brown; venter yellow except for diffuse brown spot on hind coxa. Crown flat in profile, marginal rim relatively thin, forming shelf over frontoclypeus, ocelli well separated from anterior margin. Forewing with supernumerary crossveins in corium and clavus, inner apical cell narrow and relatively short. Hind tibial rows PD, AD, and AV with 20, 14 and 14 macrosetae, respectively. Style apophysis slightly sinuate, somewhat expanded toward midlength, then gradually tapered to apex, apex curved dorsomesad and terminating in blunt tip. Aedeagus with shaft broad in lateral view, curved dorsad and tapered toward apex, with broad, poorly sclerotized unpaired process arising on left side and extended along shaft to apex, shaft apex rounded; gonopore preapical on posterior surface. Female sternite VII with posterior margin roundly produced. Second valvulae short and broad, dorsal margin broadly concave, without hump, distal teeth relatively short and indistinct.

\section{Remarks}

This species corresponds to the OTU labeled "Platyjassini gen. n. 1, sp. 2" in the phylogeny of Krishnankutty et al. (2016).

Pseudocurtara nigripicta gen. et sp. nov. urn:1sid:zoobank.org:act:289F407A-8939-4EFB-B024-A0A39C33D563

Figs $3 \mathrm{E}, 12 \mathrm{~N}-\mathrm{Q}$

\section{Etymology}

The species name refers to the large black markings on the pronotum of this species.

\section{Material examined}

Holotype

MADAGASCAR - ô; "MADAGASCAR: Toamasina, Réserve Nationale Intégrale Betampona,

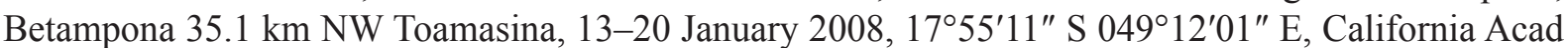
of Sciences, coll. B.L. Fisher, rainforest, malaise trap, elev 525 m, coll. code: BLF19594 04"; CAS.

\section{Descrption}

Length of male $9.0 \mathrm{~mm}$ (female unknown). Ground color of dorsum stramineous, crown with three irregular anterior brown spots and two large posterolateral black maculae in addition to usual pair of round black spots, face dark brown to black except middle of frontoclypeus yellow, pronotum with two pairs of large black submedial maculae and three smaller black maculae along lateral margin, mesonotal triangles brown, forewing heavily marked with crimson along veins, femora mostly dark brown, front and middle tibiae dark brown apically. Crown distinctly concave in profile, marginal rim relatively thin and forming shelf over frontoclypeus, ocelli well separated from anterior margin. Forewing with many supernumerary crossveins in corium and clavus. Hind tibial rows PD, AD and AV with 26, 15, and 18 macrosetae, respectively. Style apophysis slightly sinuate in lateral view, curved dorsad, gradually tapered to blunt dorsomedially curved apex. Aedeagus atrium with poorly sclerotized plate between arms of $\mathrm{V}$, shaft strongly and evenly recurved dorsally, approximately parallel-sided in lateral and posterior views, asymmetrical in posterior view, with long, acuminate spine arising on right side and extended beyond shaft apex, shaft apex truncate, gonopore apical. 


\section{Pseudocurtara quadrata gen. et sp. nov. urn:1sid:zoobank.org:act:441E7573-1AFF-4DFE-99EF-161679B1FE4E Figs $3 \mathrm{~F}, 13 \mathrm{~A}-\mathrm{C}, 17 \mathrm{~S}-\mathrm{U}$}

\section{Etymology}

The species name refers to the quadrate ventral lobe of the aedeagus of this species.

\section{Material examined}

\section{Holotype}

MADAGASCAR - 3 ; "MADAGASCAR: Province Antananarivo, $46 \mathrm{~km}$ NE of Ankazobe: Ambohitantely, $18^{\circ} 11.88^{\prime}$ S, 47 $16.89^{\prime}$ E, 14-29 November 2004, California Acad of Sciences coll: M. Irwin, R. Harin'Hala, malaise trap - in sclerophyl forest, elev 700 m, MA-27-21"; CAS.

\section{Paratypes}

MADAGASCAR - Fianarantsoa • 1 đ; Forêt de Vevembe, $66.6 \mathrm{~km} 293^{\circ} \mathrm{WNW}$ of Farafangana; $22^{\circ} 47^{\prime} 28^{\prime \prime}$ S, 47 $10^{\prime} 55^{\prime \prime}$ E; alt. 600 m; 23 Apr. 2006; B.L. Fisher et al. leg.; Malaise trap; rainforest transitioning to montane forest; BLF 14118; INHS - 1 \%; Parc National Ranomafana, Vohiparara, at broken bridge; $21^{\circ} 13.57^{\prime} \mathrm{S}, 47^{\circ} 22.19^{\prime} \mathrm{E}$; alt. $1110 \mathrm{~m}$; 14-21 Jan. 2002; M. Irwin and R. Harin'Hala leg.; Malaise trap; high altitude rainforest; MA-02-09A-12; INHS. - Antsiranana 1 \%; Sakalava Beach, dwarf littoral forest; $12^{\circ} 15^{\prime} 46^{\prime \prime} \mathrm{S}, 49^{\circ} 23^{\prime} 51^{\prime \prime}$ E; alt. 10 m; 20 Mar.-7 Apr. 2001; M. Irwin and R. Harin'Hala leg.; Malaise trap across sandy trail; MA-01-04B-05; CAS • 1 +; Parc National Montagne d'Ambre; 12³0'52" S, 49¹0'53" E; alt. 960 m; 29 Jan. 2001; M.E. Irwin leg.; netted by hand; MA-0101A-05; INHS.

\section{Description}

Length of male $7.8 \mathrm{~mm}$; female 7.8-9.2 mm. Dorsum yellow with extensive brown markings; pair of spots on crown behind ocelli, anterior band of irregular spots, two pairs of posterior maculae on pronotum and pair of spots on mesonotum black; forewings with brown irroration, veins tinged with red; area just beneath marginal rim of head black, remainder of venter pale yellow. Crown slightly concave in profile, marginal rim relatively thin, forming shelf over frontoclypeus, ocelli well separated from anterior margin. Forewing with supernumerary crossveins in corium and clavus, inner apical cell relatively broad and long but not extended to wing apex. Hind tibial rows PD, AD, and AV with 27, 13 and 17 macrosetae, respectively. Style sinuate in lateral view, gradually widened toward middle, then gradually tapered to apex. Aedeagus with quadrate ventral keel at base in lateral view; shaft slender, tapered, evenly curved dorsad, gonopore apical; unpaired basal process similar in width but longer than shaft, curved dorsad and closely parallel to shaft through most of length, apex slightly twisted and attenuate. Female sternite VII with posterior margin truncate. Second valvulae short and broad, dorsal margin humped beyond midlength, with row of several relatively long, irregular teeth distally, apex acuminate.

\section{Pseudocyrta gen nov. urn:lsid:zoobank.org:act:2BE223A4-A6D1-42A1-89D4-723E338C9F5B}

Figs $3 \mathrm{G}, 13 \mathrm{D}-\mathrm{G}$

\section{Type species}

Pseudocyrta hyalina sp. nov.

\section{Etymology}

The genus name, a feminine noun, combines 'pseudo-' ('false') with Cyrta, the name of a superficially similar genus belonging to Deltocephalinae: Stegelytrini. 


\section{Diagnosis}

This genus may be distinguished by the following combination of features: body medium-sized; dorsum dark brown, without distinct spots or stripes; vertex not produced or spatulate, not overlapping anterolateral margin of eye, crown transversely striate; forewing mostly hyaline, without extra crossveins, appendix striolate; hindwing veins $\mathrm{R} 4+5$ and $\mathrm{M} 1+2$ confluent preapically but separate near apex; hind femur with many supernumerary macrosetae; style without denticuli, apex foot-like; aedeagus with pair of preapical spines extended distad.

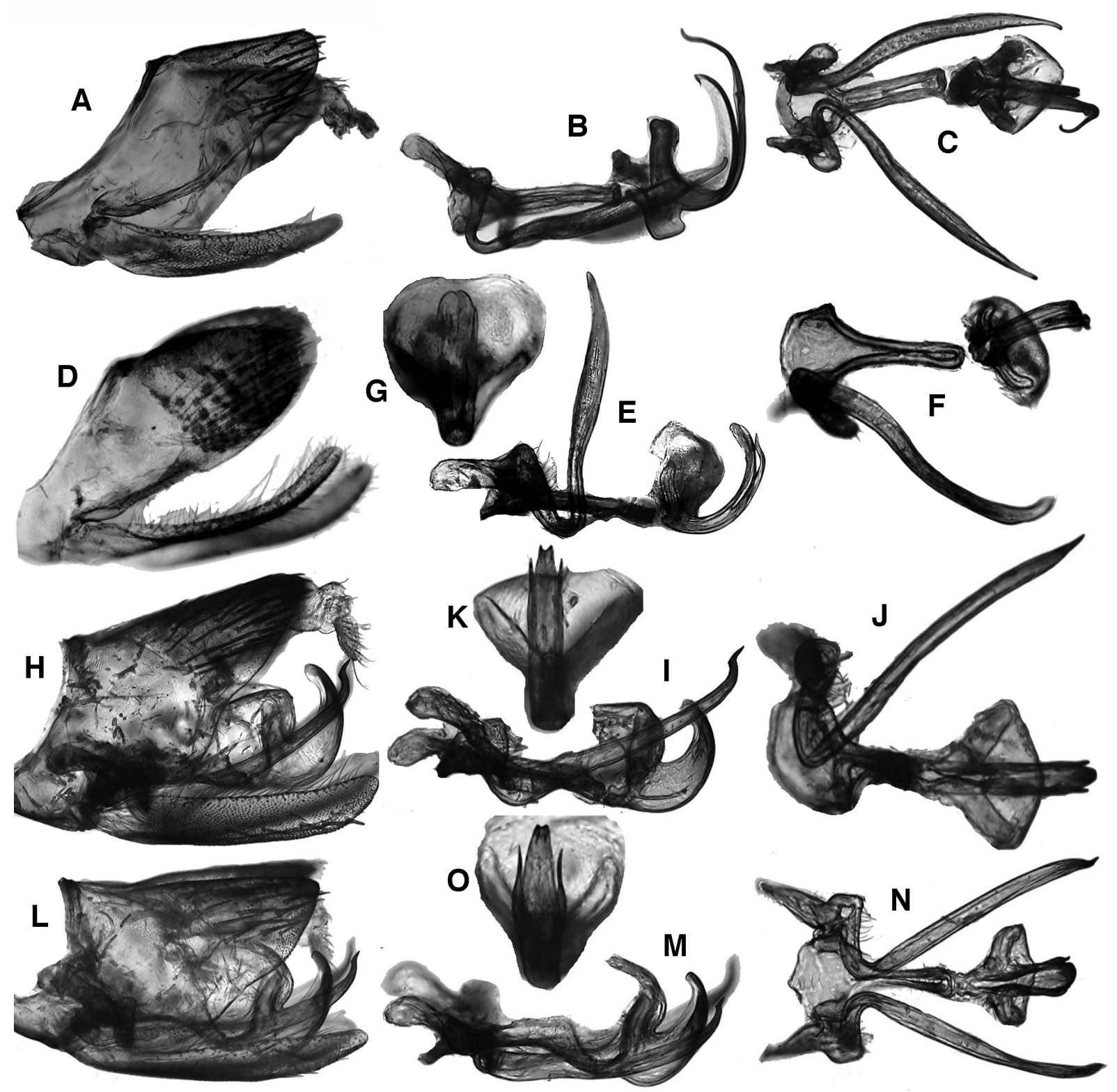

Fig. 13. Pseudocurtara gen. nov., Pseudocyrta gen. nov. and Pseudomarganana gen. nov. A-C. Pseudocurtara quadrata sp. nov. A. Genital capsule, lateral view. B. Genitalia, lateral view. C. Same, ventral view. - D-G. Pseudocyrta hyalina sp. nov. D. Genital capsule, lateral view. E. Genitalia, lateral view. F. Same, ventral view. G. Aedeagus, posterior view. - H-K. Pseudomarganana olivacea sp. nov. H. Genital capsule, lateral view. I. Genitalia, lateral view. J. Same, ventral view. K. Aedeagus, posterior view. - L-O. Pseudomarganana rosea sp. nov. L. Genital capsule, lateral view. M. Genitalia, lateral view. N. Same, ventral view. O. Aedeagus, posterior view. Photos not to scale. 


\section{Description}

Habitus. Medium sized platyjassines $(8.2 \mathrm{~mm})$. Color dark brown without distinct paired markings.

HEAD. Crown declivous, slightly convex, with numerous well delimited transverse striations over entire length, anterior and posterior margins parallel, anterior margin well delimited in lateral view but only weakly produced and forming obtuse angle with face in profile, vertex without anterolateral extension over eye; ocelli mesad of anteromesal corners of eyes, closer to midline than to eyes. Frontoclypeus convex, without median dorsal depression, transversely rugulose; antennal ledge oblique, not overlapping frontoclypeus; lateral frontal suture extended to crown margin above antennal ledge; gena slightly emarginate below eye and relatively broad more ventrad, completely concealing proepisternum; lorum small, flat; anteclypeus slightly convex, lateral margin strongly divergent distally; rostrum broad, extended to middle coxae.

THorax. Pronotum strongly declivous, in profile continuing contour of crown, much wider than head, lateral margins strongly divergent posteriorly, transverse striations well delimited. Forewing without supernumerary crossveins, appendix very broad, striolate and extended to wing apex, inner apical cell long and relatively broad. Hindwing veins $\mathrm{R} 4+5$ and $\mathrm{M} 1+2$ confluent preapically, then separate near apex. Front femur rows IC and AV well delimited, with stout setae of similar sizes, somewhat irregular; dorsal surface of tibia flattened and with few macrosetae between PD and AD. Hind femur macrosetal formula with two distal pairs of macrosetae and several more basad, tibial row AD without smaller setae between successive macrosetae; tarsomere I with plantar setae scattered.

AвDOMEn. Male pregenital sternite distinctly longer than sternite VII, posterior margin truncate. Male pygofer base band-like, dorsally without median posterior projection; lobe separated from base by membranous cleft, with numerous macrosetae in distal half, processes and spines absent, ventral margin without distinct group of fine setae. Subgenital plate with median longitudinal row or band of macrosetae, dorsolateral margin with band of long fine setae. Style apophysis slender, without ventral denticuli, apex curved dorsomesad, with small foot-like apical extension. Connective stem long, arms weakly developed, anterior margin convex. Aedeagus with atrium V-shaped in posterior view, with weakly pigmented plate connecting arms of $\mathrm{V}$; shaft simple, with pair of slender symmetrical lateral spines arising near midlength and extended distad, gonopore apical. Female unknown.

\section{Remarks}

This genus, erected based on a single male, resembles Pseudocurtara gen. nov. and Pseudomarganana gen. nov. in having the head very short and broad in dorsal view, with the anterior margin relatively thick and not produced over the frontoclypeus in profile, but with numerous transverse striations. It differs from the two mentioned genera in having the forewing mostly hyaline, with the appendix unusually broad and striolate.

Pseudocyrta hyalina gen. et sp. nov. urn:1sid:zoobank.org:act:CA7B7624-9EF3-41E5-B749-CC75770C4A01

Figs $3 \mathrm{G}, 13 \mathrm{D}-\mathrm{G}$

\section{Etymology}

The species name refers to the mostly hyaline forewing of this species.

\section{Material examined}

\section{Holotype}

MADAGASCAR • Õ; "MADAGASCAR: Antsiranana Province, Réserve Spéciale de l'Ankarana, 13.6 $\mathrm{km} 192^{\circ} \mathrm{SSW}$ Anivorano Nord, Elev 210m, 16-20 Feb 2001, $12^{\circ} 51^{\prime} 49^{\prime \prime} \mathrm{S} 49^{\circ} 13^{\prime} 33^{\prime \prime} \mathrm{E}$, malaise in 
tropical dry forest, coll. Fisher, Griswold et al., Calif. Academy of Sciences collection code: BLF3011"; CAS.

\section{Description}

Length of male $8.2 \mathrm{~mm}$ (female unknown). Dorsum dark brown to black; head black except gena stramineous; pronotum dark orange brown, heavily marked with symmetrical black spots; mesonotum dark orange brown with black basolateral triangles; scutellum yellow; venter of thorax and legs stramineous, heavily marked with black. Crown very short, marginal rim weakly developed and not forming shelf over frontoclypeus, ocelli nearly touching anterior margin. Forewing without supernumerary crossveins, inner apical cell relatively broad and extended to wing apex. Hind tibial rows PD, AD, and AV with 20, 12 and 16 macrosetae, respectively. Style apophysis sinuate and of nearly same width throughout, apex curved dorsomesad and tapered, with few minute serrations preapically on dorsal surface. Aedeagus simple, shaft evenly curved dorsad and nearly semicircular in lateral view, tubular, nearly same width thoughout length, with single long spine arising near midlength on right side of shaft and extended distad, but not reaching shaft apex; shaft apex slightly depressed and somewhat broadened in posterior view, gonopore preapical on posterior surface.

Pseudomarganana gen. nov. urn:1sid:zoobank.org:act:274736D9-D03A-4A09-96B8-9B859C062032

Figs $3 \mathrm{H}-\mathrm{I}, 13 \mathrm{H}-\mathrm{O}, 18 \mathrm{~A}-\mathrm{C}$

\section{Type species}

Pseudomarganana olivacea sp. nov.

\section{Diagnosis}

This genus may be distinguished by the following combination of features: body medium-sized; dorsum ochraceous to olivaceous, with pair of black symmetrical spots on crown; vertex not overlapping anterolateral margin of eye, crown transversely striate; forewing with very few or no supernumerary crossveins; hindwing veins $\mathrm{R} 4+5$ and $\mathrm{M} 1+2$ confluent preapically but separate near apex; hind femur macrosetal formula $2+2+1$; style without denticuli, apex foot-like; aedeagal shaft symmetrical, with pair of lateral preapical spines directed distad.

\section{Etymology}

The genus name, a feminine noun, combines 'pseudo-' ('false') with Marganana, the name of a superficially similar American genus belonging to tribe Gyponini.

\section{Description}

HaBitus. Medium-sized platyjassines (8.6-9.4 mm). Color olive brown to reddish brown, with pair of round black spots posterad of ocelli on crown and symmetrical black markings along anterior margin of pronotum.

Head. Crown declivous, slightly convex, with numerous well delimited transverse striations over entire length, anterior and posterior margins parallel, anterior margin well delimited by pair of parallel transverse carinae, not spatulate, forming only slight ledge over dorsal part of face, vertex without anterolateral extension over eye; ocelli mesad of anteromesal corners of eyes, closer to midline than to eyes. Frontoclypeus moderately convex with median dorsal depression, transversely rugulose; antennal ledge oblique, not overlapping frontoclypeus; lateral frontal suture extended to crown margin above antennal ledge; gena slightly emarginate below eye and relatively broad more ventrad, completely concealing proepisternum; lorum small, flat; anteclypeus slightly convex, lateral margin strongly divergent distally; rostrum broad, extended to middle coxae. 
THORAX. Pronotum strongly declivous, in profile continuing contour of crown, much wider than head, lateral margins strongly divergent posteriorly, transverse striations well delimited. Forewing with very few or no supernumerary crossveins, appendix broad and extended to wing apex, inner apical cell relatively long and narrow. Hindwing veins $\mathrm{R} 4+5$ and $\mathrm{M} 1+2$ confluent preapically, then separate near apex. Front femur rows IC and AV well delimited, with stout setae of similar sizes, somewhat irregular; dorsal surface of tibia flattened and with few macrosetae between PD and AD. Hind femur macrosetal formula $2+2+1$, tibial row $\mathrm{AD}$ without smaller setae between successive macrosetae; tarsomere I with plantar setae scattered.

AвDOMEn. Male pregenital sternite distinctly longer than sternite VII, posterior margin truncate. Male pygofer base band-like, dorsally without median posterior projection; lobe separated from base by membranous cleft, with numerous macrosetae in distal half, processes and spines absent, ventral margin without distinct group of fine setae. Subgenital plate with median longitudinal row or band of macrosetae, dorsolateral margin with band of long, fine setae. Style apophysis slender, without ventral denticuli, apex curved dorsomesad, with small, foot-like apical extension. Connective stem long, arms weakly developed, anterior margin convex. Aedeagus with atrium V-shaped in posterior view, with weakly pigmented plate connecting arms of $\mathrm{V}$; shaft simple, with pair of slender symmetrical lateral spines arising near midlength and extended distad, gonopore apical. Female ovipositor extended to pygofer apex; first valvula moderately slender, dorsal sculpturing strigate; second valvulae moderately slender throughout length, dorsal margin with several short, irregular teeth distally.

\section{Remarks}

This genus closely resembles Pseudocurtara gen. nov., but differs in having the forewing opaquely sclerotized and uniform in coloration, without extra crossveins.

Key to species of Pseudomarganana gen. nov. (males)

1. Dorsal coloration olivaceous, without red pigment (Fig. 3H); lateral spines of aedeagus straight in posterior view (Fig. 13K) Pseudomarganana olivacea gen. et sp. nov.

- Dorsal coloration stramineous, with forewing heavily marked with red pigment (Fig. 3I); lateral spines of aedeagus slightly bowed laterad in posterior view (Fig. 13O)

Pseudomarganana rosea gen. et sp. nov.

\section{Pseudomarganana olivacea gen. et sp. nov. urn:lsid:zoobank.org:act:A5D4B19C-B28E-474B-AE50-00D8BEB58DD8}

Figs $3 \mathrm{H}, 13 \mathrm{H}-\mathrm{K}, 18 \mathrm{~A}-\mathrm{C}$

\section{Etymology}

The species name refers to the olivaceous dorsal coloration of this species.

\section{Material examined}

Holotype

MADAGASCAR - O'; "MADAGASCAR: Fianarantsoa, Parc National Ranomafana, Belle Vue at Talatakely, elev 1020 m, 16 Oct -8 Nov 2001, $21^{\circ} 15.99^{\prime}$ S, 47 $25.21^{\prime}$ E, coll: M. Irwin, R. Harin'Hala, California Acad of Sciences, malaise, secondary tropical forest MA-02-09C-01"; CAS.

\section{Paratypes}

MADAGASCAR - Fianarantsoa - 1 \%; Parc National Ranomafana, Belle Vue at Talatakely; $21^{\circ} 15.99^{\prime} \mathrm{S}, 47^{\circ} 25.21^{\prime} \mathrm{E}$; alt. $1020 \mathrm{~m}$; 31 Mar.-7 Apr. 2002; M. Irwin and R. Harin'Hala leg.; Malaise trap; secondary tropical forest; MA-02-09C-23; CAS • 1 万े; same collection data as for preceding; $8-15$ Nov. 2001; MA-02-09C-02; CAS. - Antananarivo • 1 \%; 46 km NE of Ankazobe, Ambohitantely; 
18¹1.88' S, 47¹6.89' E; alt. 700 m; 29 Nov.-7 Dec. 2004; M. Irwin and R. Harin'Hala leg.; Malaise trap; sclerophyll forest; MA-27-22; INHS.

\section{Description}

Length of male 8.6-9.4 mm; female 10.7-11.4 mm. Dorsum olivaceous, with dark markings limited to pair of round black spots on crown posterad of ocelli, anterior band of irregular spots on pronotum and diffuse maculae at forewing apex; venter unmarked except for diffuse brown spots on femora and tibiae. Forewing with few or no supernumerary crossveins, inner apical cell extremely narrow and not extended to wing apex. Crown flat in profile, marginal rim relatively thick, not forming shelf over frontoclypeus. Hind tibial rows PD, AD and AV with 24, 12 and 11 macrosetae, respectively. Style apophysis slender and of nearly same width throughout, apex curved slightly dorsad and tapered to sharp tip with dorsal preapical angle. Aedeagus with atrium V-shaped, with poorly sclerotized plate connecting arms of V, shaft curved strongly dorsad, with pair of acuminate lateral spines arising laterally near midlength and extended nearly to apex, closely parallel to shaft and straight in posterior view, shaft parallel-sided in posterior view, shaft apex tapered and distinctly emarginate, gonopore apical. Female sternite VII with posterior margin truncate. Second valvulae moderately slender, slightly broadened from base to near apex, then tapered, dorsal margin with numerous close-set, irregular teeth in distal half.

Pseudomarganana rosea gen. et sp. nov. urn:1sid:zoobank.org:act:C85A19AC-047F-40CF-89A5-969BE1CA2244

Figs 3I, 13L-O

\section{Etymology}

The species name refers to the pinkish-red dorsal coloration of this species.

\section{Material examined}

\section{Holotype}

MADAGASCAR - ô; "MADAGASCAR: Province Fianarantsoa, Parc National Ranomafana, radio

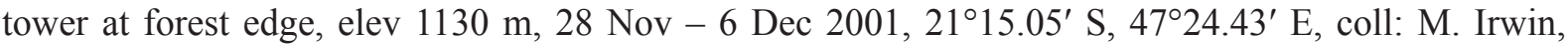
R. Harin'Hala, California Acad of Sciences, malaise, mixed tropical forest, MA-02-09B-05"; CAS.

\section{Description}

Length of male $8.7 \mathrm{~mm}$ (female unknown). Dorsum dull stramineous with sparse symmetrical dark brown markings, face unmarked, venter of thorax unmarked, pronotum with several symmetrically arranged black spots anteriorly, forewing infused with reddish pigment, front and middle tibia with indistinct brown bands dorsally, macrosetae of all legs with dark brown to black bases, hind tibia with some dorsal macrosetae black. Crown flat in profile, marginal rim relatively thick, not forming shelf over frontoclypeus, ocelli nearly touching anterior margin. Forewing with few or no supernumerary crossveins, inner apical cell elongate and narrow. Hind tibial rows PD, AD and AV with 21, 12 and 10 macrosetae, respectively. Style apophysis curved gradually dorsad over most of length, tapered to small, foot-like apex extended slightly dorsomesad. Aedeagus with atrium V-shaped, with weakly sclerotized plate between arms of $\mathrm{V}$; shaft curved strongly dorsad, with pair of acuminate lateral spines arising laterally near midlength, bowed slightly laterad and extended nearly to apex, closely parallel to shaft in posterior view, shaft slightly ovoid in posterior view, shaft apex tapered and slightly emarginate, gonopore apical.

\section{Remarks}

The male genitalia of this species closely resemble those of $P$. olivacea sp. nov., but the aedeagal shaft is ovoid rather than parallel-sided in posterior view and the lateral spines are bowed outward rather than straight. Pseudomarganana olivacea sp. nov. is also considerably larger and lacks red pigment on the forewing. 


\author{
Pulchrijassus gen. nov. \\ urn:1sid:zoobank.org:act:AA66B90F-54BF-4F17-ABC6-655742CDC17A \\ Figs $3 \mathrm{~J}-\mathrm{Q}, 14,18 \mathrm{D}-\mathrm{R}$
}

\title{
Type species
}

Pulchrijassus anjozorobensis sp. nov.

\section{Diagnosis}

This genus may be distinguished by the following combination of features: body medium-sized; dorsum heavily marked with symmetrical black, brown or red stripes or other maculae; vertex strongly overlapping anterolateral margin of eye, crown irregularly rugose; forewing usually with supernumerary crossveins between $\mathrm{R}$ and $\mathrm{M}$; hindwing veins $\mathrm{R} 4+5$ and $\mathrm{M} 1+2$ completely confluent apically; hind femur macrosetal formula $2+2+1$; style without denticule; aedeagus without processes, shaft simple, recurved.

\section{Etymology}

The genus name, a masculine noun, combines the Latin prefix 'pulchri-' ('beautiful') with the common suffix for genera of Iassinae, '-jassus'.

\section{Description}

HABITUS. Medium-sized to large platyjassines $(6.4-11.0 \mathrm{~mm})$. Color variable, dorsum usually strikingly marked with alternating pale and dark longitudinal stripes.

HEAD. Crown flattened, subequal to or slightly shorter than pronotum, with numerous irregular transverse striations, becoming less prominent posteriorly, anterior margin strongly produced, spatulate, forming hood over dorsal part of face, strongly overlapping eye margin; ocelli anteromesad of eyes, relatively distant from eyes and from anterior margin of crown. Frontoclypeus moderately convex, punctate medially, without median dorsal depression; antennal ledge absent, apparently coinciding with anterior margin of head; lateral frontal suture extended anterad beyond antennal pit, but not reaching head margin; gena slightly emarginate below eye, proepisternum partially exposed; lorum small, flat; anteclypeus convex, lateral margins evenly divergent distally; rostrum slender, not surpassing front trochanters.

Thorax. Pronotum slightly declivous, in profile continuing contour of crown, much wider than head, lateral margins strongly divergent posterad, transverse striations distinct. Forewing with numerous supernumerary crossveins in distal half between $\mathrm{R}, \mathrm{M}$ and $\mathrm{Cu}$, appendix broad and extended to wing apex, inner apical cell elongate, slender. Hindwing veins R4+5 and M1+2 completely confluent distally. Front femur row IC with setae in single row; AV with single row of stout setae in basal half, dorsal surface of tibia rounded, $\mathrm{PD}$ and $\mathrm{AD}$ macrosetae only partially differentiated. Hind femur macrosetal formula $2+2+1$, tibial row $\mathrm{AD}$ with one or more smaller setae between successive macrosetae; tarsomere I with two plantar rows, pecten with 3 platellae.

ABDOMEN. Male pregenital sternite distinctly longer than sternite VII, posterior margin truncate. Pygofer base band-like, dorsally with median posterior projection; lobe fused to base, membranous cleft absent, with numerous macrosetae in distal half, apex narrowly rounded, processes and spines absent, ventral margin without distinct group of fine setae. Subgenital plate relatively broad and strongly depressed, with median longitudinal row of macrosetae, dorsolateral margin with few sparse, short setae. Style apophysis slender, acuminate, without conspicuous denticuli. Aedeagus without processes, shaft simple, stout, recurved, apex rounded in lateral view. Female abdominal sternite VII with posterior margin weakly trilobed. Second valvulae broadened beyond basal third, then tapered to apex, dorsal margin serrate, with numerous distinct teeth in distal half. 


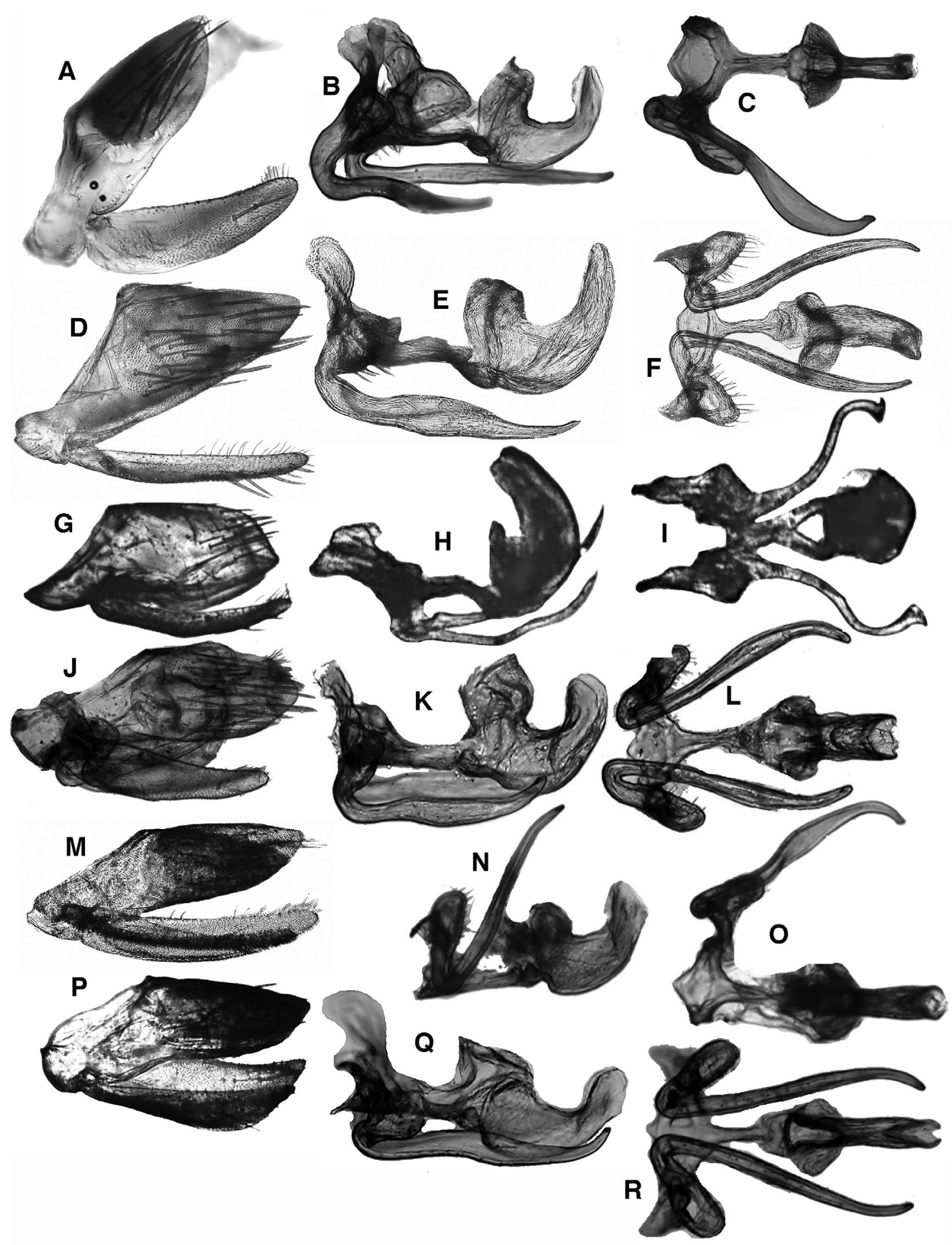

Fig. 14. Pulchrijassus gen. nov. - A-C. Pulchrijassus anjozorobensis sp. nov. A. Genital capsule, lateral view. B. Genitalia, lateral view. C. Same, ventral view. - D-F. Pulchrijassus eunsunae sp. nov. D. Genital capsule, lateral view. E. Genitalia, lateral view. F. Same, ventral view. - G-I. Pulchrijassus pallescens sp. nov. G. Genital capsule, lateral view. H. Genitalia, lateral view. I. Same, ventral view. J-L. Pulchrijassus roseus sp. nov. J. Genital capsule, lateral view. K. Genitalia, lateral view. L. Same, ventral view. - M-O. Pulchrijassus sindhuae sp. nov. M. Genital capsule, lateral view. N. Genitalia, lateral view. O. Same, ventral view. - P-R. Pulchrijassus talatakelyensis sp. nov. P. Genital capsule, lateral view. Q. Genitalia, lateral view. R. Same, ventral view. Photos not to scale. 


\section{Remarks}

This genus closely resembles Plexijassus gen. nov. overall, but differs in having the dorsal coloration consisting of symmetrical black, brown or red markings and in lacking long supernumerary costal crossveins.

\section{Key to species of Pulchrijassus gen. nov.}

1. Eyes completely bordered with black or brown pigment on crown and pronotum in dorsal view (Fig. 3J)

- Eyes not bordered with black pigment in dorsal view ...........................................................6

2. Black pigment bordering eyes consisting of stripes with medial margins straight, forming continuous, slightly divergent lines along crown and pronotum (Fig. 3P)

Pulchrijassus talatakelyensis gen. et sp. nov.

- Black pigment bordering eyes consisting of curved stripes or crown entirely black (Fig. 3J) ...3

3. Crown black, with medial pale area, if present, indistinct (Fig. 3O)

- Crown with large pale area medially (Fig. 3J-K)

Pulchrijassus sindhuae gen. et sp. nov.

4. Median longitudinal dark stripe on pronotum not expanded posteriorly (Fig. 3J)

Pulchrijassus anjozorobensis gen. et sp. nov.

- Median longitudinal dark stripe on pronotum abruptly expanded posteriorly (Fig. 3K) ........5

5. Dorsum yellow with dark brown markings (Fig. 3K) .......Pulchrijassus eunsunae gen. et sp. nov.

- Dorsum ivory with pale brown markings (Fig. 3Q) ...Pulchrijassus toamasinensis gen. et sp. nov.

6. Dorsum almost entirely bright red, pronotum without longitudinal stripes (Fig. 3M)

- Dorsum with longidudinal stripes (Fig. 3L, N)

Pulchrijassus roseus gen. et sp. nov.

7. Dorsum mostly pale stramineous, pronotum with two pairs of narrow brown longitudinal stripes (Fig. 3L)

..Pulchrijassus pallescens gen. et sp. nov.

- Dorsum ochraceous, with reddish stripes (Fig. 3N) ....Pulchrijassus rubrilineatus gen. et sp. nov.

Pulchrijassus anjozorobensis gen. et sp. nov.

urn:lsid:zoobank.org:act:DCAD73AC-404E-40AD-9F52-9D70154363DC

Figs 3J, 14A-C, 18D-F

\section{Etymology}

The species name is derived from that of the town closest to the type locality.

\section{Material examined}

\section{Holotype}

MADAGASCAR • 3 ; "MADAGASCAR: Province d'Antananarivo $3 \mathrm{~km} 41^{\circ} \mathrm{NE}$ Andranomay, 11.5

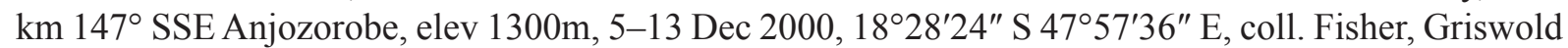
et al., California Acad. of Sciences, montane rainforest, malaise trap, coll. code: BLF2375"; CAS.

\section{Paratypes}

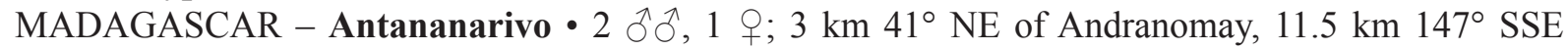
of Anjozorobe; 18²8'24" S, 4757'36" E; alt. 1300 m; 5-13 Dec. 2000; Fisher, Griswold et al. leg.; 
Malaise trap; montane rainforest; coll. code: BLF2375; CAS $\bullet 1$ त, 1 \%; same collection data as for

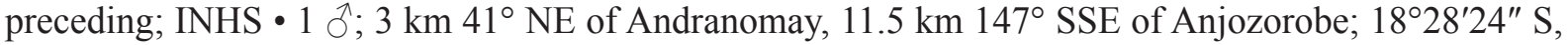
475'36" E; alt. 1300 m; 5-13 Dec. 2000; Fisher, Griswold et al. leg.; Malaise trap; montane rainforest; coll. code: BLF2372; CAS • 1 §ో; same collection data as for preceding; INHS.

\section{Description}

Length of male 6.4-7.4 mm; female 8.1-8.2 mm. Dorsum with pair of bold, curved, black lateral stripes extending from crown apex around margins of eyes to lateral margin of pronotum, median longitudinal black stripe on crown thin, broad and ovoid on pronotum; mesonotum and scutellum pale medially, with black basolateral triangles, forewing smoky with black maculae at base and slightly beyond midlength of costal area, veins darker than membrane. Hind tibial rows PD, AD and AV with 23, 16 and 18 macrosetae, respectively. Style apophysis sinuate, slightly broadened distally in ventral view, apex curved dorsomesad and blunt. Connective anterior margin trilobed. Aedeagus with shaft compressed, broad basally in lateral view, evenly curved dorsad and narrowed to blunt apex, bulb-shaped in ventral view, gonopore preapical on posterior surface. Female abdominal sternite VII with posterior margin weakly trilobed, with median lobe slightly shorter than lateral lobes. Second valvulae with dorsal margin forming distinctly angulate peak basad of midlength, dorsal margin slightly concave beyond peak, teeth sharply pointed and alternating between sides.

Pulchrijassus eunsunae gen. et sp. nov. urn:1sid:zoobank.org:act:5F2810BE-F976-43F3-91AF-60D53D2D169E

Figs 3K, 14D-F

\section{Etymology}

This species is named in honor of Eun Sun Nam, attorney and former University of Illinos student who sorted and prepared many of the specimens included in this study.

\section{Material examined}

\section{Holotype}

MADAGASCAR - ${ }^{\lambda}$; "MADAGASCAR: Province d'Antsiranana, Parc National Montagne d'Ambre, el 1125 m, 12-14 May 2001, 12³1'13" S, 49¹0'45" E, California Acad. of Sciences, Coll: M. Irwin, R. Harin'Hala, malaise trap, MA-01-01D-10"; CAS.

\section{Description}

Length of male $9.2 \mathrm{~mm}$ (female unknown). Color pattern resembling that of $P$. anjozorobensis sp. nov. overall, but pale areas of dorsum with reddish tinge, median black macula of pronotum abruptly widened posteriorly and scutellum with pair of submedial black maculae. Hind tibial rows PD, AD and AV with 22, 14 and 16 macrosetae, respectively. Style apophysis broadened medially, then acuminate distally, bowed laterad in ventral view, nearly straight in lateral view, with apex gradually curved slightly dorsad. Connective with anterior margin convex. Aedeagus with shaft U-shaped, tubular, tapered from base to bluntly rounded apex.

Pulchrijassus pallescens gen. et sp. nov. urn:1sid:zoobank.org:act:FA47089B-3B4C-4F88-87FF-2B9E7465A0CF

Figs 3L, 14G-I, 18G-I

\section{Etymology}

The name of this species refers to its pale overall coloration. 


\section{Material examined}

Holotype

MADAGASCAR - $\hat{o}$; "MADAGASCAR: Province Fianarantsoa, Parc National Ranomafana,

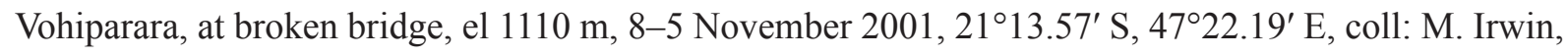
R. Harin'Hala, California Acad of Sciences, malaise trap in high altitude rainforest, MA-02-09A-02"; CAS.

\section{Paratype}

MADAGASCAR - Fianarantsoa - + ; Parc National Ranomafana, radio tower, at forest edge; $21^{\circ} 15.05^{\prime}$ S, 47 $24.43^{\prime}$ E; alt. 1130 m; 27 Feb.-9 Mar. 2003; M. Irwin and R. Harin'Hala leg.; Malaise trap; mixed tropical forest; MA-02-09B-54; CAS.

\section{Description}

Length of male $7.5 \mathrm{~mm}$; female $9.0 \mathrm{~mm}$. Dorsum pale yellow, crown with median and paired lateral, thin reddish longitudinal stripes, pronotum with pair of thin curved submedial maculae and lateral margins dark brown, forewing dull yellow, with veins slightly darker than membrane and dark brown macula in apical third of costal area, venter uniformly stramineous. Hind tibial rows PD, AD and AV with 28, 15 and 24 macrosetae, respectively. Style apophysis extremely thin, sinuate, apex slightly broadened in ventral view, curved mesad, then hooked laterad to sharp tip. Connective anterior margin with narrow trapezoidal emargination. Aedeagus with shaft robust, curved dorsad, slightly tapered to quadrate apex in lateral view, bulbous in ventral view, gonopore apical. Female abdominal sternite VII with posterior margin weakly trilobed, with median lobe slightly longer than lateral lobes. Second valvulae with dorsal margin evenly convex, including distal toothed section and basal entire section, teeth relatively large and blunt-tipped, alternating between sides.

Pulchrijassus roseus gen. et sp. nov.

urn:1sid:zoobank.org:act:E0D54762-A550-4603-A965-2EE2EA23410A

$3 \mathrm{M}, 14 \mathrm{~J}-\mathrm{L}$

\section{Etymology}

The species name refers to the red overall coloration of this species.

\section{Material examined}

\section{Holotype}

MADAGASCAR - ô; "MADAGASCAR: Province Fianarantsoa, Parc National Ranomafana, Belle Vue at Talatakely, elev $1020 \mathrm{~m}, 16$ Oct -8 Nov 2001, 21 ${ }^{\circ} 15.99^{\prime} \mathrm{S}, 4^{\circ} 25.21^{\prime} \mathrm{E}$, coll: M. Irwin, R. Harin'Hala, California Acad of Sciences, malaise, secondary tropical forest MA-02-09C-01, SMK DNA voucher MIAS3"; CAS.

\section{Description}

Length of male $11 \mathrm{~mm}$ (female unknown). Dorsum mostly bright red, pronotum with pair of large subquadrate submedial maculae anteriorly, diffuse black transverse band extended across base of forewing and mesonotum, clavus with irregular brown macula along commissural margin; venter stramineous, tinged with red. Crown parabolically produced, as long as pronotum. Hind tibial rows PD, $\mathrm{AD}$ and $\mathrm{AV}$ with 27, 13, and 17 macrosetae, respectively. Style apophysis slender, of nearly same width throughout length, apex curved dorsad, slightly tapered and blunt-tipped. Connective with anterior margin concave. Aedeagus short, broad, strongly but unevenly curved dorsad, base of shaft trough-like, gonopore large, on posterior surface of apex. 


\section{Remarks}

This species corresponds to the OTU referred to as "Platyjassus sp. n. 2" in the phylogeny of Krishnankutty et al. (2016).

Pulchrijassus rubrilineatus gen. et sp. nov.

urn:lsid:zoobank.org:act:5D0E77EB-47BF-417F-8B78-B357422B9CAA

Figs $3 \mathrm{~N}, 18 \mathrm{~J}-\mathrm{L}$

\section{Etymology}

The species name refers to the red longitudinal stripes on the dorsum.

\section{Material examined}

\section{Holotype}

MADAGASCAR • + ; "MADAGASCAR: Province Fianarantsoa, Parc National Ranomafana, Belle Vue at Talatakely, elev 1020 m, 14-23 April 2002, 21 ${ }^{\circ} 15.99^{\prime}$ S, 47²5.21' E, coll: M. Irwin, R. Harin'Hala, California Acad of Sciences, malaise, secondary tropical forest, MA-02-09C-25"; CAS.

\section{Description}

Length of female $8.0 \mathrm{~mm}$ (male unknown). Dorsum pale yellow with reddish to ochraceous markings; pair of wide lateral reddish orange stripes extended from crown apex across pronotum, narrower median wedge-shaped stripe extended from crown apex to scutellum, pronotum with two pairs of indistinct longitudinal lateral brown stripes superimposed on red lateral stripes, forewing ochraceous, with costal margin in basal half yellow; venter uniformly pale yellow. Crown parabolically produced, slightly longer than pronotum. Forewing without supernumerary crossveins. Hind tibial rows PD, AD and AV with 23,13 , and 18 macrosetae, respectively. Female abdominal sternite VII with short acute projection posteromedially. Second valvulae slender, tapered through most of length, dorsal margin serrate distally, with teeth rounded and alternating between sides.

Pulchrijassus sindhuae gen. et sp. nov. urn:1sid:zoobank.org:act:63AFA704-D210-49DE-83B6-F5BDFEAA9A24

Figs $3 \mathrm{O}, 14 \mathrm{M}-\mathrm{O}$

\section{Etymology}

This species is named in honor of Dr. Sindhu M. Krishnankutty, whose comprehensive phylogenetic study of Iassinae established the relationship between Platyjassini and other tribes.

\section{Material examined}

\section{Holotype}

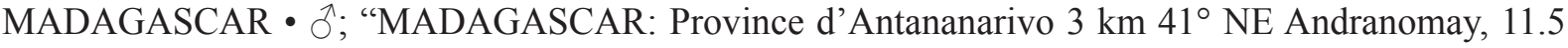
km $147^{\circ}$ SSE Anjozorobe, elev 1300m, 5-13 Dec 2000, 18²8'24" S 4757'36" E, coll. Fisher, Griswold et al., California Acad. of Sciences, montane rainforest, malaise trap, coll. code: BLF2372"; CAS.

\section{Paratypes}

MADAGASCAR - Antananarivo • 1 ○; $3 \mathrm{~km} 41^{\circ} \mathrm{NE}$ of Andranomay, $11.5 \mathrm{~km} 147^{\circ} \mathrm{SSE}$ of Anjozorobe; $18^{\circ} 28^{\prime} 24^{\prime \prime}$ S, 4757'36" E; alt. 1300 m; 5-13 Dec. 2000; Fisher, Griswold et al. leg.; Malaise trap; montane rainforest; coll. code: BLF2372; CAS • 1 సं; same collection data as for preceding; coll. code: BLF2375; INHS. - Fianarantsoa 1 oj; Parc National Ranomafana, radio tower at forest edge; 
$21^{\circ} 15.05^{\prime} \mathrm{S}, 47^{\circ} 24.43^{\prime} \mathrm{E}$; alt. 1130 m, 15-21 Dec. 2001; M. Irwin and R. Harin’Hala leg.; Malaise trap; mixed tropical forest; MA-02-09B-07; INHS • 1 o ; Parc National Ranomafana, Belle Vue at Talatakely; $21^{\circ} 15.99^{\prime} \mathrm{S}, 47^{\circ} 25.21^{\prime} \mathrm{E}$; alt. $1020 \mathrm{~m}$; 14-23 Apr. 2002; M. Irwin and R. Harin'Hala leg.; Malaise trap; secondary tropical forest; MA-02-09C-25; CAS.

\section{Description}

Length of male 8.8-9.6 mm (female unknown). Color pattern resembling that of P. anjozorobensis sp. nov. overall, but darker markings more extensive, crown dark brown except pair of yellow spots posterad of ocelli; mesonotum and scutellum with large median black macula; venter and legs mostly dark brown. Hind tibial rows PD, AD and AV with 21, 15, and 17 macrosetae, respectively. Style apophysis slightly broadened toward midlength, thence slightly tapered toward rounded apex, sinuate in lateral view, nearly straight, with slight mesal curve distally in ventral view. Connective with anterior margin obtusely angulate. Aedeagus with shaft relatively broad and somewhat compressed basally in lateral view, tapered distally, dorsal margin curved dorsad at right angle; gonopore apical on posterior surface.

Pulchrijassus talatakelyensis gen. et $\mathrm{sp}$. nov. urn:lsid:zoobank.org:act:C08BE455-A060-4717-9F7B-B17F350685FC

Figs 3P, 14P-R, 18M-O

\section{Etymology}

The species name refers to the type locality.

\section{Material examined}

\section{Holotype}

MADAGASCAR - ô; "MADAGASCAR: Province Fianarantsoa, Parc National Ranomafana, Belle

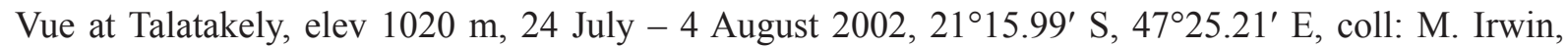
R. Harin'Hala, California Acad of Sciences, malaise, secondary tropical forest, MA-02-09C-36"; CAS.

\section{Paratypes}

MADAGASCAR-Fianarantsoa - 1 o; Parc National Ranomafana, Belle Vue at Talatakely; $21^{\circ} 15.99^{\prime}$ S, 47²5.21' E; alt. 1020 m; 31 Mar.-7 Apr. 2002; M. Irwin and R. Harin'Hala leg.; Malaise trap; secondary tropical forest; MA-02-09C-23; CAS • 1 के same collection data as for preceding; INHS • $1 \mathrm{~J}^{\top}$; Parc National Ranomafana, radio tower at forest edge; $21^{\circ} 15.05^{\prime} \mathrm{S}, 47^{\circ} 24.43^{\prime} \mathrm{E}$; alt. $1130 \mathrm{~m}$, 15-21 Dec. 2001; M. Irwin and R. Harin'Hala leg.; Malaise trap; mixed tropical forest; MA-02-09B-07; CAS - 1 क; same collection data as for preceding but 24 May-4 Jun. 2002; MA-02-09B-30; INHS.

\section{Description}

Length of male $7.3-7.5 \mathrm{~mm}$, female $8.4 \mathrm{~mm}$. Dorsum with pair of broad longitudinal black stripes extended from crown apex across eyes and pronotum, continuous with black basolateral triangles of mesonotum; median longitudinal black stripe extended from crown apex to scutellar suture; forewing dull stramineous, with black macula at base and slightly beyond midlength of costal area, veins little or no darker than membrane; venter uniformly pale stramineous. Style sinuate, distal half acuminate and gradually curved dorsomesad to sharp tip. Connective anterior margin broadly concave. Aedeagus with shaft very strongly compressed, very broad in lateral view, arcuate, apex rounded. Female abdominal sternite VII with posterior margin weakly trilobed, with median lobe slightly longer than lateral lobes. Second valvulae with broadly convex area basad of toothed section, toothed section straight, teeth blunttipped. 


\section{Pulchrijassus toamasinensis gen. et sp. nov. urn:1sid:zoobank.org:act:700FCAAF-D6E6-41DD-8B2F-07EC3247492E \\ Figs 3Q, 18P-R}

\section{Etymology}

The species name is based on that of the province containing the type locality.

\section{Material examined}

\section{Holotype}

MADAGASCAR - 9 ; Toamasina Province, botanic garden near entrance to Andasibe National Park; $18^{\circ} 55.58^{\prime}$ S, 48²4.47' E; alt. 1025 m; 8-16 Oct. 2001; M. Irwin and R. Harin'Hala leg.; Malaise trap; tropical forest; MA-01-08B-15; CAS.

\section{Description}

Length of female $9.8 \mathrm{~mm}$ (male unknown). Dorsum ivory, heavily marked with brown; crown with eyes bordered in reddish brown mesally, pronotum with broad median T-shaped mark and pair of curved lateral maculae light brown, mesonotum with basolateral triangles light brown; forewing with dark brown spots corresponding with crossvein m-cu2, apices of claval veins and claval apex, veins bright red near middle of wing; venter stramineous, infused with brown. Crown parabolically produced, as long as pronotum. Hind tibial rows $\mathrm{PD}, \mathrm{AD}$ and $\mathrm{AV}$ with 26, 17 and 20 macrosetae, respectively. Female abdominal sternite VII with posterior margin weakly trilobed. Second valvulae with dorsal margin convex basad of toothed section, teeth numerous, close-set and square-tipped, except smaller and more acute near apex, alternating from left to right sides.

Punctijassus gen. nov. urn:1sid:zoobank.org:act:8A20AEAB-D5DB-4B63-BBDE-7E11564E84AC

Figs 3R-T, 15, 18S-U

\section{Type species}

Punctijassus compressus sp. nov.

\section{Diagnosis}

This genus may be distinguished by the following combination of features: body small to medium-sized, dorsum stramineous, hind coxa with black spot, vertex overlapping less than half of anterolateral margin of eye, crown uniformly shagreen, margin spatulate; forewing without supernumerary crossveins; hindwing veins $\mathrm{R} 4+5$ and $\mathrm{M} 1+2$ confluent preapically but separate near apex; hind femur macrosetal formula usually $2+2+1$; style without denticuli; aedeagus with single long process arising from preatrium directly below shaft.

\section{Etymology}

The genus name, a masculine noun, combines 'puncti-' ('spotted') with '-jassus', a common suffix for genera in this subfamily, and refers to the distinct spots on the venter.

\section{Description}

HaBitus. Small platyjassines (4.9-6.5 mm). Color stramineous, with darker pigment at apex of forewing and conspicuous black spot ventrolaterally on hind coxa; additional paired dark spots often present ventrally on femora and thoracic sternites.

HEAD. Crown flattened, uniformly shagreen, anterior margin produced, spatulate, forming hood over dorsal part of face, vertex with lateral extension overlapping less than half of eye margin; ocelli 
anteromesad of eyes. Frontoclypeus moderately convex with slight median dorsoapical depression; antennal ledge transverse, strongly overlapping frontoclypeus; lateral frontal suture present above antennal ledge but not extended to crown margin; gena slightly emarginate below eye, but completely concealing proepisternum; lorum small, flat; anteclypeus slightly convex, lateral margins only slightly divergent distally; rostrum slender, not surpassing front trochanters.

Thorax. Pronotum slightly declivous, in profile continuing contour of crown, much wider than head, lateral margins strongly divergent posterad, transverse striations weakly delimited. Forewing without supernumerary crossveins, appendix broad and extended to wing apex, inner apical cell relatively short. Hindwing veins $\mathrm{R} 4+5$ and $\mathrm{M} 1+2$ confluent preapically but separate near apex. Front femur row IC with $\sim 10-14$ setae, somewhat irregularly arranged basally; AV with 5 stout setae in basal half, dorsal surface of tibia rounded, PD with 4 widely spaced macrosetae. Hind femur macrosetal formula $2+2+1$, tibial row $\mathrm{AD}$ with one or more smaller setae between successive macrosetae; tarsomere I plantar row single and weakly developed.

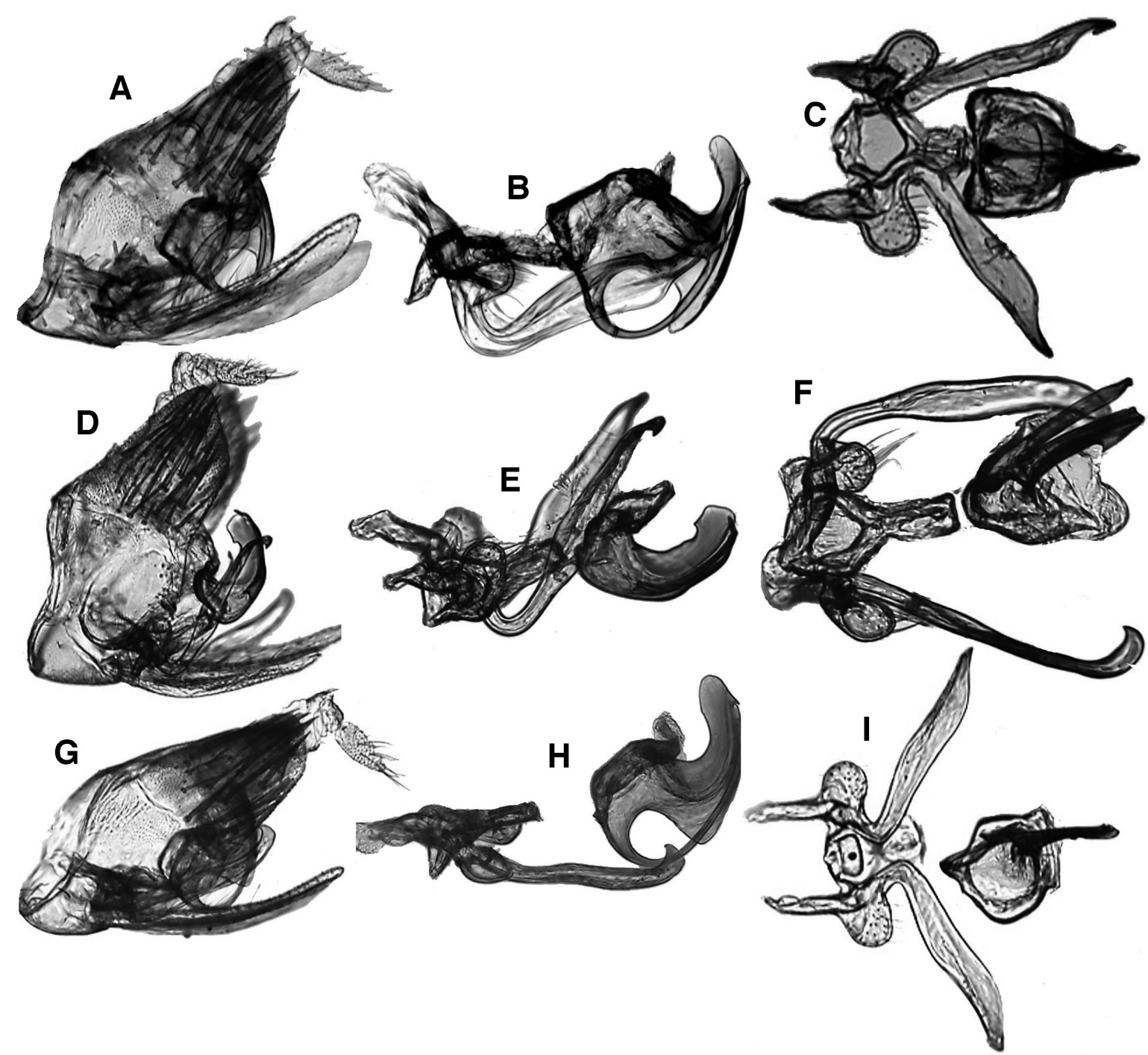

Fig. 15. Punctijassus gen. nov. - A-C. Punctijassus circularis sp. nov. A. Genital capsule, lateral view. B. Genitalia, lateral view. C. Same, ventral view. - D-F. Punctijassus compressus sp. nov. D. Genital capsule, lateral view. E. Genitalia, lateral view. F. Same, ventral view. - G-I. Punctijassus ivohibensis sp. nov. G. Genital capsule, lateral view. H. Genitalia, lateral view. I. Same, ventral view. Photos not to scale. 


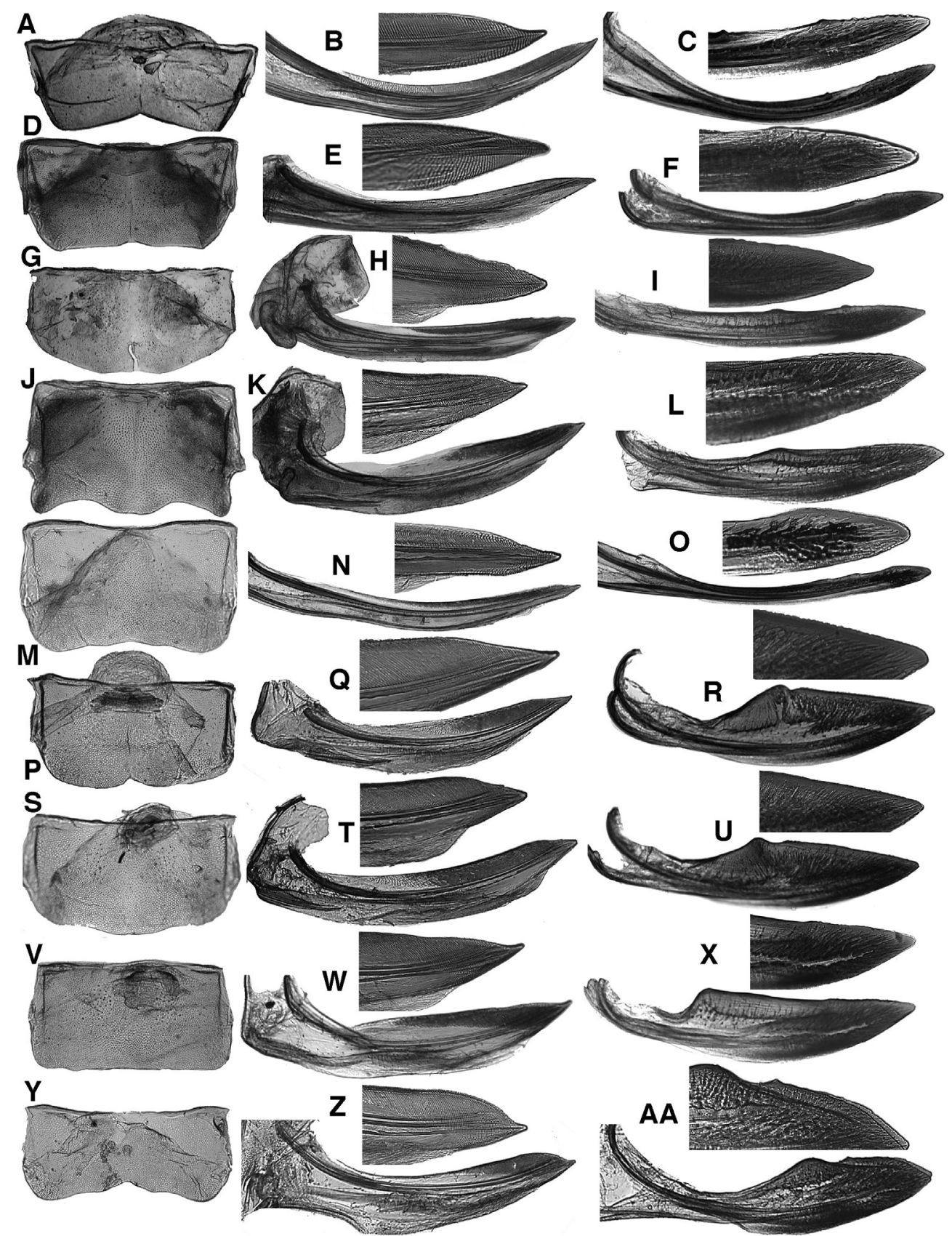

Fig. 16. Female terminalia. - A-C. Pachyjassus basifurcatus sp. nov. A. Sternite VII. B. First valvula with detail of apex. C. Second valvulae with detail of apex. - D-F. Pachyjassus ranomafanensis sp. nov. D. Sternite VII. E. First valvula with detail of apex. F. Second valvulae with detail of apex. G-I. Pallijassus sp. G. Sternite VII. H. First valvula with detail of apex. I. Second valvulae with detail of apex. - J-L. Petalojassus ochrescens sp. nov. J. Sternite VII. K. First valvula with detail of apex. L. Second valvulae with detail of apex. - M-O. Phaiojassus acutus sp. nov. M. Sternite VII. N. First valvula with detail of apex. O. Second valvulae with detail of apex. - P-R. Pictojassus kirindiensis sp. nov. P. Sternite VII. Q. First valvula with detail of apex. R. Second valvulae with detail of apex. S-U. Pictojassus productus sp. nov. S. Sternite VII. T. First valvula with detail of apex. U. Second valvulae with detail of apex. $-\mathbf{V}-\mathbf{X}$. Pictojassus tulearensis sp. nov. V. Sternite VII. W. First valvula with detail of apex. X. Second valvulae with detail of apex. - Y-AA. Platyjassella andohahelensis sp. nov. Y. Sternite VII. Z. First valvula with detail of apex. AA. Second valvulae with detail of apex. Photos not to scale. 


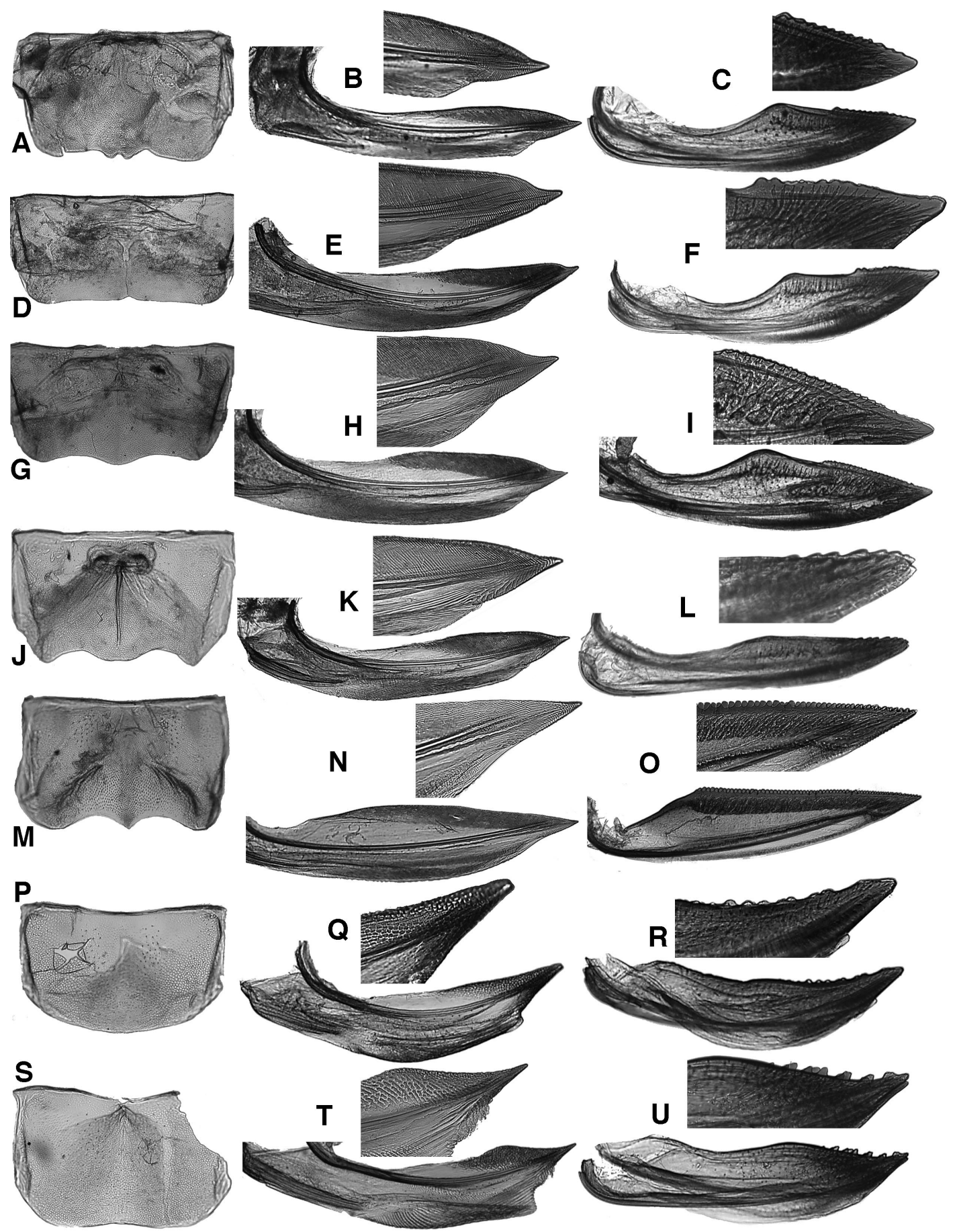

Fig. 17. Female terminalia. - A-C. Platyjassula mahajangensis sp. nov. A. Sternite VII. B. First valvula with detail of apex. C. Second valvulae with detail of apex. - D-F. Platyjassus fisheri sp. nov. D. Sternite VII. E. First valvula with detail of apex. F. Second valvulae with detail of apex. - G-I. Platyjassus griswoldi sp. nov. G. Sternite VII. H. First valvula with detail of apex. I. Second valvulae with detail of apex. - J-L. Platyjassus pedistylus sp. nov. J. Sternite VII. K. First valvula with detail of apex. L. Second valvulae with detail of apex. - M-O. Plexijassus caliginosus sp. nov. M. Sternite VII. N. First valvula with detail of apex. O. Second valvulae with detail of apex. $-\mathbf{P}-\mathbf{R}$. Pseudocurtara minima sp. nov. P. Sternite VII. Q. First valvula with detail of apex. R. Second valvulae with detail of apex. S-U. Pseudocurtara quadrata sp. nov. S. Sternite VII. T. First valvula with detail of apex. U. Second valvulae with detail of apex. Photos not to scale. 


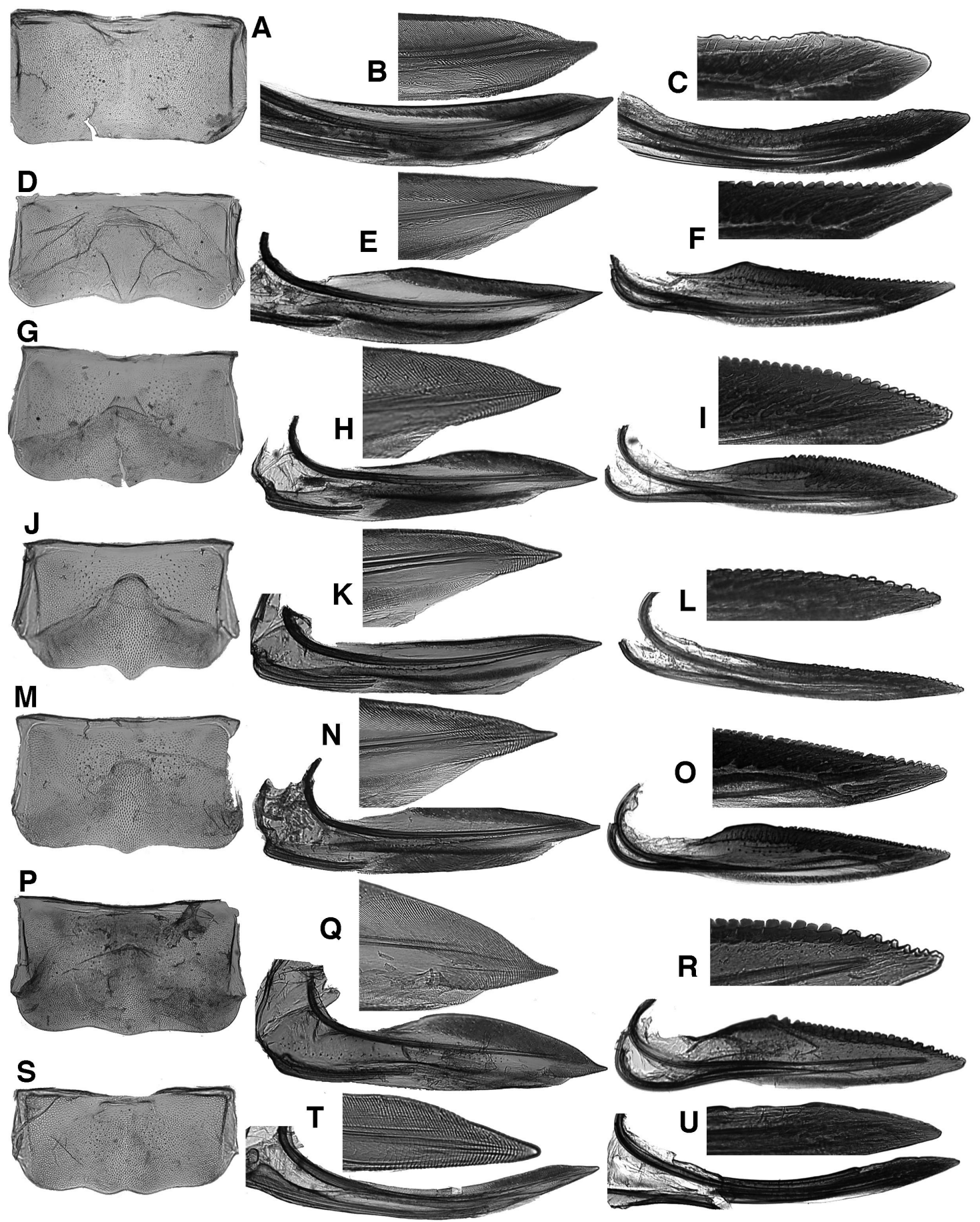

Fig. 18. Female terminalia. - A-C. Pseudomarganana olivacea sp. nov. A. Sternite VII. B. First valvula with detail of apex. C. Second valvulae with detail of apex. - D-F. Pulchrijassus anjozorobensis sp. nov. D. Sternite VII. E. First valvula with detail of apex. F. Second valvulae with detail of apex. G-I. Pulchrijassus pallescens sp. nov. G. Sternite VII. H. First valvula with detail of apex. I. Second valvulae with detail of apex. - J-L. Pulchrijassus rubrilineatus sp. nov. J. Sternite VII. K. First valvula with detail of apex. L. Second valvulae with detail of apex. - M-O. Pulchrijassus talatakelyensis sp. nov. M. Sternite VII. N. First valvula with detail of apex. O. Second valvulae with detail of apex. P-R. Pulchrijassus toamasinensis sp. nov. P. Sternite VII. Q. First valvula with detail of apex. R. Second valvulae with detail of apex. - S-U. Punctijassus ivohibensis sp. nov. S. Sternite VII. T. First valvula with detail of apex. U. Second valvulae with detail of apex. Photos not to scale. 
ABDOMEN. Male pregenital sternite slightly longer than sternite VII, posterior margin weakly bilobed; pygofer base band-like, dorsally with median posterior concavity; lobe separated from base by membranous vertical cleft, with numerous macrosetae in distal half, apex broadly rounded, processes and spines absent, ventral margin with slight lobe near base bearing several fine setae. Subgenital plate without macrosetae, dorsolateral margin with row of long, fine setae. Style apophysis slender, smooth, without denticuli, apex curved dorsad, with sharp tooth-like tip. Connective stem slightly longer than arms. Aedeagus with atrium V-shaped in posterior view, shaft simple, compressed, curved dorsad, with single slender basal process arising below shaft base and extended along shaft posterior margin through most of length, gonopore preapical on posterior surface. Female abdominal sternite with small median, posterior notch. First valvulae slender, with dorsal sculupturing strigate. Second valvulae slender, with two indistinct, widely separated distal preapical teeth.

\title{
Remarks
}

This genus resembles Platyjassula gen. nov. in coloration, form and in the structure of the male genitalia, but differs in the smaller overall body size, presence of distinct spots on the hind femur and coxa, and in lacking two divergent attenuate points on the style apex. It also resembles Platyjassus, but the included species are much smaller, have the basal process of the aedeagus situated directly below the shaft, rather than offset to one side, and have a distinct black spot laterally on the hind coxa, as in Pachyjassus gen. nov.

\section{Key to species of Punctijassus gen. nov. (males)}

1. Aedeagus with basal process closely adjacent to shaft at base (Fig. 15E)

- Aedeagus with basal process well separated from shaft at base (Fig. 15B)

2. Style apophysis abruptly constricted preapically (Figs 15B-C); aedeagal shaft with ventral extension longer than its basal width in lateral view (Fig. 15B) ...........Punctijassus circularis gen. et sp. nov.

- Style apophysis gradually narrowed distally (Fig. 15I); aedeagal shaft with ventral extension shorter than its basal width in lateral view (Fig. $15 \mathrm{H}$ ) ..Punctijassus ivohibensis gen. et sp. nov.

\author{
Punctijassus circularis gen. et sp. nov. \\ urn:1sid:zoobank.org:act:80798746-46E2-4BA4-BA53-DE2A76AB4EF6
}

Figs 3R, 15A-C

\section{Etymology}

The species name refers to the circle formed by the posteroventral margin of the aedeagal shaft and the ventral aedeagal process in lateral view.

\section{Material examined}

\section{Holotype}

MADAGASCAR - O'; "MADAGASCAR: Toliara, Forêt de Kirindy, $15.5 \mathrm{~km} 64^{\circ}$ ENE Marofandilia,

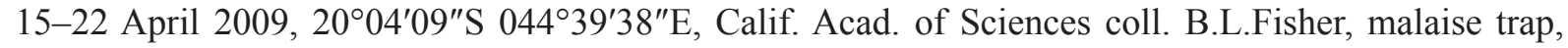
tropical dry forest, el 30 m BLF18285_76"; CAS.

\section{Description}

Length of male $5.9 \mathrm{~mm}$ (female unknown). Crown with marginal rim and anterodorsal part of frontoclyepus black; middle and hind femur with conspicuous black spot on anterior surface of apex. Crown shorter than pronotum, anterior margin broadly rounded. Hind tibial rows PD, AD and AV with 17-18, 12-13, 14-15 macrosetae, respectively. Style apophysis nearly straight, slightly expanded 

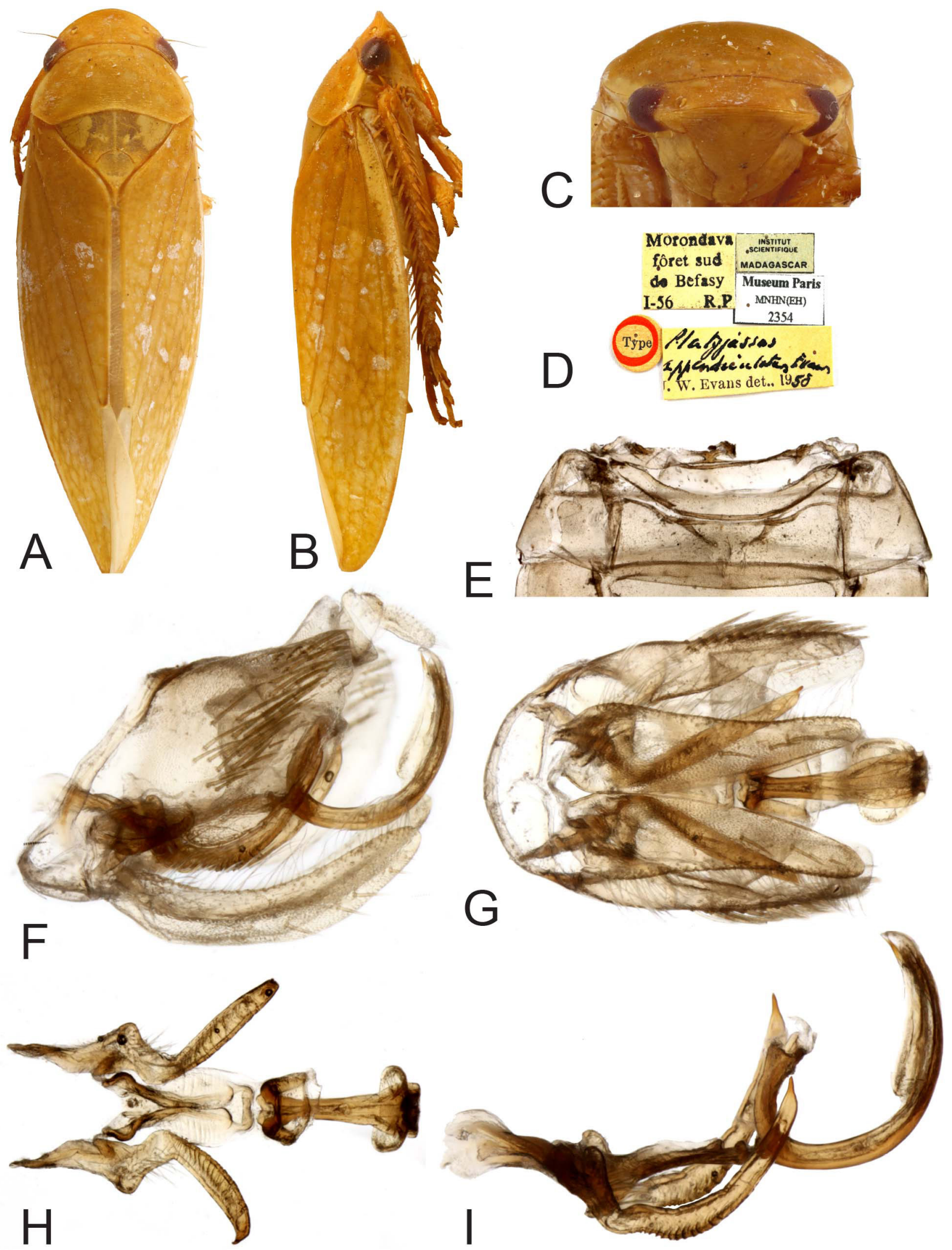

Fig. 19. Holotype male of Platyjassus appendiculatus Evans, 1959 (MNHN(EH) 2354), type species of Plerujassus gen. nov. A-B. Dorsal and lateral habitus. C. Anterior view of head and thorax. D. Specimen labels. E. Base of abdomen, ventral view. F. Genital capsule, lateral view. G. Same, ventral view. H. Genitalia, ventral view. I. Same, lateral view. Photos by O. Evangelista. 


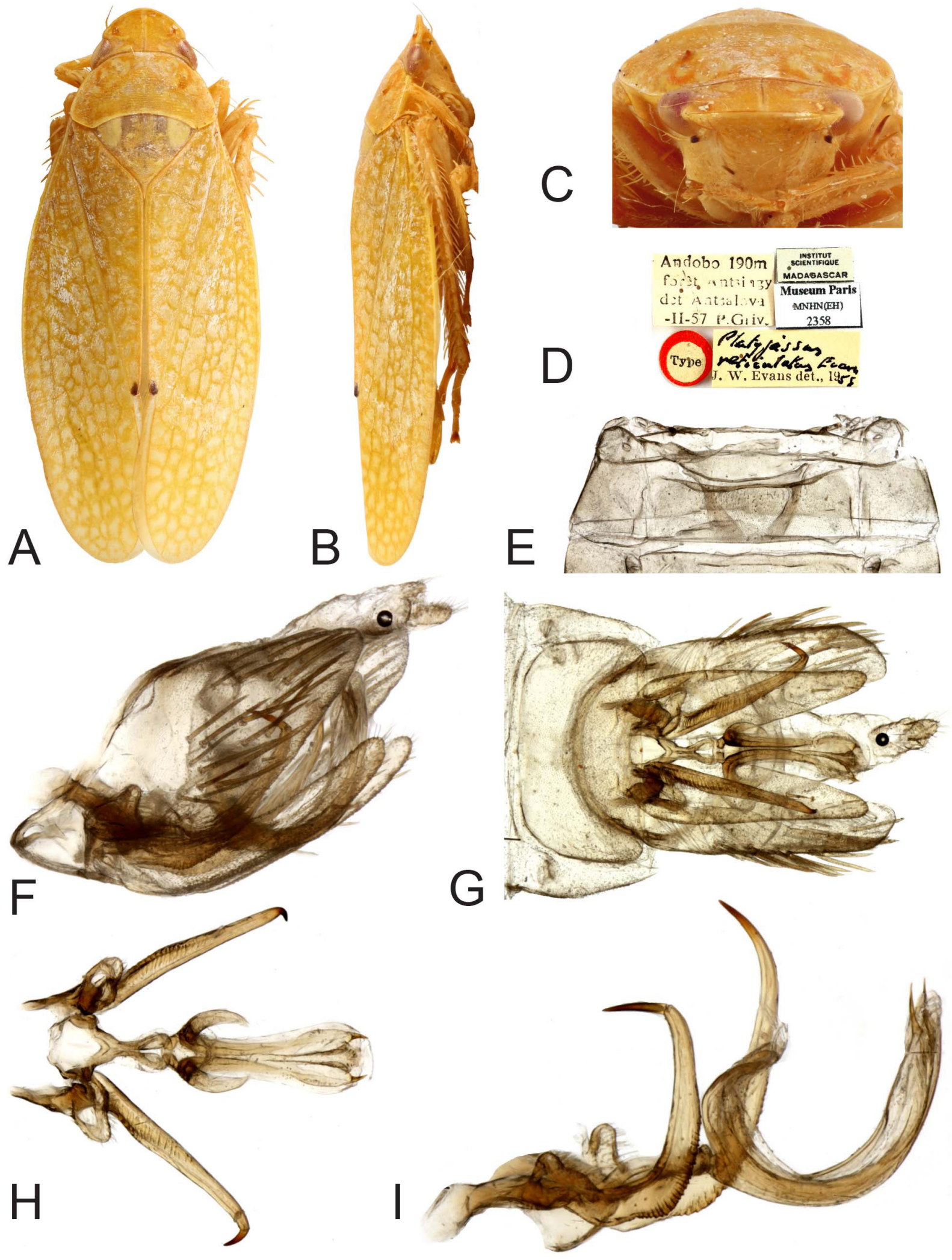

Fig. 20. Holotype male of Platyjassus reticulatus Evans, 1959 (MNHN(EH) 2358), now placed in Pallijassus gen. nov. A-B. Dorsal and lateral habitus. C. Anterior view of head and thorax. D. Specimen labels. E. Base of abdomen, ventral view. F. Genital capsule, lateral view. G. Same, ventral view. H. Genitalia, ventral view. I. Same, lateral view. 


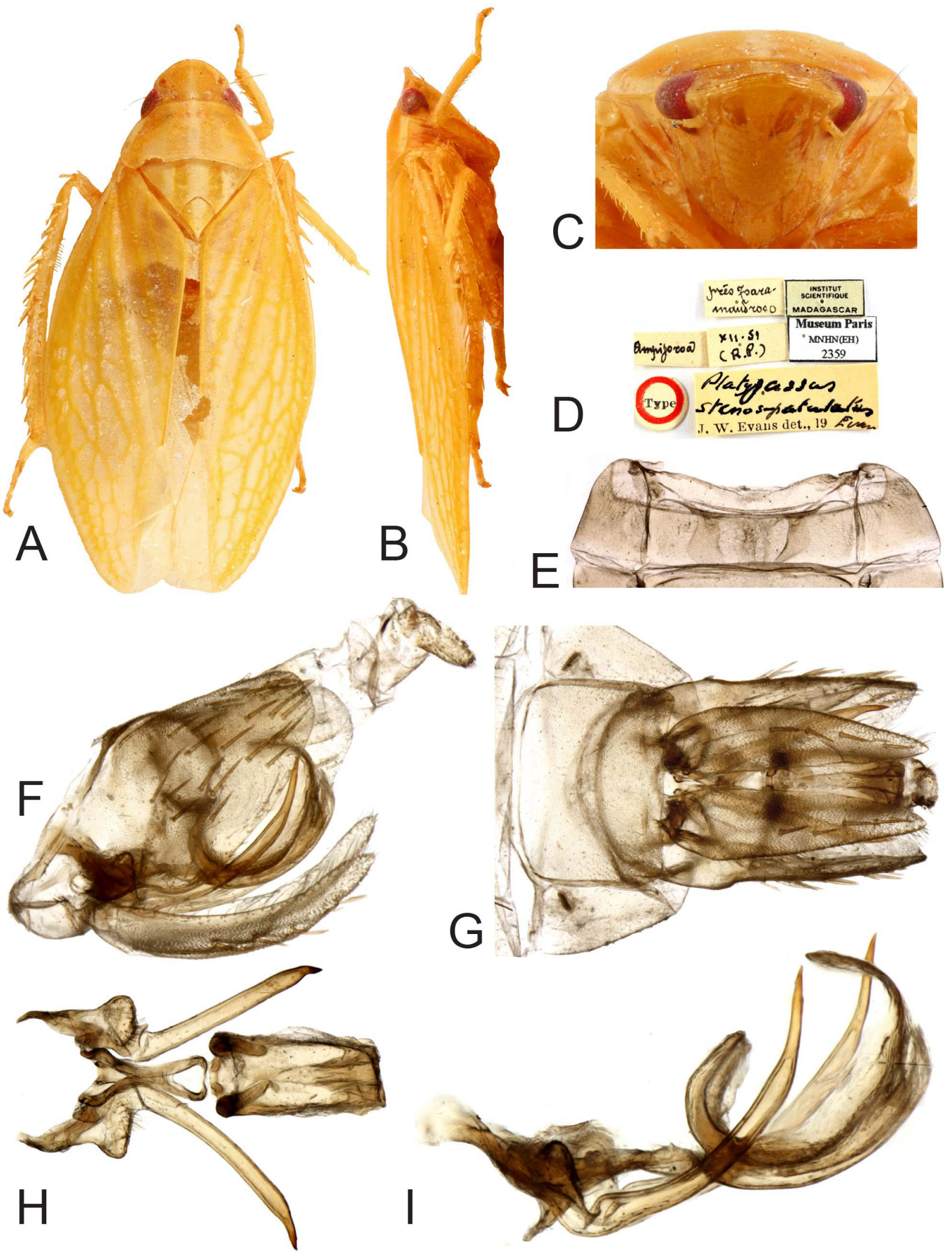

Fig. 21. Males of Platyjassus stenospatulatus Evans, 1959, type species of Pallijassus gen. nov. A-D. Holotype (MNHN(EH) 2359). A-B. Dorsal and lateral habitus. C. Anterior view of head and thorax. D. Specimen labels. - E-I. Male paratype (MNHN(EH) 2361). E. Base of abdomen, ventral view. F. Genital capsule, lateral view. G. Same, ventral view. H. Genitalia, ventral view. I. Same, lateral view. 
through most of length, abruptly constricted preapically, apex curved dorsomesad, in ventral view nearly straight, tapered in distal fourth. Connective with anterior margin roundly produced. Aedeagus with shaft large, strongly compressed, broad in lateral view, curved dorsad, with ventral extension longer than basal width, gonopore on posterior surface near apex; basal process long, evenly curved dorsad, extended nearly to gonopore.

Punctijassus compressus gen. et sp. nov.

urn:1sid:zoobank.org:act:6C3E9540-859D-4D69-9689-FB0C3E606252

Figs 3S, 15D-F

\section{Etymology}

The species name refers to the compressed aedeagal shaft.

\section{Material examined}

\section{Holotype}

MADAGASCAR - O'; "MADAGASCAR: Tulear Province, Cap Ste Marie Special Reserve, el 150m,

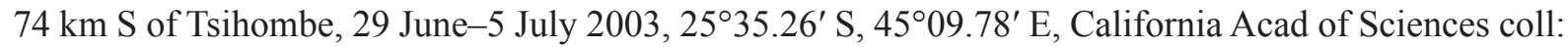
M. Irwin, R. Harin'Hala, malaise trap in bush, MA-23A-03"; CAS.

\section{Paratypes}

MADAGASCAR - Toliara - 1 đ̊; Cap Ste Marie Special Reserve, 74 km S of Tsihombe; $25^{\circ} 35.26^{\prime}$ S, $45^{\circ} 09.78^{\prime}$ E; alt. 150 m; 20-31 Aug. 2003; M. Irwin and R. Harin'Hala leg.; Malaise trap in bush; MA-

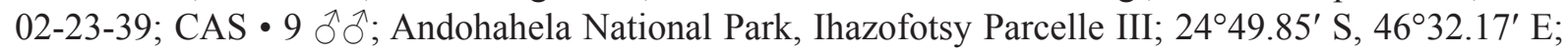
alt. 80 m; 15-26 Oct. 2003; M. Irwin, F. Parker and R. Harin'Hala leg.; Malaise trap; dry spiny forest; MA-02-21-35; CAS, INHS.
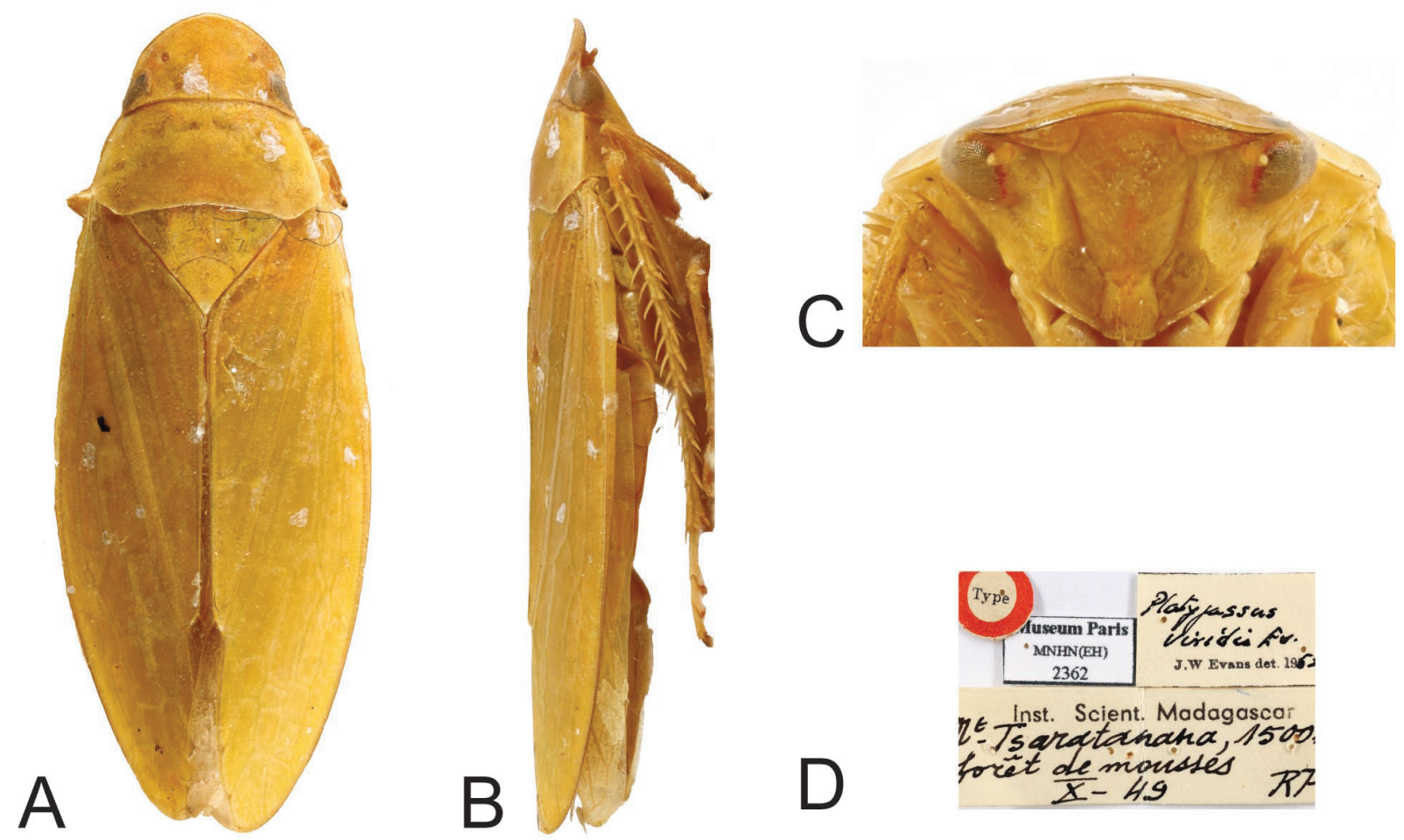

Fig. 22. Holotype female of Platyjassus viridis Evans, 1953 (MNHN(EH) 2362). A-B. Dorsal and lateral habitus. C. Anterior view of head and thorax. D. Specimen labels. 


\section{Description}

Length of male $4.9 \mathrm{~mm}$ (female unknown). Crown with marginal rim and anterodorsal part of frontoclyepus black; middle and hind femur with conspicuous black spot on anterior surface of apex. Crown shorter than pronotum, anterior margin broadly rounded. Hind tibial rows PD, AD, AV with 17, 11, and 12 macrosetae, respectively. Style apophysis slender in basal fourth, broader distally, apex curved dorsomesad, in ventral view curved mesad. Connective with anterior margin truncate. Aedeagus with shaft strongly compressed, moderately broad in lateral view, curved dorsad, apex falcate, gonopore apical on posterior surface; basal process arising on left side of shaft near base curved and closely parallel to shaft, slightly longer than shaft.

Punctijassus ivohibensis gen. et sp. nov.

urn:lsid:zoobank.org:act:1B9D34BA-76F9-4219-A55A-D167B6D3F405

Figs 3T, 15G-I, 18S-U

\section{Etymology}

The species name refers to the forest where the holotype was collected.

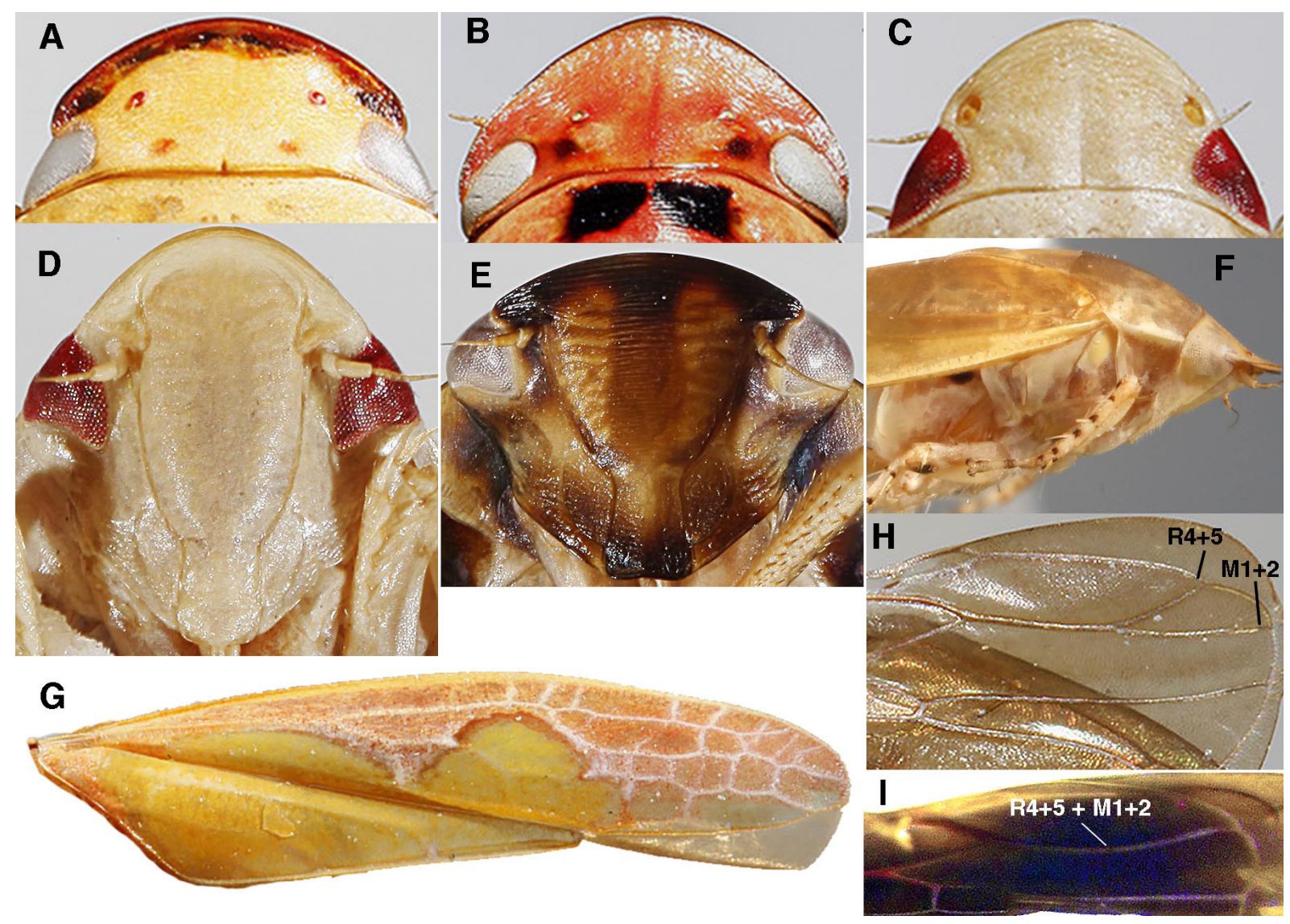

Fig. 23. A-C. Head, dorsal view. A. Pachyjassus alatus sp. nov. B. Pulchrijassus roseus sp. nov. C. Pallijassus stenospatulatus (Evans, 1959). - D-E. Face, anteroventral view. D. Pallijassus stenospatulatus. E. Plerujassus brunnescens sp. nov. - F. Punctijassus compressus sp. nov., lateral view showing black spot on hind coxa (cs). - G-H. Petalojassus ochrescens sp. nov. G. Forewing. H. Detail of hindwing apex showing preapically confluent but apically separate veins R4+5 and M1+2. - I. Pulchrijassus eunsunae sp. nov., detail of hindwing apex showing completely confluent veins R4+5 and $\mathrm{M} 1+2$. 


\section{Material examined}

Holotype

MADAGASCAR • つ’; "MADAGASCAR: Toliara Foret Ivohibe $55.0 \mathrm{~km}$ N Tolagnaro, 2-4 Dec 2006, $24^{\circ} 34^{\prime} 08^{\prime \prime}$ S $047^{\circ} 12^{\prime} 14^{\prime \prime}$ E, California Acad of Sciences coll. B.L. Fisher et al., malaise trap, elev 200 $\mathrm{m}$, rainforest, BLF15448"; CAS.

\section{Paratype}

MADAGASCAR • 1 गे, 1 q; Toliara, Foret Ivohibe, $55.0 \mathrm{~km} \mathrm{~N}$ of Tolagnaro; $24^{\circ} 34^{\prime} 08^{\prime \prime} \mathrm{S}, 4^{\circ} 12^{\prime} 14^{\prime \prime} \mathrm{E}$; alt. 200 m; 2-4 Dec. 2006; B.L. Fisher et al. leg.; Malaise trap; rainforest; BLF15448; INHS.

\section{Description}

Length of male $5.9 \mathrm{~mm}$, female $6.5 \mathrm{~mm}$. Crown with marginal rim and anterodorsal part of frontoclyepus black; middle and hind femur with conspicuous black spot on anterior surface of apex. Crown shorter than pronotum, anterior margin broadly rounded. Hind tibial rows PD, AD and AV with 17-18, 12-13, 14-15 macrosetae, respectively. Style apophysis slightly sinuate, nearly parallel-sided through most of length, apex curved dorsad, in ventral view nearly straight, evenly tapered in distal fourth. Connective with anterior margin roundly produced. Aedeagus with shaft large, strongly compressed, broad in lateral view, curved dorsad, with ventral lobe not longer than basal width, gonopore on posterior surface near apex; basal process long, evenly curved dorsad, extended nearly to gonopore. Female abdominal sternite VII with posterior margin weakly bilobed medially.

\section{Discussion}

The leafhopper fauna of Madagascar is diverse, with high levels of endemism, but remains poorly studied. The 14 new genera and 54 new species described here increase the total known fauna of Malagasy Cicadellidae to 103 genera and 297 species, 81 genera (78.6\%) and 278 species $(93.6 \%)$ of which are considered endemic. These levels of endemism are comparable to those of plants and many other groups of terrestrial animals (Goodman \& Benstead 2003). Because 21 of the new species of Platyjassini included here are known from single specimens, it seems likely that additional collecting in Madagascar, particularly using light traps or by fogging forest canopies, methods not employed during the recent bioinventory, will lead to the discovery of many additional species of this tribe. Study of recently collected samples from the Madagascar terrestrial arthropod bioinventory led by the California Academy of Sciences indicates that several other leafhopper groups are represented by large numbers of undescribed species. These include Deltocephalinae and Typhlocybinae, the largest leafhopper subfamilies worldwide but for which only 49 and 19 species, respectively, have so far been reported from Madagascar in the literature. The cosmopolitan genus Xestocephalus Van Duzee, 1892 also appears to include many undescribed species in Madagascar (unpublished observation). In contrast, some leafhopper groups that are diverse and widespread elsewhere in the Old World tropics, including Evacanthinae and Ledrinae, appear to be rare or absent in Madagascar.

A phylogenetic analysis of Iassinae (Krishnankutty et al. 2016) recovered Platyjassini as monophyletic and sister to a clade comprising the New World (mostly Neotropical) tribes Gyponini and Lipokrisnini. This analysis also revealed Platyjassini to be an early-diverging lineage of the subfamily, with a time of origin estimated at approximately 96-103 million years ago, after Madagascar had separated from Africa but was still joined to the Seychelles-Indian block. Two other leafhopper subfamilies, Deltocephalinae and Eurymelinae, are also known to include early diverging lineages (Acostemmini Evans, 1972 and Nesocerini Xue et al., 2020, respectively) that are largely or entirely restricted to Madagascar. The crown age of Platyjassini was estimated to be approximately 42 million years (Krishnankutty et al. 2016), suggesting that diversification occurred following the initiation of orographic precipitation during the late Paleocene/early Eocene (Yoder \& Nowak 2006). More detailed phylogenetic analyses within 
Platyjassini are needed to determine whether this group exhibits a similar pattern of east-west intraisland diversification to that observed in the distantly related leafhopper genus Nesocerus Freytag \& Knight, 1966 (Krishnankutty \& Dietrich 2011a).

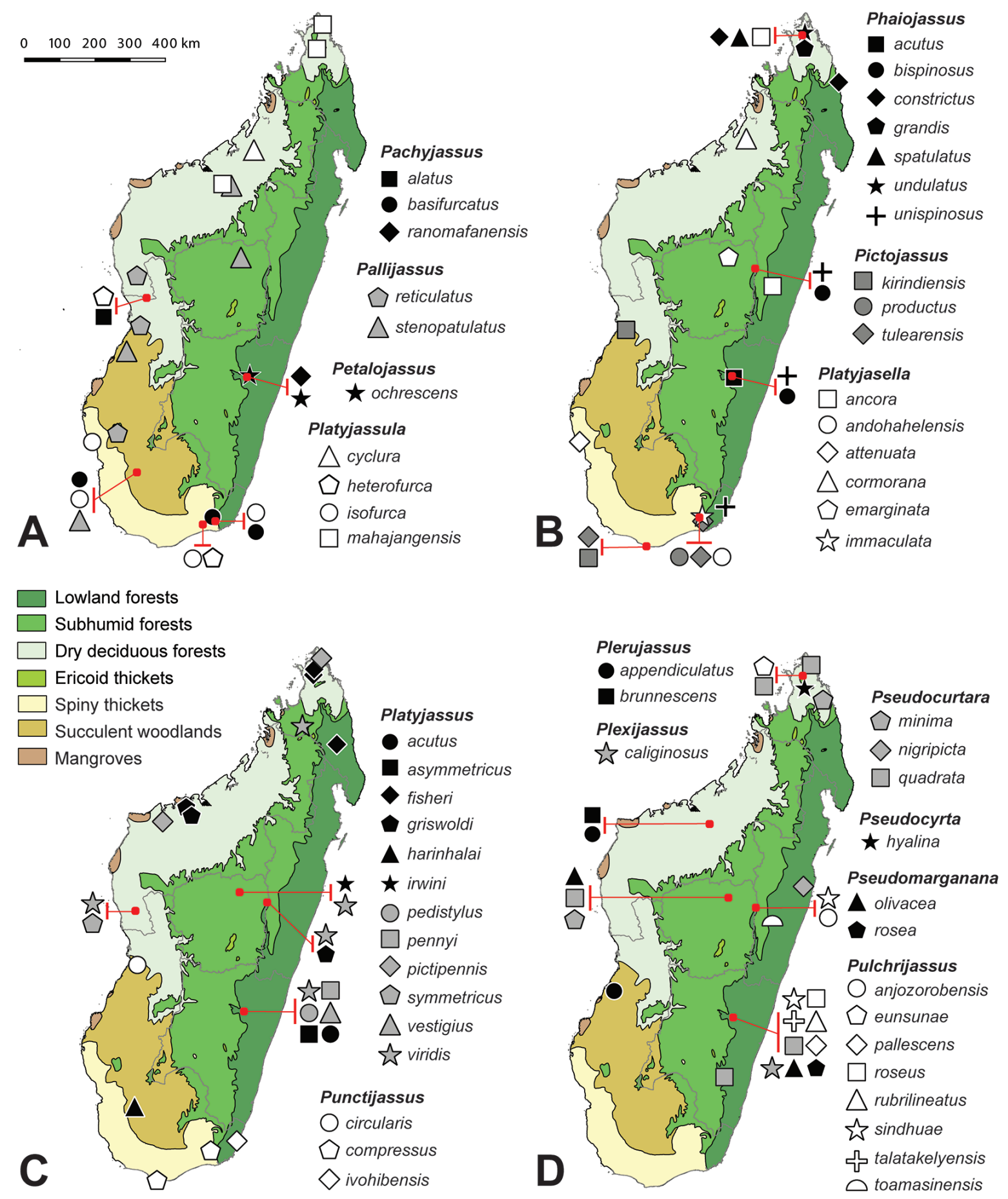

Fig. 24. Distributions of Platyjassini in Madagascar. A. Pachyjassus gen. nov., Pallijassus gen. nov., Petalojassus gen. nov. and Platyjassula gen. nov. B. Phaiojassus gen. nov., Pictojassus gen. nov. and Platyjassella gen. nov. C. Platyjassus Evans, 1953 and Punctijassus gen. nov. D. Plerujassus gen. nov., Plexijassus gen. nov., Pseudocurtara gen. nov., Pseudocyrta gen. nov., Pseudomarganana gen. nov. and Pulchrijassus gen. nov. Red dots indicate localities with multiple species. 


\section{Acknowledgments}

We are grateful to the following individuals and institutions for lending specimens: N.D. Penny and C.C. Grinter (CAS), A. Soulier-Perkins (MNHN), M.D. Webb (BMNH) and J.R. Cryan (North Carolina Museum of Natural Sciences, Raleigh). L. Fauvre (MNHN) and O. Evangelista (Australia National Insect Collection, Canberra) kindly provided photographs of type material at the MNHN. C.C. Gonçalves (Universidad Federal do Rio de Janeiro) tested the keys. E.S. Nam and S.M. Krishnankutty also contributed to the initial sorting, preparation, and identification of specimens for the study. We also thank the editor and two anonymous referees for several helpful suggestions that improved the manuscript. RBM was funded by Coordenação de Aperfeiçoamento de Pessoal de Nível Superior (CAPES) under the program Ciência sem Fronteiras to pursue her summer undergraduate internship at the University of Illinois in 2015. This work was funded in part by US National Science Foundation grants DEB-9978026, 0529679 and 1639601, and Conselho Nacional de Desenvolvimento Científico e Tecnológico (CNPq) grants 313677/2017-4 and 423821/2016-4.

\section{References}

Blanchard E. 1840. Histoire naturelle des Insectes: Orthoptères, Névroptères, Hémiptères, Hyménoptères, Lépidoptères et Diptères. P. Duménil, Paris.

Available from https://www.biodiversitylibrary.org/page/39159721 [accessed 9 Jul. 2020].

Dietrich C.H. 2005. Keys to the families of Cicadomorpha and subfamilies and tribes of Cicadellidae (Hemiptera: Auchenorrhyncha). Florida Entomologist 88: 502-517. https://doi.org/10.1653/0015-4040(2005)88[502:KTTFOC]2.0.CO;2

Evans J.W. 1947. A natural classification of leaf-hoppers (Jassoidea, Homoptera). Transactions of the Entomological Society of London 98: 105-271. https://doi.org/10.1111/j.1365-2311.1947.tb01054.x

Evans J.W. 1953. Les Cicadellidae de Madagascar. Mémoires de l'Institut scientifique de Madagascar Tananarive (E) 4: 87-137.

Evans J.W. 1959. Quelques nouveaux Cicadellidae (Homopteres) de Madagascar. Mémoires de l'Institut scientifique de Madagascar Tananarive (E) 11: 481-507.

Goodman S.M. \& Benstead J.P. 2003. (eds) The Natural History of Madagascar. University of Chicago Press, Chicago.

Jones J.R. \& Deitz L.L. 2009. Phylogeny and systematics of the leafhopper subfamily Ledrinae (Hemiptera: Cicadellidae). Zootaxa 2186 (1): 1-120. https://doi.org/10.11646/zootaxa.2186.1.1

Kirkaldy G.W. 1903. Einige neue und wenig bekannte Rhynchoten. Wiener Entomologische Zeitung 22: $13-17$.

Krishnankutty S.M. \& Dietrich C.H. 2011a. Taxonomic revision and phylogeny of the endemic leafhopper genus Nesocerus (Hemiptera: Cicadellidae: Idiocerinae) from Madagascar. Zoological Journal of the Linnaean Society 162: 499-543. https://doi.org/10.1111/j.1096-3642.2010.00690.x

Krishnankutty S.M. \& Dietrich C.H. 2011b. Review of mileewine leafhoppers (Hemiptera: Cicadellidae: Mileewinae) in Madagascar, with description of seven new species. Annals of the Entomological Society of America 104: 636-648. https://doi.org/10.1603/AN11022

Krishnankutty S.M., Dietrich C.H., Dai W., \& Siddappaji M. 2016. Phylogeny and historical biogeography of leafhopper subfamily Iassinae (Hemiptera: Cicadellidae) with a revised tribal classification based on morphological and molecular data. Systematic Entomology 41: 580-595.

https://doi.org/10.1111/syen.12175 
Linnavuori R. \& Quartau J.A. 1975. Revision of the Ethiopian Cicadellidae (Hemiptera - Homoptera): Iassinae and Acroponinae. Etudes du Continent africain 3: 1-170.

Stål C. 1864. Hemiptera nonnulla nova vel minus cognita. Annales de la Société entomologique de France (Sér. 4) 4: 47-68.

Yoder A.D. \& Nowak M.D. 2006. Has vicariance or dispersal been the predominant biogeographic force in Madagascar? Only time will tell. Annual Review of Ecology, Evolution, and Systematics 37: 405-431. https://doi.org/10.1146/annurev.ecolsys.37.091305.110239

Manuscript received: 4 February 2020

Manuscript accepted: 3 June 2020

Published on: 3 August 2020

Topic editor: Nesrine Akkari

Desk editor: Danny Eibye-Jacobsen

Printed versions of all papers are also deposited in the libraries of the institutes that are members of the EJT consortium: Muséum national d'histoire naturelle, Paris, France; Meise Botanic Garden, Belgium; Royal Museum for Central Africa, Tervuren, Belgium; Royal Belgian Institute of Natural Sciences, Brussels, Belgium; Natural History Museum of Denmark, Copenhagen, Denmark; Naturalis Biodiversity Center, Leiden, the Netherlands; Museo Nacional de Ciencias Naturales-CSIC, Madrid, Spain; Real Jardín Botánico de Madrid CSIC, Spain; Zoological Research Museum Alexander Koenig, Bonn, Germany; National Museum, Prague, Czech Republic. 